\title{
Legal and Social Concerns to the Development of Bioremediation Technologies
}
G. R. Bilyard
H. A. Kirwan-Taylor
G. H. MicCábe
M. D.-McKinney
K. A. White
F. B. Metting
S. W. Gajewski
T. F. Grant
F.A. Morris
P. L. Hendrickson
M.Skumanich
J. A. Jaksch'
L.A.Stevénsón

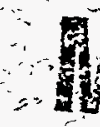

September 1996

Prepared for the U.S.Department of Energy under Contract DEAC06-76RLO 1830

Pacific Northwest National Laboratory Operated for the US.Department of Energy by Battelle 


\section{DISCLAIMER}

This report was prepared as an account of work sponsored by an agency of the United States Government- Neither the United States Government nor any agency thereof, nor Báttelle Memorial Institute, nor-any of their employees, makes any warranty, express or implied, or assumes any legal liability or responsibility for the accüracy, completeness, or usefulness of any information, apparatus, product, or process disclosed, or represents that its use would not infringe privately owned rights: Reference herein to any specific commercial productiprocess, or service by trade name, trademark, manufacturer, or otherwise does not necessarily constitute or imply its endorsement, recommendation, or favoring by the United States Government or any agency thereof, or Battelle Mèmorial Institute. The views and opinions of authors expressed herein do not necessarily state or reflect those of the United States Government or any agency thereof.

\section{PACIFIC NORTHWEST NATIONAL LABORATORY operated by \\ BATTELLE \\ for the \\ UNITED STATES DEPARTMENT OF ENERGY under Contract $D E-A C 06=76 R L O 1830$}

\footnotetext{
Printed in the United States of America

Available to DOE and DOE contractors from the Office of Scientific and Technical Information, P.O. Box 62, Oak Ridge, TN 37831; prices available from (615) $576-8401$.
}

Available to the public from the National Technical Information Service, U.S. Department of Commerce, 5285 Port Royal Rd., Springfield, VA 22161 


\section{DISCLAIMER}

Portions of this document may be illegible in electronic image products. Images are produced from the best available original document. 
PNNL-11301

UC-630

Legal and Social Concerns to the Develópment of Bioremediation Technologies : : $: \cdots$.
G.R. Bilyard
H.A. Kirwan-Taylor
G.H. McCabe .
M.D. McKinney
K.A. White
F.B. Metting
S.W. Gajewski.
F.A. Morris
T.F. Grant
M. Skumanich

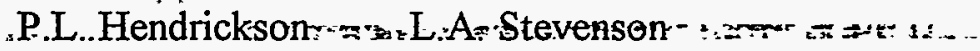
J.A. Jaksch

September 1996

Prepared for the

U.S. Department of Energy

under Contract DE-AC06-76RLO 1830

Pacific Northwest National Laboratory

Operated for the U.S. Department of Energy

by Battelle 



\section{Acknowledgments}

The authors wish to thank T.F. Grant, P.L. Hendrickson, S. R. May, D. E. McKinley, O.H. Paananen, L.M. Schwegel, and P. Warden for their technical support during the preparation of this report. The editorial assistance of R.A. Buchanan is gratefully acknowledged. 



\section{Abbreviations and Acronyms}

AE'C

APHIS

ARARs

BCC

BDAT

CAA

CAFC

CERCLA

CRADA

CWA

DOE

DOD

DOT

EC

EIS

EPA

EPC

EPO

ERDA

EU
Atomic Energy Commission

Animal and Plant Health Inspection Service

applicable or relevant and appropriate requirements

Biotechnology Coordination Committee

Best Demonstrated Available Technology

Clean Air Act

Court of Appeals for the Federal Circuit

Comprehensive Emergency Response, Compensation, and Liability Act

Cooperative Research and Development Agreement

Clean Water Act

U.S. Department of Energy

U.S. Department of Defense

U.S. Department of Transportation

European Commission

environmental impact statement

U.S. Environmental Protection Agency

European Patent Convention

European Patent Office

Energy Research and Development Administration

European Union 
FIFRA Federal Insecticide, Fungicide, and Rodenticide Act

FPPA Federal Plant Pest Act

GATT General Agreement on Tariffs and Trade

GEMs genetically engineered microorganisms

GOCOs government owned contractor operated facilities

GOGOs government owned government operated facilities

LDRs Land Disposal Restrictions

MACT maximum achievable control technology

MCLs maximum containment levels

NAAQSs national ambient air quality standards

NABIR Natural and Accelerated Bioremediation Research

NCP National Contingency Plan

NEPA National Environmental Policy Act

NESHAPs National Emission Standards for Hazardous Air Pollutants

OSC on-scene coordinator

OSHA Occupational Safety and Health Act

PCB polychlorinated biphenyls

PCT Patent Cooperation Treaty

PMN premanufacture notice

PNNL Pacific Northwest National Laboratory

PPA Plant Patent Act

PTO Patent and Trademark Office 
PVPA Plant Variety Protection Act

R\&D research and development

RCRA Resource Conservation and Recovery Act

SDWA Safe Drinking Water Act

SWMU solid waste management unit

TCE trichloroethylene

TRIPs trade related intellectual property rights

TSCA Toxic Substances Control Act

TSD treatment, storage, or disposal

UNCED United Nations Conference on the Environment and Development

USDA U.S. Department of Agriculture

USTs underground storage tanks

VOCs volatile organic compounds

VOC-Arid ID VOC Arid Site Integrated Demonstration

WIPO World Intellectual Property Organization 



\section{Executive Summary}

The social and legal framework within which bioremediation technologies must be researched, developed, and deployed in the United States are discussed in this report. Discussions focus on policies, laws and regulations, intellectual property, technology transfer, and stakeholder concerns. These discussions are intended to help program managers, scientists and engineers understand the social and legal framework within which they work, and be cognizant of relevant issues that must be navigated during bioremediation technology research, development, and deployment activities. The intended audience for this report is program managers, scientists, and engineers within the U.S Department of Energy (DOE) complex. However, personnel within the U.S. Department of Defense (DoD) and other agencies may benefit from its contents. Readers are cautioned that social and legal frameworks evolve through time, and consequently, that the accuracy and applicability of the contents of the report will decrease over time.

While this report focuses on the legal and social environment within which the DOE operates, the laws, regulations and social processes could apply to DoD and other sites nationwide. The stakeholders interviewed for this report come from the communities surrounding Hanford and other DOE sites. However, their concerns and receptiveness to involvement strategies are likely to be shared by their counterparts nationwide.

This report identifies specific issues related to bioremediation technologies, including those involving the use of plants; native, naturally occurring microbes; non-native, naturally occurring microbes; genetically engineered organisms; and microbial products (e.g., enzymes, surfactants, chelating compounds). It considers issues that fall within the following general categories:

- U.S. biotechnology policy and the regulation of field releases of organisms

- U.S. environmental laws and waste cleanup regulations

- intellectual property and patenting issues

- technology transfer procedures for commercializing technology developed through government-funded research

- stakeholder concerns about bioremediation proposals

- methods for assuring public involvement in technology development and deployment.

Legal and regulatory issues associated with microbial biotechnology arise from three sources. First, the United States has no coherent policy that defines its national biotechnology goals. Because Congress has not set national goals, government agencies and private industry face difficult decisions about investing in the research and development of new biotechnology products. Very little information exists regarding the possible threat genetically altered or exotic 
organisms pose when introduced into native ecosystems, and technology developers may face uncertain liability and public opposition. Citizens aware of the damage caused by exotic species worry that underregulation of field releases of genetically altered organisms may result in similarly severe and unforeseeable problems.

Second, the United States has no coherent set of statutes related to bioremediation, but instead regulates bioremediation largely within the scope of existing statutes drafted for the regulation of other activities (e.g., protection of surface waters from contamination; regulation and permitting of chemicals for industrial, commercial, and private use). These statutes may overlap or impose conflicting requirements and inappropriate performance standards. Cleanup projects must often operate under overlapping agency oversight of remediation activities.

Third, the U.S. Environmental Protection Agency and certain state governments are now moving toward the adoption of risk-based policies and approaches to regulatory compliance. These policies and approaches are being adopted and implemented within the framework of the existing "command and control" statutes and regulations, often necessitating the development of new, unique approaches to regulatory compliance.

As a consequence of the above three sources of issues, bioremediation developers and users must first conduct thorough analyses of potentially applicable statutes and regulations, based on their knowledge of the kinds of activities that will be conducted and the kinds of residuals that will be generated. They must then work cooperatively with regulators to develop mutually acceptable compliance strategies and demonstration endpoints.

The U.S. patent code provides inventors with a limited monopoly to control the manufacture, sale, and use of their patented subject matter for 20 years. This allows researchers to recover some of their investment before the protected process or invention becomes part of the public domain. While historically the U.S. Patent and Trademark Office has not issued patents on living material, recent case law and agency notices have clarified that inventors may obtain patent protection for genetically altered organisms and for processes involving living matter. In addition, purified forms of natural substances are also patentable.

The patent application process can be lengthy and expensive, and technology developers must assess whether obtaining patent protection is a worthwhile investment. To qualify for a patent, inventors must file the patent application within a year of first publishing or publicly field testing their inventions. However, an inventor will not be able to obtain international patent protection if the invention was published at any time before filing.

Current U.S. technology transfer policy encourages contractors receiving government funding to take title to the resulting inventions. Once laboratories own the patents on the products of basic research, they can form cooperative research and development agreements with private industry to develop the inventions into a marketable form. By encouraging private investment in commercializing basic research, the government helps assure that the public can benefit from the basic research financed with government funds. However, government-funded bioremediation 
technologies are likely to be attractive to commercial investors when they fill a void in the set of already available commercial technologies.

Discussions with stakeholders at Hanford and other DOE sites provided additional insight into the issues of concern during the research and development, demonstration, and deployment of bioremediation technologies. Principal concerns are in the areas of performance, environmental health and safety, and regulatory compliance.

Stakeholders want bioremediation technologies that are able to remediate all of the contaminants that are encountered. Stakeholders prefer simple technologies over complex ones, as they perceive that more complex technologies tend to be more expensive, more likely to fail, and more difficult to rectify if any failures occur. Stakeholders recognize that research, development, and deployment times tend to be long, making bioremediation technologies generally unsuitable for high-risk conditions that require immediate action. They appreciate that bioremediation may be cost-effective, but prefer that the safest and most environmentally sound remediation technology be used. They are concerned about assuring the control of released microbes and compliance with standards and permitting requirements.

To ensure that stakeholders are involved in a productive manner, bioremediation projects must involve them early, preferably at the initial stages of research specific to the contaminated site. Existing fora permit stakeholders to obtain periodic updates on the progress of research. Sharing the results of peer reviews of research help stakeholders understand the quality of research. Providing citizen committees with reports and evaluations helps keep stakeholders informed and involved. 



\section{Contents}

Acknowledgments $\ldots \ldots \ldots \ldots \ldots \ldots \ldots \ldots \ldots \ldots \ldots \ldots \ldots \ldots \ldots \ldots \ldots \ldots \ldots \ldots$ iii

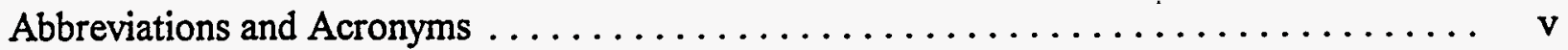

Executive Summary $\ldots \ldots \ldots \ldots \ldots \ldots \ldots \ldots \ldots \ldots \ldots \ldots \ldots \ldots \ldots \ldots \ldots$ ix

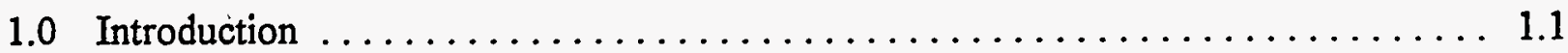

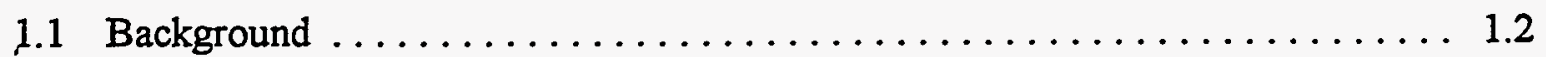

1.2 Why Scientists and Engineers Should Care About the Legal and Social

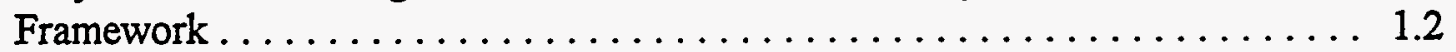

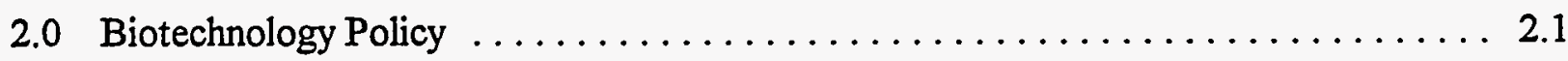

2.1 Historical Policy Attempts in Biotechnology Regulation $\ldots \ldots \ldots \ldots \ldots 2.1$

2.2 The Coordination Framework for Regulation of Biotechnology $\ldots \ldots \ldots \ldots 2.2$

2.3 Regulation of the Naturally Occurring Exotic Species $\ldots \ldots \ldots \ldots \ldots \ldots 2.6$

2.4 International Regulation of Biotechnology $\ldots \ldots \ldots \ldots \ldots \ldots \ldots \ldots 2.8$

3.0 U.S. Environmental Laws and Regulations $\ldots \ldots \ldots \ldots \ldots \ldots \ldots \ldots \ldots \ldots \ldots .1$

3.1 Overview of U.S. Environmental Laws . . . . . . . . . . . . . . . 3.2

3.2 Federal Laws Specifically Relevant to Biological Remediation Methods . . . . . . 3.13

3.3 Identifying Regulatory Issues $\ldots \ldots \ldots \ldots \ldots \ldots \ldots \ldots \ldots \ldots \ldots \ldots \ldots \ldots \ldots .16$

4.0 Intellectual Property and Patenting $\ldots \ldots \ldots \ldots \ldots \ldots \ldots \ldots \ldots \ldots \ldots \ldots \ldots \ldots \ldots \ldots$

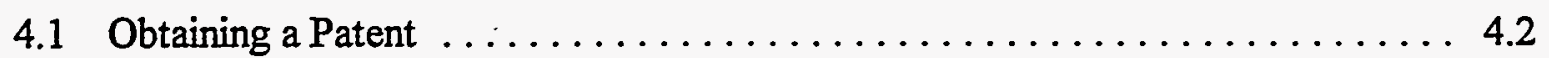

4.3 International Intellectual Property Law $\ldots \ldots \ldots \ldots \ldots \ldots \ldots \ldots \ldots .13$

4.4 Alternatives to Patent Protection: Trade Secret Law $\ldots \ldots \ldots \ldots \ldots \ldots .4 .21$

5.0 Technology Transfer $\ldots \ldots \ldots \ldots \ldots \ldots \ldots \ldots \ldots \ldots \ldots \ldots \ldots \ldots \ldots \ldots \ldots \ldots \ldots \ldots .1$ 
5.1 History of Technology Transfer Policy in the United States $\ldots \ldots \ldots \ldots .2$

5.2 Modern Technology Transfer Policy ...................... 5.3

5.3 Issues for Bioremediation Technology $\ldots \ldots \ldots \ldots \ldots \ldots \ldots \ldots \ldots .6$

6.0 Stakeholder Perceptions and Acceptance of Bioremediation

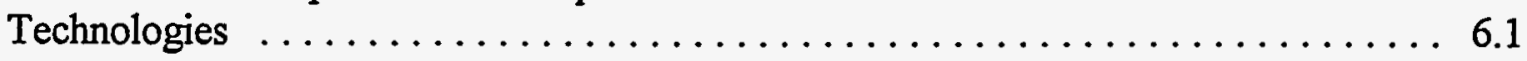

6.1 Stakeholder Involvement Process $\ldots \ldots \ldots \ldots \ldots \ldots \ldots \ldots \ldots \ldots \ldots .2$

6.2 Overview of Stakeholder Comments Related to Bioremediation

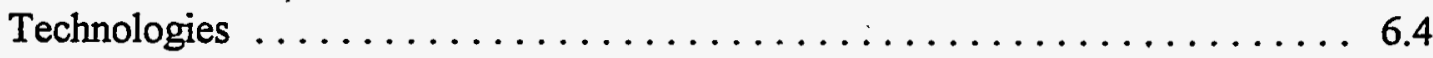

6.3 Stakeholder Comments Related to Specific Types of Microorganisms

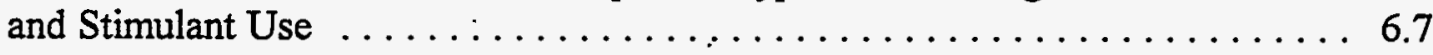

6.4 Recommendations on How to Involve Stakeholders $\ldots \ldots \ldots \ldots \ldots \ldots \ldots .12$

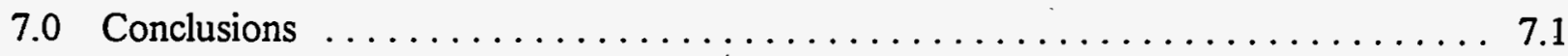

7.1 Policy, Legal, and Regulatory Issues $\ldots \ldots \ldots \ldots \ldots \ldots \ldots \ldots \ldots \ldots \ldots \ldots$

7.2 Intellectual Property and Patenting Issues $\ldots \ldots \ldots \ldots \ldots \ldots \ldots \ldots .2$

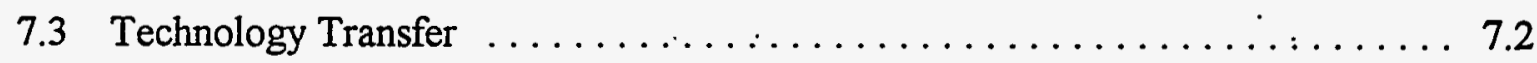

7.4 Stakeholder Considerations $\ldots \ldots \ldots \ldots \ldots \ldots \ldots \ldots \ldots \ldots \ldots \ldots \ldots \ldots \ldots \ldots \ldots \ldots .2$

7.5 Recommendations for Involving Stakeholders $\ldots \ldots \ldots \ldots \ldots \ldots \ldots .2$

8.0 References $\ldots \ldots \ldots \ldots \ldots \ldots \ldots \ldots \ldots \ldots \ldots \ldots \ldots \ldots \ldots .1$.

Appendix A: Ethical, Legal and Social Issues Protocol $\ldots \ldots \ldots \ldots \ldots \ldots \ldots$ A.1

Appendix B: Issues - Design of VOC-Arid ID $\ldots \ldots \ldots \ldots \ldots \ldots \ldots \ldots \ldots \ldots \ldots$

Appendix C: Compilation of Hanford Stakeholder Issues $\ldots \ldots \ldots \ldots \ldots \ldots \ldots \ldots$ C.1

Appendix D: Stakeholder Issues From Other DOE Sites $\ldots \ldots \ldots \ldots \ldots \ldots \ldots$ D. 1

Appendix E: Major Legislative Themes in Federal Technology Transfer .......... E.1 


\subsection{Introduction}

This report describes the social and legal framework within which bioremediation technologies must be researched, developed, and deployed in the United States. Discussions focus on policies, laws and regulations, intellectual property, technology transfer, and stakeholder concerns. These discussions are intended to help program managers, scientists and engineers understand the social and legal framework within which they work, and be cognizant of relevant issues that must be navigated during bioremediation technology research, development, and deployment activities. The intended audience for this report is program managers, scientists, and engineers. within the U.S Department of Energy (DOE) complex. However, personnel within the U.S. Department of Defense (DoD) and other agencies may benefit from its contents. Readers are cautioned that social and legal frameworks evolve through time, and consequently, that the accuracy and applicability of the contents of the report will decrease over time.

This report discusses specific legal and social issues that are related to bioremediation technologies involving the use of plants; native, naturally occurring microbes; non-native, naturally occurring microbes; genetically engineered organisms; and microbial products (e.g., enzymes, surfactants, chelating compounds). It emphasizes legal and social issues related to

- U.S. biotechnology policy and the regulation of field releases of organisms

- U.S. environmental laws and waste cleanup regulations

- intellectual property and patenting

- technology transfer procedures for commercializing technology developed through government-funded research

- stakeholder concerns about bioremediation

- methods for assuring public involvement in technology development and deployment.

Legal and social issues relevant to the development, testing, and deployment of bioremediation technologies at Hanford are identified and discussed within the broader national context. In addition, as a result of preliminary engagement of selected Hanford stakeholders, this report recommends preferred methods that biotechnology developers should use to engage Hanford stakeholders.

Experience with the Hanford Site bioremediation demonstration (conducted as part of the Arid Sites Integrated Demonstration) confirmed that stakeholders must be engaged throughout technology development, testing, and deployment activities if the resulting technology is to be fully accepted and deployable when finished. It also confirmed that stakeholder ideas and comments were valuable to the technology development process, and that those ideas and 
comments helped produce better technologies than would have been produced otherwise. The primary purpose of this report is to provide biotechnology developers with sufficient understanding of legal and social issues and the stakeholder engagement process so they can resolve critical issues in a timely manner.

\subsection{Background}

Bioremediation promises more effective cleanup technologies at lower cost. The DOE is now embarking on a 10-year Natural and Accelerated Bioremediation Research (NABIR) program, the purpose of which is "to provide the scientific understanding needed to harness natural processes and to develop methods to accelerate these processes for the bioremediation of contaminated soils, sediments, and groundwater at DOE facilities". The goals of the program are to

- conduct research basic to remediating complex contaminant mixtures in natural environments

- establish field research centers for long-term research on the scientific foundations underpinning bioremediation

- develop knowledge and techniques needed to implement bioremediation technologies and predict their effectiveness

- train scientists and engineers in the biogeochemistry of complex environments

- identify opportunities for other applications of new knowledge (e.g., ex situ waste treatment, pollution prevention)

- develop effective partnerships among government agencies, regulators, the public, and the research and development community to address legal and social issues related to bioremediation and bioprocessing in general.

If the NABIR Program is to reach its full potential relative to the first five goals listed above, it must develop the partnerships necessary to address relevant legal and social issues related to bioremediation and bioprocessing. An understanding of the legal and social framework, and of the issues associated with that framework, is a necessary prerequisite to successful partnering. To date, however; knowledge of the legal and social landscape is fragmentary and not easily accessed by scientists and engineers working in the laboratory and field.

\subsection{Why Scientists and Engineers Should Care About the Legal and Social Framework}

To fully research, develop, and deploy a technology, scientists and engineers must understand the legal and social framework within which they operate. They must identify the legal and social issues (e.g., regulatory compliance) relevant to that technology, and navigate those issues before 
they hinder or block deployment. In addition, they must be cognizant of the opportunities afforded by the legal and social system (e.g., patent protection), so as to take full advantage of those opportunities when they arise. Only by navigating issues and seizing opportunities can technology researchers, developers, and deployers ensure that their technologies will be deployed to their full potential. Failure to recognize issues and opportunities, and to engage those issues and opportunities directly can result in less than full deployment, or even a prohibition on deployment of the technology.

This report will help bioremediation technology researchers, developers, and deployers understand the U.S legal and social framework, and to a lesser extent the international legal and social framework. Wherever possible, it identifies issues that must be navigated and opportunities that can be seized during the research, development, and deployment of bioremediation technologies. Focal areas for the report include biotechnology policy, U.S. environmental laws and regulations, intellectual property and patenting, technology transfer, and stakeholder perceptions and acceptance of bioremediation technologies.

The issues and opportunities faced by bioremediation technology researchers, developers, and deployers arise for a number of reasons, including the following:

- The U.S. lacks a coherent biotechnology policy. Lacking such a policy, various states and even local governments have implemented their own regulations to govern biotechnology deployment. If such state and local regulation continue to proliferate, biotechnology deployers could be faced with insurmountable requirements for demonstrations of compliance.

- U.S. laws and regulations governing the release of microbes are poorly coordinated and considerable difference in their interpretation and enforcement may exist across regulatory agencies and offices. Hence, biotechnology deployers may be faced with very different regulatory compliance requirements among similar sites in different federal and state jurisdictions.

- Many U.S. regulatory agencies and offices are moving away from command and control regulation and toward risk-based regulation of waste cleanup projects. The risk-based approach allows regulators to impose different requirements for cleanup at different sites, based on the potential risks that each site poses. To meet these requirements, technology developers and deployers must therefore have information about the risks of deploying the biotechnology, and about the residual risks that will remain after the technology is deployed. Much of that information should be collected during the research and development of the biotechnology.

- The U.S. patent system is complex. It must be navigated carefully, deliberately, and from an informed position to obtain intellectual property protection for biotechnologies. 
- Foreign patent systems differ from those in the U.S., and therefore pose additional, complex challenges that must be understood by technology researchers and developers.

- Government sponsored researchers may need partner with private industry to commercialize the results of their basic research. For many government technology researchers and developers, partnering with industry represents a new way of doing business for which they have no or little experience.

- Public acceptance of bioremediation technologies is essential for deployment. Public interest groups have the ability to prohibit or inhibit technology deployment. However, effective public engagement beginning during the research phase and continuing through technology deployment can result in public support for the technology, and can enhance the effectiveness of the technology. 


\subsection{Biotechnology Policy}

At present, the United States has no coherent policy defining its national biotechnology goals (Gore 1991). While industry participants in the policy process hope to develop strong intellectual property protection and minimal regulatory barriers to deployment of new biological inventions and processes, environmentalists and concerned citizens argue that current scientific understanding is inadequate to support effective risk-based protections for public health and the environment.

Congress has not passed any legislation specific to biotechnology. Currently, the industry is governed by an executive policy that describes how several government agencies should use existing law to regulate different aspects of biotechnology research and industrial application. Lack of progress at the federal level has led several states, and an occasional county, to implement their own regulations for biotechnology. The danger is that without a unified federal policy, legal . and regulatory system, biotechnology companies will be faced with 50 or more regulatory systems that will threaten industry success and international competitiveness. The judicial system may play a significant role in resolving policy conflicts between state and federal regulations. However, current legislative and regulatory processes do not provide for significant public involvement, and current tension between industry requests for lenient regulation and public demand for more stringent safeguards remains unresolved.

\subsection{Historical Policy Attempts in Biotechnology Regulation}

In 1974, members of the scientific community began voicing concerns about the need for regulation and government oversight of biotechnology and the use of recombinant DNA techniques. Scientists gathered at the Gordon Conference on Nucleic Acids requested guidance from the American Academy of Science and approached the National Institutes of Health with suggestions for establishing committees to review and monitor research into recombinant DNA (Vito 1993, p. 332). Many scientists agreed to a voluntary moratorium on genetic engineering research while they waited for appropriate guidelines to be developed. The resulting debate crystallized in an international gathering at the Asilomar conference on the ethical and legal implications of genetic engineering, in which scientists, industry representatives and policy makers debated safety standards and regulatory enforcement for the evolving field (Vito 1993, p. 333).

The National Institutes of Health (NIH) issued guidelines based on suggestions from the - Asilomar conference in 1976. The NIH Guidelines for Research Involving Recombinant DNA Molecules (NIH Guidelines) established standards for assuring that all genetically altered material and organisms would remain contained within research laboratories, and included an unqualified prohibition on the release of genetically engineered organisms into the environment. However, the Guidelines only applied to research funded or sponsored by the NIH, so compliance by private sector researchers was strictly voluntary (Vito 1993, p. 333; Vandenbergh 1986, p. 1536). 
As scientific and public confidence in the safety of research involving genetic manipulation grew, the NIH revised the Guidelines several times, removing the absolute ban on release experiments and relaxing containment regulations (Vito 1993, p. 334). By 1982 the NIH delegated oversight of biotechnology research and authority to approve release experiments to locally based peer-review Institutional Biosafety Committees.

Congress held several series of hearings on the dangers and benefits of genetic engineering between 1974 and 1983. While at least twelve pieces of legislation addressing these issues were introduced, none passed into law (Vandenbergh 1986, p. 1534).

While Congress considered and rejected legislative regulation of biotechnology and the release of genetically altered organisms, the White House Cabinet Council on Natural Resources and the Environment considered how to coordinate federal agencies' overlapping authority under existing law. By the end of 1984, the White House Office of Science and Technology Policy (OSTP) proposed an integrated regulatory scheme called the Coordinated Framework for Regulation of Biotechnology (hereinafter Coordinated Framework) (Vito 1993, p. 334). The initial version of the Coordinated Framework included statements from the FDA, EPA and USDA explaining how they would cooperate in regulating genetic engineering research and development. However, substantial uncertainty remained regarding regulation of commercial development and other activities not included in these agencies' jurisdictional authority (Vito 1993, p. 335).

In 1986, the White House Biotechnology Science Coordinating Committee (BSCC) issued a second draft of the Coordinated Framework (51 FR 23302 (1986); Vito 1993, p. 335). The Coordinated framework includes separate descriptions of the regulatory policies related to biotechnology of the Food and Drug Administration (51 FR 23309), EPA (51 FR 23313), the Occupational Safety and Health Administration (51 FR 23347), and the U.S. Department of Agriculture as well as the research policies of the National Institutes of Health (51 FR 23349), the National Science Foundation, EPA, and the U.S. Department of Agriculture (USDA).

\subsection{The Coordinated Framework for Regulation of Biotechnology}

The Coordinated Framework proposes a risk-based decision making process for federal regulators. Earlier biotechnology regulations, including the NIH Guidelines, employed a productor standard-based regulatory scheme, which focused scrutiny on all organisms and products resulting from genetic manipulation. Many scientists advocated moving from a standards-based to risk-based regulatory framework, as originally articulated in a seminal article published in Ecology by leading scientists in microbial ecology and plant population biology (Tiedje et al. 1989). Since the same physical and biological laws govern the response of organisms modified by modern molecular methods as those produced by classical methods, many biotechnology inventors claim no regulatory distinction should exist between the products of classical selective breeding methods and genetic manipulation. 
The Framework establishes four general principles for regulating biotechnological developments. First, regulatory agencies will apply existing laws rather than new ones focused on specific risks posed by biotechnology. Second, the regulations will be based on the risk posed by genetically altered organisms and processes, rather than regulating all technology resulting from genetic manipulations. Third, the risk posed by GEMs and biotechnology processes must be evaluated on a case by case basis. Finally, the Framework provides guidelines for coordinating regulatory efforts among federal agencies (Kim 1993, p. 1180).

Under the Coordinated Framework, most genetically engineered organisms are regulated by the EPA and the USDA. The USDA administers the release of GEMs into the environment based on the its authority under the Plant Pest Act and the Plant Quarantine Act. Since many genetic engineering processes use viruses and other organisms classified as plant pests, the USDA has claimed authority to require permits for the interstate transport and release of GEMs. The USDA jurisdiction over GEMs appears to be limited to their use for agricultural purposes (Vito 1993, p. 337).

The EPA derives its authority to regulate GEMs from FIFRA, which gives the agency authority to regulate pesticides. The EPA used the Coordinated Framework to claim authority to regulate any GEMs that acted as pesticides. The EPA also derives authority to regulate other commercial uses of GEMs from the TSCA, which gives the agency power to regulate "chemical substances." By redefining "chemical substances" to include organisms containing genetic material from a different genus, the EPA obtained jurisdiction over most non-agricultural uses of genetically engineered organisms (Vito 1993, p. 338).

In addition, the EPA has authority to regulate microbes used in bioremediation efforts, which may also fall under the jurisdiction of other agencies if the wastes were generated through agricultural practices.

The FDA regulates food products and pharmaceuticals under the Food Drug and Cosmetic Act. Genetically altered organisms and biotechnological processes for producing food, food additives and drug products may be regulated by the FDA. It is unclear what separates the FDA jurisdiction to regulate food and the USDA authority to regulate crop species and agricultural biotechnology research (Kim 1993, p. 1182).

\subsubsection{Criticisms of the Coordinated Framework}

Some commentators have criticized the Coordinated Framework, claiming that pre-existing environmental laws do not adequately address the risks and regulatory issues specific to biotechnology. The TSCA may not properly address the environmental risks of releasing genetically altered organisms into the environment because TSCA only permits regulation of "substantial quantities" of chemicals that pose an "unreasonable risk to human health or the environment" (15 USC 2604(a)(1)(B); Chadwick 1995, p. 236). The statute does not authorize the EPA to regulate chemicals and organisms whose harmfulness is not yet clearly understood, 
making some commentators fear that field release experiments will continue without producing a clearer understanding of the environmental and health risks transgenic organisms might create (Kim 1993, p. 1181).

The TSCA does appear to permit the EPA to regulate small releases of genetically engineered organisms. This reflects current knowledge about risk, since without clearer scientific understanding, researchers cannot predict whether a small quantity of released organisms will multiply, posing unforeseen risks to the enviroriment. As one scientist commented, "One of the biggest biohazards is our lack of knowledge" (Chadwick 1995, p. 243). Regulators face a policy dilemma: since they only have 90 days to evaluate the possible hazards posed by the release of an organism, they must rely on limited scientific understanding to determine whether the release poses an unreasonable risk. However, the TSCA does not authorize the EPA to require testing or implement regulations without demonstrating that the organisms pose an "unreasonable risk," and scientific understanding may not be clear enough to support that designation in the face of a court challenge by industry (Chadwick 1995, p. 247).

Under TSCA and FIFRA, the EPA requires industry to issue a Pre-Manufacturing Notice (PMN), describing the intended use of the organisms, and any foreseeable hazards associated with the experiment. The EPA only has 90 days to evaluate the PMN to determine if the release poses . an "unreasonable risk." If the agency fails to find conclusive evidence of risk within that time, the experiment goes forward, even if the risks remain unknown (Saperstein 1991, p. 257).

Others complain that the overlapping jurisdiction of regulatory agencies can force biotechnology firms to obtain a "quiver of licenses" to conduct field-release experiments (Kim 1993 , p. 1178). Obtaining proper permits can be very costly and time consuming for companies, and it can be difficult to decipher exactly what regulations may apply to a particular technology or experiment (Kim 1993, p. 1178).

However, the Coordinated Framework may not apply to numerous genetically altered organisms. It does not cover animals that are not insects, nor insects that are not plant pests, nor plants that are not parasites (7 CFR Sec. 340.1 (1990)). In addition the Framework only applies to government funded experimental biotechnology and to the commercial distribution of products. - Privately funded research may be exempt from regulation under the Framework unless specific permitting regulations happen to apply to the particular organisms or processes under study (Auchincloss 1993, p. 53).

In addition, the regulations only apply to organisms with genetic material from another genus, exempting genetically altered organisms containing DNA from other species. However, the taxonomy of microorganisms has not defined reliable methods for discerning species and genera, and biologists have not analyzed whether the risk posed by a genetically altered organism bears any relationship to the genetic distance between the host and transferred genetic material (Auchincloss 1993, p. 51). 


\subsubsection{Questions for future policy initiatives}

Some commentators claim the Coordinated Framework approach to U.S. biotechnology regulation represents a triumph for the biotechnology industry. Others are less enthusiastic, arguing that major responsibilities for regulating biotechnology products remain with overlapping agencies implementing statutes that did not respond to the particularities of biotechnology. Many citizens fear that inadequate regulation of genetically altered organisms is inevitable, since current scientific understanding cannot predict the results of field releases (Auchincloss 1993, p. 55).

In September 1994 (59 FR 45526) the EPA issued its proposed rule covering regulation of microbial products of biotechnology under the TSCA. While the EPA's Regulatory Agenda in the November 28, 1995, Federal Register states that a final rule is expected to be issued in June 1996 , the rule has not been finalized at the time of this publication. The proposed rule is intended to provide a mechanism to screen new microorganisms before they are introduced into commerce and prevent unreasonable risk to human health and the environment without imposing unnecessary regulatory burdens on the biotechnology industry. EPA defines new microorganisms as those formed by deliberate combinations of genetic material from organisms in different genera.

However, these regulations do not appear to address the deeper problems in U.S. biotechnology policy. Field testing or release of many genetically engineered organisms still escape regulatory review, and the EPA bears the burden of proving that an "unreasonable risk" is "reasonably likely" to result from experiments in order to require further studies (Chadwick 1995, p. 236). While this policy furthers industrial development of organisms for bioremediation, agriculture, and pharmaceutical purposes, it is unclear what additional regulatory measures the public may demand to assure more stringent protection of human health and the environment. Since the federal legislative and rulemaking processes do not provide mechanisms for significant public involvement, concerned citizens may turn to state and local governments to implement biotechnology regulations (Vito 1993, p. 360).

The fact that several states have considered or passed state-level regulations of biotechnology indicates that citizens are not satisfied with the level or regulation implemented by the federal government. Hawaii, Florida, West Virginia and Wisconsin have expanded their state environmental laws to encompass genetically engineered organisms and field release regulations. California and New Jersey have created interagency task forces to oversee the integration of existing state laws related to biotechnology. North Carolina, Minnesota, Illinois, and Oklahoma have passed new legislation independent of existing health and environmental statutes specifically addressing biotechnology issues. Maine and New York have created new legislative agencies empowered to promulgate state-level regulations of biotechnology and genetically altered organisms (Vito 1993, p. 363).

State-level approaches to biotechnology policy are not uniform, and developers of bioremediation technology may face regulatory difficulty in deploying new technology in different 
states while complying with overlapping federal agency regulations in addition to state level restrictions. It is unlikely that these regulatory tangles can be removed without an act of Congress creating a coherent biotechnology policy which preempts state regulatory authority in this area:

\subsection{Regulation of the Naturally Occurring Exotic Species}

Public doubt about whether current biotechnology regulations are adequate to preserve the quality of public health and the environment may flow from public understanding of the devastation naturally occurring exotic species have caused in U.S. ecosystems. The environmental impact of the field release of genetically altered organisms is poorly understood, just as the potential harm caused by the release of exotic species has been poorly understood in the past. Some scientists argue that GEMs are less likely to cause harm since the genetic changes altering the organisms may be clearly understood, and control mechanisms may be included in the new organisms.

Others counter that this reassurance is premature, since very little data on the consequences of field release experiments has been compiled (Auchincloss 1993, p. 52). However, genetically altered species are currently being released, and researchers are learning more about the consequences of larger-scale non-experimental projects. Science recently reported that Monsanto's genetically engineered cotton is not performing as expected, now that it has been widely marketed and planted on over 2 million acres. The cotton produces a toxin $\mathrm{B} t$, which has been used to control pests on organic crops. However, the genetically engineered cotton has been plagued with bollworms and budworms which appear to be developing resistance to the toxin at an accelerated rate in response to exposure to the genetically altered plants (Kaiser 1996).

Scientific understanding of the impact of some exotic species is more-complete, and many caused economic as well as environmental devastation. The 1981 outbreak of gypsy moths, forest pests native to Europe, caused over $\$ 760$ million in damages in the northeastern United States. Almost half of serious insect pests and over half of weeds in America are exotics. The lamprey has devastated the Great Lakes fishery industry, and zebra mussels may force the power industry to spend over $\$ 800$ million in redesigning power plants to minimize the damage caused by mussels clogging water lines. Eurasian cheat grass has replaced more than 40 million hectares of native grasses in the western United States, contributing to the increased fire damage on rangeland. Interbreeding of exotic hatchery salmon and native stocks in the Northwest threatens the genetic integrity of endangered runs. The Mediterranean Fruit Fly caused over $\$ 2$ billion in damage to Californian agricultural crops, and public opposition to the spraying campaign to eradicate the pest illustrates the political as well as scientific difficulty in eradicating exotics. (Bright 1995).

The introduction of pathogenic exotics or species carrying pathogens can harm public health and the environment. European colonists brought exotic germs to the American continent, resulting in the death of an estimated 30 million native Americans in the 18th and 19th Centuries. 
More recently, international trade in wood products led to the spread of Dutch Elm Disease and Chestnut blight, which killed vast numbers of American trees (Bright 1995).

Under current law, the release of exotic species is far less regulated than releases of genetically altered organisms. While tort and nuisance law may provide some compensation for harm caused by the release of exotic species, it can be almost impossible to prove who was responsible for the release and how the damage was caused: Few individuals would be able to provide compensation for the amount of damage that has resulted from some exotic introductions. Tort remedies are only available after harm has occurred, and the limited impact of individual lawsuits has little deterrent effect on the release of exotic species. Some legal commentators have suggested the use of pollution control laws to punish people who release exotic species, but this theory remains untested (Dentler 1993, p. 203).

Congress plays a limited role in regulating the release of exotic species. In 1900, Congress passed the Lacey Act, which makes it a federal crime to import, export, transport, sell, or purchase plant and animal species in violation of existing federal and state law. However, the Act only limits the importation and transport of a few specific species known to pose a serious threat to public health and the environment (Kurdila 1988, p. 103). Environmentalists have criticized this "dirty list" approach, since few species are regulated until their release has caused enough harm to alert the regulators, when the damage may be controlled but not prevented. The impact of listing under the Lacey Act is very limited, since harmful species may be imported under a permit from the Fish and Wildlife Service. Unlisted species may be imported once a declaration has been filed with the U.S. Customs Service (Dentler 1993, p. 212). Federal law does not control the actual release of exotic species, and many states have deliberately introduced game fish and wildlife which have multiplied and threatened native stocks (Bright 1995).

While the release of exotic species once they have been imported is regulated entirely under state law, President Carter attempted to implement more federal control in Executive Order 11,987 , which authorized federal agencies to restrict the introduction of exotic species into federal lands, and encouraged agencies to cooperate with state and local regulatory bodies in implementing regulations to preserve native habitat. The executive order banned the importation of exotic species until the Secretaries of Agriculture and the Interior were satisfied that the species did not pose an unreasonable danger to native ecosystems. It encouraged agencies to use the NEPA EIS system for reviewing proposals to introduce exotic species (Kurdila 1988, p. 103). However, the Executive Order was never implemented through regulations, and state law remains the major force in regulating the release of exotics. Since species movement through an ecosystem is not stopped at state borders, individual states have little assurance that a banned exotic will not be released in a neighboring state and migrate across into its jurisdiction (Kurdila 1988, p. 108; Dentler 1993, pp. 215-6).

Recently Congress held hearings on the "National Invasive Species Act of 1996," which had been introduced but not passed in a different form in 1990. The proposed legislation would establish voluntary guidelines for limiting the introduction of ballast water from international 
cargo vessels into U.S. waters. While the impact of HR 3217 would be limited, the EPA and marine biologists support this step toward regulating the release of exotic marine species (Testimony July 17, 1996).

While the impact of exotic species may not provide an accurate model for evaluating the hazards of releases of genetically altered organisms or microbes used for bioremediation, public understanding of biotechnology is informed by reports of exotic pests and problems. Technology developers must engage public concerns about their control over released organisms, both to assure public support and to preclude environmental damage from poorly researched releases.

\subsection{International Regulation of Biotechnology}

While the United states has implemented risk-based regulation of biotechnology based on preexisting legislative frameworks, other countries have implemented a variety of different regulatory structures. The United States regulates biotechnology based on the problems associated with the product of genetic manipulation, rather than restricting the deployment of all technologies and inventions produced through genetic engineering processes. U.S. policies assume that genetically engineered organisms pose no more risk than organisms produced through traditional breeding methods unless scientific evidence suggests an additional risk.

Most other countries either regulate all orgànisms, substances, and processes produced through genetic manipulation, or they have not implemented biotechnology regulations at all.

\subsubsection{Process Based Regulations}

Germany, Denmark, Japan and the United Kingdom have implemented biotechnology regulations that affect all organisms, processes or substances produced through recombinant DNA techniques. These countries' laws vary in their impact on industrial competitiveness and in the public involvement provisions included in the legislation.

\section{Denmark}

Denmark was the first European country to enact legislation which specifically addressed biotechnology. While The Environmental and Gene Technology Act of 1986 initially banned all field releases of genetically altered organisms, subsequent amendments have relaxed the requirements for scientists and industrial researchers to demonstrate the safety of their field release experiments. Current law requires all field releases to pass a review by the Ministry of the Environment (Kim 1993, p. 1171).

\section{Germany}

While the German biotechnology industry ranks among the most successful in the world, the German parliament has passed stringent regulations affecting biotechnology research and field 
releases. In addition, public involvement in requiring strict regulations is strong. The Green Party platform calls for an end to government funding of genetic engineering experimentation and opposes the release or commercial use of genetically altered organisms (Kim 1993, p. 1172).

In 1990, the German parliament passed the Genetic Technology Law, which regulates the release of all genetically altered organisms based on the risk they pose to human health and the environment. The law creates a classification structure for defining the level of risk posed by each organism, and provides for civil liability and criminal penalties for harm caused by non-compliance (Kim 1993, p. 1173). The Genetic Technology Law also provides for public involvement in government assessments of proposed release experiments and commercial enterprises. In one instance, the government received 16,000 public objections to the Max-Delbrick Laboratory's plans to grow genetically altered petunias in an open field, delaying the research and adding expense (Kim 1993, p. 1173). There is some evidence that the regulatory environment in Germany is causing biotechnology firms to relocate their research operations in the United States, where regulations are less stringent and public involvement is less intense (Kim 1993, p. 1174).

\section{Japan}

Like Denmark and Germany, Japan has enacted legislation regulating all products of genetic recombination techniques. Restrictions on field releases are stringent, and public interest in the area is relatively intense. Japanese researchers performed the first GEM field release experiments in 1991, years after U.S. field releases were approved (Kim 1993, p. 1175). While government regulation of field releases is restrictive, the Japanese government is also making significant investments in promoting the biotechnology industry, providing over $\$ 600$ million in R\&D funding in 1989 (Kim 1993, p. 1175). The Ministry of Agriculture, Forestry, and Fisheries is responsible for regulating field releases, and the agency promulgated guidelines for the use of GEMs in 1989 (Kim 1993, p. 1175).

\section{United Kingdom}

The United Kingdom implemented some of the first legislation addressing biotechnology in the 1974 Health and Safety at Work Act. The Act established the Health and Safety Commission, which regulates the safety of workplaces, and the Health and Safety Executive regulates the use of genetic manipulation and microorganisms in industrial applications. The Advisory Committee on Genetic Modification advises both entities on regulation of genetically modified organisms. The Environmental Protection Act of 1990, administered by the Department of the Environment, now regulates the field release of GEMs in a manner consistent with larger European Union regulations on field releases (Kim 1993, p. 1177).

\section{Canada}

Canadian industry has complained for years that regulations governing the introduction of new biotechnology products are cumbersome (Powell 1991). Some critics charge that Canadian 
regulations are a decade behind the United States and that Canadian industry suffers as a result. Current delays and regulatory uncertainties are discouraging new research and investments in commercial facilities, which drive up the costs of innovation and undermine the public's confidence in biotechnology.

Specific complaints focus on the approval process for pharmaceuticals. One suggested approach to short cutting the approval process for new pharmaceuticals is to cut out the duplication of clinical trials that have already been held in the United States. Another complaint is that the regulations governing 1200 or so field tests of genetically altered plants conducted in Canada since 1988 are antiquated and confusing, while in other areas regulations are non existent. Canadian businesses are unwilling to invest in areas of regulatory uncertainty.

\subsubsection{Countries Without Field Release Regulations}

Many countries, including South Korea and Taiwan, have chosen to encourage the development of a biotechnology industry by declining to regulate the release of genetically altered organisms. Other countries with no regulations for biotechnology include Latin American, Caribbean, and Eastern European nations. Many of these nations are now considering national level regulations or participation in international regulatory agreements. In the meantime, researchers from countries with more stringent regulations have sometimes performed field release experiments in countries with lenient or non-existent regulations. For instance, the Wistar Institute of Philadelphia sent scientists to Argentina to conduct tests for a genetically engineered cattle vaccine (Kim 1993, p. 1184).

\subsubsection{International Agreements Regulating Biotechnology}

\section{Organization of Economic Co-Operation and Development}

The Organization of Economic Co-Operation and Development (OECD), formed by 24 industrialized nations for the purpose of promoting economic growth, issued a 1986 report titled Recombinant DNA Safety Considerations - Safety Considerations for Industrial, Agricultural and Environmental Applications of Organisms Derived by Recombinant DNA Techniques (1986 Report). The 1986 Report, which reflected U.S. policies, encouraged member countries to regulate those products of genetic engineering that posed health and environmental risks, rather than imposing restrictions on all substances produced through biotechnological processes. The Report also encouraged countries to permit field release experiments and to exchange information regarding the results ( $\mathrm{Kim} 1993$, p. 1188).

The United States played a leading role in developing OECDs 1992 report on Safety Considerations for Biotechnology (1992 Report). The 1992 Report established Good Development Principles (GDPs) for the design and assessment of small scale field release experiments involving GEMs and genetically altered plants. The 1992 report differs from many 
national laws by encouraging risk-based regulation and review based on the categories of organisms involved, rather than review on a case-by-case basis ( $\operatorname{Kim} 1993$, p. 1189).

\section{Agenda 21 and the Biodiversity Treaty}

The 1992 United Nations Conference on the Environment and Development considered several international agreements affecting biotechnology regulation, Agenda 21 was signed by 182 nations while 153 nations signed the Treaty on Biological Diversity (Kim 1993, p. 1185). Agenda 21 calls for nations to cooperate in promoting sustainable economic development, and contains provisions encouraging responsible environmental management and restrictions on the use of toxic chemicals. The Treaty on Biological Diversity does not address the regulation of genetically modified organisms directly, but it does include provisions for developing an international agreement in the future ( $\mathrm{Kim} 1993$, p. 1187).

In November, 1995, signatories to the Biodiversity Treaty met in Jakarta, Indonesia, to discuss a draft treaty regulating the transboundary movement of genetically engineered organisms. The draft treaty outlined several principles to govern the international movement of biotechnology, including procedures for obtaining informed consent from affected countries, implementing adequate precautionary measures for transport and releases outlined in the biodiversity treaty, and encouraging member nations to implement national level biotechnology regulations (Graziano 1996, p. 179).

The United States has voiced opposition to an international biosafety protocol, claiming that such regulations would impede the progress of biotechnology research and divert funding from projects to produce pharmaceuticals and agricultural improvements. Some biotechnology advocates argue that there is insufficient evidence linking genetically altered organisms with environmental risk, and that additional regulation will stifle innovation (Miller 1996).

\section{European Community Biotechnology Regulations}

Whereas U.S. agencies have largely included biotechnology within the scope of existing statues, the EC regulates genetically manipulated organisms by a combination of horizontal legislation and product-based sectorial legislation. The EC is moving toward a "one door/one key" procedure for risk assessment. In the United States no such commitment exists, and it appears that the regulations of several agencies (e.g., FDA, USDA, and EPA) may be involved.

At the pre-marketing $R \& D$ stage a remarkable similarity exists between the United States and $\mathrm{EC}$ approaches with respect to risk assessment of environmental releases. However, the scope of the regulation is different in the U.S., and greater flexibility exists within that defined scope.

The EC has adopted (approximately 1990) two directives concerning the regulation of genetically modified organisms. The first directive focused on the contained use of genetically 
modified microorganisms and addresses all-activities, from R\&D to production, where genetically modified microorganisms are used. The directive has several purposes:

- to establish a case-by-case risk assessment for all operations

- to identify the cases where the contained use could entail a risk

- to establish working practices and containment measures corresponding to the hazard the microorganism presents

- to prevent, in the case of hazardous microorganisms, their accidental release and limit the consequences of such accidents where they occur.

The second directive addresses the deliberate release to the environment of genetically modified organisms, including microorganisms, plants, and animals. It applies to all stages of release to the environment from small- to large-scale experimental introductions, as well as release through product marketing. Some products may be exempted from the directive's provisions if they are covered by other legislation which includes a similar environmental risk assessment. The main elements of this directive are that

- an environmental risk assessment must always be carried out before any release to the environment whether, in an experiment or product

- no releases may be carried out without the conșent of the competent authorities

- a national approval procedure is foreseen for experimental releases

- a community approval procedure is foreseen for releases made by marketing a product.

Once approval is received for a product it can circulate freely throughout the community. The $\mathrm{EC}$ adopted the directives to provide a common regulatory framework, which is seen as a prerequisite for the development of the biotech industry. 


\subsection{U.S. Environmental Laws and Regulations}

This chapter presents an overview of the general organization of environmental law in the United States, and then focuses on the regulations that are specifically relevant to bioremediation. Federal, state, and local laws are reviewed.

While most U.S. environmental regulations specify what cleanup procedures must be used and what standards must be met, EPA and certain state government environmental agencies are now adopting the idea that environmental protection activities, including cleanup of contaminated sites, should be structured through risk-based regulations. This risk-based approach would allow regulators to impose different requirements for cleanup at different sites, based on the potential risks that each site poses.

One visible effort to use risk-based decision making is the EPA's Risk-Based Strategic Planning effort. Under this effort, the EPA headquarters and all 10 EPA regional offices are developing long-range risk-based strategic plans to guide their efforts. This planning process includes using risk information in an integrated manner to identify and assess environmental issues, to set priorities among these issues, and to develop appropriate strategies to manage these issues. The EPA has also begun to assist state governments in the same process. Another effort is DOE's 10 year integrated strategic planning, budgeting, and management system for. environmental management, in which risk reduction is a major factor. ${ }^{1}$

Attempts to remediate contaminated soil containing listed hazardous wastes could benefit from risk-based regulations, since current efforts are governed by all of the requirements of the RCRA and the CERCLA. The regulatory requirements apply regardless of what concentration of waste is present in the soil, and regardless of the health and environmental risks posed by the contamination. Current rules do not account for the end use of remediated media. For example, cleanup of groundwater is often required to meet drinking water standards, even if the groundwater does not serve as a source for drinking water. Furthermore, being "close" to the standard is insufficient-the cleanup technology must meet the standard exactly.

Requiring all cleanups to meet certain performance standards has been recognized by many observers as not only being costly, but also in some cases as having perverse consequences in terms of addressing any actual health and environmental hazards. For example, incineration of soils in state-of-the-art incinerators may guarantee high levels of decontamination, but it also requires difficult and expensive movement of soils that may actually increase the risk of worker and community exposure. As another example, treatment of contaminated sites is sometimes delayed because no feasible technology can be guaranteed to meet required performance standards-yet the delay in treatment may itself pose ongoing risks to the environment.

1 Alvin L. Alm, DOE Internal Memo, June 10, 1996, "Integrated Strategic Planning, Budgeting, and Management System/10-Year Plan. 


\subsection{Overview of U.S. Environmental Law}

The EPA is the primary federal agency with jurisdiction over environmental management. With few exceptions, EPA implements the laws related to environmental protection, including the major laws governing the remediation of contaminated land. In addition, through its series of research laboratories, EPA engages in research into causes of environmental contamination and into techniques for monitoring and treating contamination.

The federal environmental laws implemented by EPA are primarily organized by the different environmental media. Separate laws govern the release of contaminants into the air (the CAA), onto surface waters (the Federal Water Pollution Control Act, also known as the CWA), into groundwater (the SDWA), and onto land (the RCRA).

In addition to these media-based laws, a key law relating to the management of contaminants in the environment is CERCLA, also known as "Superfund." Unlike the other laws that govern the permitted release of contaminants, CERCLA is designed to address the accidental and uncontrolled release of contaminants into the environment. CERCLA covers releases from catastrophic accidents such as chemical spills, as well as releases that occur over long periods of time (e.g., from a leaking landfill or other land-based industrial activity). (The term "Superfund" arises from the name given to the trust fund set up under CERCLA to pay for cleanup efforts.)

To complement CERCLA and the other. "release-based" laws, there are also two major laws that regulate chemical compounds before any potential release into the environment: the TSCA and the FIFRA. Both of these laws are designed to screen compounds that are potentially hazardous to human health or the environment before they are marketed and used. TSCA provides authority to EPA for review of new and exiting chemicals, and allows EPA to regulate (ban, restrict, etc.) those chemicals that present an "unreasonable risk to human health and the environment." Relevant to bioremediation efforts, TSCA has been interpreted to apply to biological agents such as microbes as well as to chemicals. (This point will be further detailed below in Section 3.3.1.) FIFRA provides similar authority to review and regulate chemicals that are used as pesticides.

Finally, several laws exist that are relevant to environmental policy, and that are overseen by agencies other than EPA. In particular, two laws of consequence are the National Environmental Policy Act (NEPA) and the Occupational Safety and Health Act (OSHA).

NEPA's focus is to ensure that federal agencies give appropriate consideration to environmental impacts in their decision making. To this end, NEPA requires that federal agencies prepare an environmental assessment (EA) or an environmental impact statement (EIS) to document their decision-making process in connection with major federal actions that significantly affect the human environment. 
OSHA is implemented by the U.S. Department of Health and Human Services. It regulates the exposure of workers to physical or health hazards, including exposure to chemical and biological agents. The purpose of the act is to ensure that "no employee will suffer material impairment of health or functional capacity" from a lifetime of occupational exposure.

\subsubsection{Federal Laws Relevant to the Remediation of Contaminated Land}

The management of land-based contamination is governed by two major laws: CERCLA and the RCRA.

\section{CERCLA}

As mentioned previously, CERCLA is designed to manage the unplanned, uncontrolled releases of hazardous substances, both releases from catastrophic accidents and releases that occur over long periods of time (e.g., from a landfill or other land-based industrial activity). In particular, CERCLA provides a system for identifying contaminated sites across the country, for establishing the liability for those sites, and for assessing the best means of remediating the site.

While the main focus of CERCLA is on abandoned hazardous waste sites, its provisions also apply to other sources of contamination, including releases from ongoing business activities (e.g., spills). One notable exception to this coverage is active RCRA-regulated TSD facilities. The regulations governing releases by TSD facilities are covered by a special section of RCRA, rather than by CERCLA.

Liability Under CERCLA. CERCLA imposes liability (and thus cleanup responsibility) with respect to "releases" or threatened releases of "hazardous substances" from a "facility." All three of these key terms are defined very broadly. "Release" is defined to include any spilling, leaking, discharging, leaching, or disposing of a substance into the environment. In this context, the environment can include a private facility site, even if public access is restricted; contamination does not have to go off site to be a release. A release is also specifically defined to include the abandonment or discarding of containers, even if they are closed. "Hazardous substance" is defined to include substances regulated under other environmental statutes, as well as substances specifically designated as hazardous substances by EPA. EPA has developed a hazardous substance list as part of its CERCLA regulations, which appears in 40 CFR Part 302. Hazardous substances under CERCLA include all RCRA hazardous waste types, as well as other contaminants. One limitation on the broad scope of CERCLA hazardous substances is that by statute petroleum and petroleum products are excluded. "Facility" is defined to include any site or area where a hazardous substance has "come to be located." Thus CERCLA facilities are not limited to buildings or structures. (Again, however, CERCLA facilities do not include TSD facilities, which are regulated by RCRA.)

National Contingency Plan (NCP). EPA's decision-making process for responding to releases of hazardous substances is specified in the National Contingency Plan (NCP) (40 CFR 
300). The NCP provides the details that govern the cleanup of all CERCLA sites, whether public or private. ${ }^{2}$

CERCLA and the NCP refer to measures that are taken to address hazardous substances releases as "response actions." Response actions may be either of two types: "removal actions" or "remedial actions." Removal actions are short-term, initial response actions that address immediate environmental threats. By contrast, remedial actions are longer-term actions designed to permanently cleanup sites. Bioremediation efforts are most likely to be used during remedial actions, as they generally would not afford the quick responsiveness needed for short-term removal actions.

The Role of ARARs in the CERCLA Process. Section 121(d) of CERCLA requires that Superfund cleanups comply with all "applicable or relevant and appropriate requirements"-also know as ARARs. ARARs refer to the attainment of standards and requirements promulgated under other federal and state environmental and facility siting laws. ARARs can be either legally "applicable," where they directly cover activities at the cleanup site, or "relevant and appropriate," where they address situations sufficiently similar to those encountered at the site that they should be applied. ARARs can apply in a variety of ways. They can establish cleanup standards, for example, by requiring that groundwater remediation achieve the "maximum contaminant levels" permissible in public drinking water supplies promulgated under the SDWA. ARARs may also impose limitations on the residuals from treatment that may be released to the environment during the course of the remedy, such as air emissions that would be regulated under the CAA or effluent discharges that would be regulated under the Federal Water Pollution Control Act. In addition, ARARs may set design or performance requirements that a remedy must meet, for example by requiring that an incineration of hazardous waste achieve the RCRA incinerator standard for destruction and removal efficiency. In certain very limited situations, CERCLA authorizes EPA to waive the application of an ARAR. Criteria that do not qualify as ARARs because they are not promulgated standards, such as health effects information, technical information, and policy statements, may also be applied at EPA's discretion and are known as "TBCs" (i.e., items "to be considered").

Of particular relevance to many remediation efforts is that if the contaminated material is a hazardous waste, the RCRA hazardous waste regulations will be considered ARARs during the remediation treatment. As discussed previously, this implies that the RCRA LDR standards would be applicable to any land-based treatment or disposal of such contaminated material, unless an exemption is available. That subject is treated in Section 2.2.4 of this report. Again, EPA has now taken the position that exemptions will generally be granted for contaminated soil and debris.

2 The guidance for CERCLA cleanup is found in Subpart $\mathrm{E}$ of the NCP. The NCP also provides guidance in responding to oil spills. 


\section{RCRA}

RCRA provides a framework for the proper management and disposal of all solid waste materials, including both hazardous and non-hazardous waste. As such it is designed to prevent uncontrolled releases of hazardous substances into the environment. The law establishes a comprehensive system to identify solid and hazardous waste, to track generation and management of waste, and to establish treatment and disposal permits and standards.

The part of RCRA most relevant to the remediation of contaminated land is Subtitle $C$, which governs hazardous waste materials (42 USC $\S 6921$ et seq.). Subtitle C regulations are contained in 40 CFR Parts 260 through 272 and apply to the generation, accumulation, treatment, storage, and disposal of hazardous waste. Of particular importance to remediation efforts is the fact that sites contaminated with materials defined as "hazardous waste" the management requirements of RCRA during cleanup activities. Discarded material may be classified as hazardous waste based one or more hazardous characteristics (ignitability, reactivity, corrosivity, toxicity), or by virtue of having been specifically "listed" as hazardous waste.

A key difference between characteristic and listed wastes is that characteristic wastes can be rendered non-hazardous by treatment that removes their characteristic property. For example, neutralization of corrosive wastes will make the wastes non-hazardous. By contrast, a listed waste retains its hazardous waste designation regardless of how it is treated. The only means of having a listed waste determined to be non-hazardous is by regulatory review in which the waste generator submits a "delisting petition" to EPA for the waste. The delisting process is generally recognized as a long and difficult process.

An important EPA policy (the "contained-in" policy) provides that contaminated media (e.g., soil or groundwater) that contain hazardous waste are subject to regulation as hazardous waste as long as they contain the hazardous waste. In the case of characteristic hazardous wastes, any mixtures, residuals derived from treatment of the waste, or any media that contain characteristic waste will be considered hazardous only if the resulting material continues to exhibit the hazardous waste characteristic. For example, biomass derived from the treatment of ignitable hazardous waste would be considered hazardous only if it exhibited ignitability directly. By contrast, any mixtures, residuals, or media that contain listed hazardous waste will be considered hazardous waste until they have undergone the long and difficult delisting process. This standard applies regardless of the amount of listed hazardous waste in the mixtures, residuals, or media. For example, biomass resulting from the treatment of a listed waste in a bioreactor would be considered hazardous waste, even if the biotreatment resulted in complete breakdown of the particular contaminant and the contaminant was no longer present.

3 The definition of hazardous waste is based on a two-step determination. First, the material must be determined . to be "solid" waste, which, according to the legal definition, is basically any material that is intended to be discarded, including solids, liquids, and even contained gases. Once a material has been defined as a solid waste, the second step is to determine whether it is also a hazardous waste-either by virtue of being a "characteristic" hazardous waste or by virtue of having been specifically "listed" as hazardous waste. 
Management of Hazardous Waste Under RCRA. Once a waste has been identified as hazardous according to RCRA, it is subject to a comprehensive set of regulations for its management, treatment, and disposal. RCRA requires "cradle-to-grave" tracing of hazardous waste by facilities that generate the waste ("generators"), by transporters of the waste, and by owners and operators of facilities that provide treatment, storage, and disposal services. .

In addition to notification and manifesting requirements, the facilities that specifically treat, store, or dispose of hazardous waste (TSD facilities) are subject to EPA permitting requirements. These permit requirements cover such things as a list of the types of wastes the facility may treat, performance standards for the treatment process; and requirements for such things as recordkeeping, environmental monitoring of the facility (e.g., groundwater monitoring), employee training, security, emergency planning, and financial responsibility. In addition, permits identify requirements related to the ultimate closure of the facility and the kinds of post-closure care that must be followed. Specific standards are also applicable to particular types of facilities, such as landfills, incinerators, containers, and tank systems.

Several exemptions to the TSD permit requirement exist, of which the following are particularly relevant to bioremediation:

- Owners or operators of totally enclosed treatment facilities and wastewater treatment facilities are fully exempt from permit requirements. A "totally enclosed" facility is defined as one "which is directly connected to an industrial production process and which is constructed and operated in a manner which prevents the release of any hazardous waste or any constituent thereof into the environment during treatment" (40 CFR 260.10). Enclosed bioreactors might qualify for this exemption.

- Onsite treatment of hazardous waste at contaminated sites being.managed under Superfund is exempt from TSD permitting requirements -- although all other RCRA requirements must be met. (These requirements include the need to perform monitoring, conduct personnel training, and so forth. However, it should be noted that most of these requirements are also specified by Superfund.)

These permit exemptions provide an opportunity to use bioremediation to treat hazardous waste without the need for a TSD permit. This represents a significant reduction in regulatory review.

Special Requirements Imposed by the Land Disposal Restrictions. The LDRs prohibit the land disposal of wastes unless they are first pretreated to specific standards. "Land disposal" is broadly defined to include not only landfills, but also surface impoundments, waste piles, injection wells, and land treatment facilities (40 CFR 268.2[a]). While the LDRs are straightforward in concept, they have certain potential implications for remediation activities, particularly those such as bioremediation which may involve various kinds of land-based treatments. 
The LDRs contain two kinds of pretreatment standards: technology standards and performance standards.

- Under technology standards, hazardous wastes must be pretreated with a specific treatment technology (e.g., incineration) prior to land disposal. Bioremediation has been identified as a treatment technology standard for 16 of the roughly 400 hazardous waste types. These wastes include wastewaters containing certain relatively uncommon chemical compounds (e.g., diethyl- and dimethyl-hydrazines, sodium azide, nitroglyclerin) as well as three pesticides (endrin, toxaphene, and 2,4-D) (Bakst 1991).

- Alternatively, under performance standards, hazardous wastes must be pretreated to specific treatment levels prior to land disposal. Any treatment technology can be used, as long as it is capable of meeting the specified treatment level. These treatment levels are referred to as "Best Demonstrated Available Technology" or BDAT standards. EPA has established BDAT levels for each hazardous waste type, based on the decontamination levels achievable through the use of treatment methods identified as the best available for that waste. Incineration has been used to set the BDAT levels for most organic hazardous wastes.

Two implications of LDRs on bioremediation are important. First, because the technology standards set for many hazardous wastes are based on levels achievable by incineration, they represent fairly aggressive treatment levels. It may be difficult for alternative treatment technologies such as bioremediation to guarantee this same level of performance. Second, eyen where bioremediation is capable of meeting the BDAT standards, the LDRs may still restrict the use of bioremediation due to the definition of "land disposal." The LDRs require treatment of hazardous waste prior to placement on land. However, many bioremediation systems are landbased (e.g., such systems as soil spreading or surface impoundments). Therefore, these systems would technically not be allowed to treat hazardous waste without some form of pretreatment of the waste. Of course, such pretreatment would probably make the bioremediation unnecessary.

The EPA has acknowledged that the LDRs may be unnecessarily discouraging the use of alternative hazardous waste treatment technologies such as bioremediation (Giamporcaro 1992). Several options exist for seeking exemptions to the LDRs:

- The LDRs do not apply where it can be demonstrated that there will be no migration of hazardous constituents out of the disposal area for as long as the waste remains hazardous. If the EPA approves of a facility's "No Migration" petition, it will be exempted from the LDR requirements, including the BDAT standards.

- A "treatability variance" provides exemption to the LDRs based on a demonstration that the particular hazardous waste to be treated differs substantially from the baseline waste used to establish the BDAT standards. Of particular importance to bioremediation of soils, EPA has recently established a policy of granting site-specific treatability variances for contaminated 
soils and debris, acknowledging that soils and debris differ significantly from most industrial hazardous wastes and should therefore not be required to meet the same BDAT levels.

- EPA has determined that if no movement of the waste occurs during remediation of sites contaminated with hazardous waste, then LDRs do not apply. This means that such treatments as in situ bioremediation would not be subject to the LDR standards.

- EPA has further determined that, if movement of waste is limited to within the contaminated area, no formal "movement" is considered to have occurred, and the LDRs do not apply. This exemption might cover certain kinds of bio-landfarming of soils, although its application is rather limited. For example, picking up contaminated soils and treating them in an onsite bioreactor would not qualify for this exemption, because the movement of soils into the bioreactor, even though onsite, would cause the LDRs to apply.

While these exemptions will not cover all cases of bioremediation, they do provide certain opportunities for the use of bioremediation to treat sites contaminated with hazardous waste in spite of the restrictive LDRs.

Summary of the Impacts of RCRA on Bioremediation Efforts. RCRA requirements will apply to bioremediation efforts to the extent that they involve the generation, treatment, storage, disposal, or land disposal of hazardous waste. Specifically, if a bioremediation project generates hazardous waste, then generator requirements will apply. If a bioremediation project involves treatment, storage, or disposal of hazardous waste, then TSD standards will apply, including the requirement to have a TSD permit-unless a permit exemption is available. Finally, if a bioremediation project involves land disposal of hazardous waste (e.g., for land-based bioremediation), then the LDRs will apply-unless exemptions to the LDRs are available.

\section{RCRA Correction Action}

Releases of contamination from RCRA hazardous waste TSD facilities are governed by a special program under RCRA: the Corrective Action Program. The RCRA Corrective Action Program is in essence a "mini-CERCLA" program, since most requirements of the Corrective Action Program are modeled after the CERCLA. Most of the RCRA Corrective Action requirements stem from provisions added to RCRA by the Hazardous and Solid Waste Amendments of 1984. These provisions require corrective action for releases of hazardous waste or hazardous constituents from any solid waste management unit (SWMU) at a TSD facility seeking a permit, as well as corrective action for release beyond the boundary of a TSD facility.

The RCRA Corrective Action Program primarily addresses."releases" from SWMUs at a TSD facility. "Releases" include releases of hazardous waste or hazardous constituents to groundwater, soil, surface water, or the air. Under the proposed rule, a SWMU is 
"any discernible unit at which solid wastes have been placed, irrespective of whether the unit was intended for the management of solid or hazardous waste. Such units include any area at a facility at which solid wastes have been routinely and systematically released:"

SWMUs include regulated hazardous waste management units (landfills, surface impoundments, waste piles, and land treatment units that received hazardous waste after July 26 , 1982). However, SWMUs also include units that have managed non-hazardous solid waste. Furthermore, the proposed rule defines "facility" to include all contiguous property under the control of the owner and operator seeking a TSD permit. These definitions have the effect of subjecting to RCRA Corrective Action all releases from SWMUs throughout the contiguous property of the TSD facility owner and operator, whether or not those units have anything to do with the owner and operator's hazardous waste management activities.

The management of SWMUs under the RCRA Corrective Action Program is currently at the beginning stages. EPA estimates that there may be as many as 60,000 SWMUs that are identified at the approximately 4,700 TSD facilities across the country (Kovalick 1992). The industries expected to be most affected by this program are chemical companies, petroleum refineries, wood preservers, and automobile manufacturers.

RCRA Corrective Action Process. It should be noted that treatment of contaminated sites under the RCRA Corrective Action Program will be fully subject to RCRA regulations, including the RCRA LDR restrictions. However, as in the case of CERCLA, exemptions from the LDR restrictions may be available. Other than LDR standards for cleanup, RCRA Corrective Action Program sites may also be required to meet health-based cleanup standards, such as the standards provided by the SDWA.

Exceptions to RCRA/CERCLA Coverage. It is important to note that certain kinds of hazardous materials and/or certain kinds of remediation activities are subject to special regulation and so may not be covered by RCRA hazardous waste regulation or by CERCLA. Included in this list are

- PCBs, which are hazardous substances regulated under the TSCA, rather than under RCRA

- oil spills, which are regulated under the CWA and the Oil Pollution Act of 1990, rather than under CERCLA

- leaking USTs, which are regulated under a separate RCRA section (Subtitle I), and are therefore not subject to RCRA Corrective Action requirements or to CERCLA.

Each of these exceptions is reviewed briefly below.

Regulation of PCBs. PCB waste is generally not regulated under RCRA but instead is regulated under a section of the TSCA, (15 USC $\$ \$ 2601$ et seq). 
EPA's PCB regulations affect bioremediation of PCB contamination in three main ways. First, any handling, storage, or transport of $\mathrm{PCB}$ wastes during bioremediation is subject to the management and manifesting requirements of TSCA. Second, prior to its applications in the field, any bioremediation technology developed for PCB degradation must qualify as an EPA-approved alternative treatment technology under the PCB disposal regulations. TSCA incinerators, TSCA landfills, and high-efficiency boilers are the authorized "nominal" PCB.disposal facilities. Third, the bioremediation effort may be required to meet the cleanup standards established under EPA's PCB Spill Cleanup Policy, which specifies cleanup standards that vary depending on the location of the spill.

Regulation of Oil Spills. Oil spills arid spills of hazardous substances into water are regulated by the CWA, rather than by CERCLA. Section 311 of the CWA prohibits the discharge of "harmful quantities" of oil or other hazardous substances into water.

Once a spill has occurred, responses are governed by the standards imposed by Subpart D of the NCP. ${ }^{4}$ Amŏng other response procedures, the NCP specifies which dispersants, other chemicals, and other spill-mitigating devices and substances may be used on a spill. Subpart J of the NCP governs the use of biological additives for marine oil spills. It identifies several options that can be used to obtain authorization for the application of a biological agent to combat a spill. In particular, the on-scene coordinator (OSC) of a spill response is authorized to use biological additives that have been preapproved by Regional Response Teams. (Under special circumstances, the OSC can select biological additives that have not been preapproved by the Regional Response Team, if the OSC first obtains the concurrence of the EPA, the affected states, and certain other agencies.) Therefore, to ensure its acceptance during the remediation of oil spills, a bioremediation technology is subject to the approval process specified by the NCP and implemented by the Regional Response Teams.

The first significant use of bioremediation for marine oil spills occurred in 1989 during the Exxon Valdez oil spill in Prince William Sound, Alaska. During remediation efforts, certain beach areas of the Sound were subject to nutrient enrichment to enhance the productivity of naturally occurring microbes, under a cooperative study by the.EPA, Exxon, and Alaska's Department of Environmental Conservation. The effort has been called a success by the EPA. Further testing of bioremediation during oil spills has continued with the Mega Borg Spill of 1990 and other spills (OTA 1991).

Leaking Underground Storage Tanks. Leaking underground storage tanks are regulated under RCRA Subtitle I, a section of RCRA that is separate from the hazardous waste regulations. The response requirements for USTs are patterned after the RCRA Corrective Action Program, although they are somewhat less complex and rigorous. In particular, the RCRA LDR standards are not applicable.

4 The NCP.covers all releases of oil and hazardous substances, including. CERCLA releases and oil spills. See Section 2.2.2. 
In many cases, the regulation for leaking USTs - particularly those that contain petroleum - has been delegated by EPA to state governments. This means that considerable variation exists among the treatment standards that must be met for cleanup of soil or groundwater contaminated by a UST. In many cases, bioremediation can meet these treatment standards and is therefore a viable means of cleanip. In fact, the remediation of petroleumcontaminated UST sites is one of the most common applications of bioremediation.

\section{Other Laws Related to Remediation of Contaminated Land}

Two other major laws relate directly to the remediation of contaminated land: NEPA (42 USC $\S \S 4321$ et seq.) and OSHA (29 USC $\S \S 651$ et seq.).

NEPA. NEPA requires all federal agencies to give appropriate consideration to the environmental consequences of any of their planned actions (including permitting or approving private actions) that may have a significant effect on the environment. Federal agencies normally analyze the environmental consequences of their actions by preparing either an Environmental Assessment, a brief description of the proposed action and its potential environmental consequences, or an EIS; a longer and more detailed environmental analysis.

NEPA has particular relevance to bioremediation activities for two reasons. First, NEPA applies to the cleanup of contaminated land if the land is owned or controlled by a federal agency, such as the DOE. Therefore, even when an agency proposes to remediate contamination, an environmentally positive activity, it must fully consider the environmental impacts of the proposed cleanup activities. Second, NEPA gives the general public an opportunity to comment on and propose changes to the federal agency's proposed actions. Depending on the nature of the proposed actions, the public's participation can result in significant obstacles to the agency's . plans. On the other hand, public participation in the NEPA process can also result in positive, creative changes to the agency's proposed actions.

OSHA. OSHA is implemented by the U.S. Department of Health and Human Services and regulates the exposure of workers to physical or health hazards, including exposure to chemical and biological agents. OSHA regulations contain occupational health standards that are directly applicable to "Hazardous Waste and Emergency Response" activities, such as those that would occur during remediation of a contaminated site (29 CFR 1910.120).

\section{Relevance of Water and Air Pollution Laws}

The CWA (33 USC $\S § 1251$ et seq.) protects surface water through volume and contaminant regulation of point - source discharges to surface water and to municipal sewer systems (the latter via "pretreatment standards"). CWA is typically administered through approved state programs. Groundwater quality is addressed by the federal SDWA, (42 USC $\S \S 300$ et seq.), which provides for state regulation of underground injection and sets drinking water standards for the protection of public water supplies. While these standards, known as maximum contaminant level goals and 
MCLs, are directly enforceable only against public water systems, they are often used to set groundwater cleanup standards for contaminated sites (i.e., they are used as CERCLA ARARs). In addition, state water pollution control acts commonly extend to the protection for groundwater, which is often a source of drinking water. The construction of wells is ordinarily subject to state regulation (see Section 3.3.2 below).

Generally, bioremediation projects that generate wastewater will need to comply with applicable discharge requirements and will have to meet ARARs for water cleanup at contaminated sites.

Air Emissions. Air emissions are subject to regulation by EPA pursuant to the CAA (42 USC $\S \S 7401$ et seq.), and by the states pursuant to their own air pollution control statutes. The EPA has established national ambient air quality standards (NAAQSs) for several common air pollutants, including sulfur dioxide, carbon monoxide, ozone, and lead. The ozone standard is interpreted to apply to VOCs that are ozone-generators. The CAA assigns responsibility for attaining the NAAQSs to the states. Each state is required to establish air quality control regions and adopt the necessary regulatory program. Section 112 of the CAA (Regulation of Air Toxics) directs the EPA to establish separate National Emission Standards for Hazardous Air Pollutants (NESHAPs). As of 1990, the EPA had established NESHAPs for a limited number of pollutants, such as arsenic and vinyl chloride. The EPA has been criticized for not regulating toxic air pollutants more aggressively. Accordingly, when the CAA was amended in 1990, Section 112 was drastically restructured to establish a new regime for the regulation of air toxics. This program is intended to reduce air emissions of toxic substances by over 75 percent within 10 years, through application of maximum achievable control technology (MACT) for the control of toxic pollutants emitted by source categories established by the EPA. The law itself lists 189 separate toxic air pollutants that will be subject to these requirements, and the list may be expanded by the EPA through rulemaking. Many organic contaminants that are found at contaminated sites are contained in this list, including TCE and other VOCs. As applied to new sources, the MACT will require essentially state-of-the-art emissions controls. In addition, the CAA air toxics program (Section 112) also requires the EPA to establish NESHAPs, including many organic contaminants commonly found at contaminated sites. This program applies MACT standards by "source category" for the toxic air pollutants.

The requirements described above could apply to the use of biofilters to directly treat airstreams, or to a bioremediation project if the project results in emissions of regulated air pollutants in excess of regulatory threshold levels. For example, if a bioremediation project causes significant volatilization of ozone-generating compounds, the new source review requirements would apply. Likewise, as the EPA promulgates regulations for the new toxic air pollutants, NESHAPs for MACT emissions controls would apply if a bioremediation project either directly or indirectly caused any of the listed contaminants to be emitted in excess of the threshold level. 


\subsection{Federal Laws Specifically Relevant to Biological Remediation Methods}

No specific regulations govern the use of bioremediation per se-as opposed to using other technologies - to clean up contaminated land. However, regulations exist that apply to the general use of biological materials during research and during commercial activities, and that are relevant to bioremediation. These regulations are primarily found under the TSCA and the Federal Plant Pest Act (FPPA).

\subsubsection{TSCA}

The TSCA (15 USC §§ 2601 et seq) is designed to provide the federal government with a means of screening compounds that are potentially hazardous to human health or the environment before they are marketed and used. It provides authority to the EPA for review of new and existing chemicals, and allows the EPA to regulate (ban, restrict, etc.) those chemicals that present an "unreasonable risk to human health and the environment." To implement TSCA, the EPA has the authority to require companies to perform a broad range of tests of their chemical substances and to provide test results to EPA. The TSCA does not apply to certain categories of chemical substances covered by other laws, including pesticides (covered by the FIFRA) and food, drugs, or cosmetics (covered by the Food and Drug Administration).

However, relevant to bioremediation efforts, TSCA has been interpreted to apply to biological agents such as microbes as well as to chemicals. In 1986, as part of an interagency policy statement on biotechnology (the Coordinated Framework for Regulation of Biotechnology), the EPA made a policy decision that intergeneric microorganisms (organisms involving genetic engineering between different genera) would qualify as new compounds under TSCA and would therefore be covered by TSCA notification and review requirements. These requirements include the submission of a PMN to the EPA, including extensive information on the microbe as well as a comprehensive risk assessment of its effects to humans and/or to the environment. Based on the review, the EPA can ban release of the microbe, or can allow its use only under certain conditions. The PMN requirements apply to commercial activities only. However, the EPA has also made a policy of strongly encouraging voluntary submission of PMNs by persons involved in research and development activities.

To date, EPA oversight of GEMs under TSCA has been directed by general policy statements rather than by formal regulation. The EPA is currently in the process of formalizing the regulations under TSCA that will govern biotechnology. Draft regulations were proposed in July 1991 and are currently under review. The proposed regulations may narrow the definition of which GEMs are subject to PMN requirements; only those GEMs that contain "deliberately modified hereditary traits" would be covered. In addition, the proposed regulations contain provisions to exempt from PMN the commercial use of GEMs in contained systems such as 
bioreactors. ${ }^{5}$ However, while these proposed regulations are pending, the current broader definition found in the policy guidance is still in effect.

\subsubsection{FPPA}

In addition to TSCA, the FPPA might affect the use of microorganisms for bioremediation is the FPPA (7 USC $\S \S 150$ et seq.). The FPPA, overseen by the USDAs Animal and Plant Health Inspection Service (APHIS), regulates the importation and interstate transport of materials that have the potential to act as pests to plants. The FPPA defines a plant pest as "that which causes damage directly or indirectly to plants or plant parts, or any processed, manufactured, or other products of plants." Use of any such materials requires a permit.

The FPPA permit requirement would be applicable to microorganisms being used for bioremediation that either are plant pests themselves, or that closely resemble plant pests (e.g., because they are in the same genus as identified plant pests). APHIS maintains a list of microorganisms that qualify as plant pests in 7 CFR 340.2 (Bakst 1991). This list must be consulted to determine whether any microbe being considered for bioremediation would require an FPPA permit.

Most microbes used for bioremediation would be exempt from the permit requirement because they are unrelated to plant pests. However, exceptions may exist. For example, uses of microbes in the Pseudomonas genus-which are being contemplated for the bioremediation of TCE-might require an FPPA permit requirement because some Pseudomonas species are plant pathogens (Clark, personal communication).

\subsubsection{Transportation Requirements}

The DOT regulates the transportation of biological materials, including transportation of microorganisms. In general, DOT requirements are intended to ensure the safe transportation of potentially dangerous chemical and biological materials. Current DOT requirements that govern biological materials are fairly straightforward, requiring proper packaging and labeling prior to transport.

The DOT is currently in the process of developing new, more restrictive regulations governing the transportation of infectious agents. This new regulatory effort has been prompted by concerns regarding the transport of dangerous pathogens such as the Acquired Immune Deficiency Syndrome (AIDS) virus. While these new regulations are not intended to impact other, nonpathogenic biological materials, some concern exists that they will be written and interpreted broadly. If this is the case, the transport of microbes for bioremediation activities may be faced with increased regulation in the near future.

${ }^{5}$ Personal Communication, E. Clark, U.S. Environmental Protection Agency. 


\subsubsection{State and Local Requirements}

In general, state environmental law tends to follow the structure of federal law. Each state has the equivalent of an EPA, with authority for overseeing environmental protection issues within the state. Federal environmental requirements will always be applicable on the state level. However, states may also exert authority for environmental protection independently from the federal government.

States may become "authorized" by the federal government to administer the federally - mandated program. In this case, states take over full administration of the federal program, including permitting and enforcement activities. While the states are still required to follow federal regulation, they have more latitude for directing the program according to their state-level priorities. Examples of federal programs often delegated to states include RCRA hazardous waste management, the UST management program; and the CAA and CWA programs.

States also have the authority in some cases to pass state-level legislation that is more stringent in its requirements than federal legislation. In the remediation of contaminated sites, four common kinds of differences between state and federal requirements are that states

- may require remediation of sites not considered by the federal government

- may regulate a larger universe of contaminants

- may require more stringent cleanup standards

- may require certain permits that the federal government, does not require.

An example of additional state permitting requirements is the injection of materials into the ground, which is generally governed by state permit programs. A state permit would be required, for example, for an in situ bioremediation project that requires injection of nutrients into the ground. Injection requirements may also be supplemented by state regulations governing well construction.

Local governments (counties, cities, etc.) do not have direct authority over most aspects of contaminated site remediation. However, local governments may become involved through their authority to set zoning, taxation, or other land-use requirements. In addition, local governments can have significant authority over issues related to public health. For example; protection of groundwater sources that serve as drinking water may be at least partially the responsibility of local governments. If a bioremediation effort were to impact such groundwater sources, it might be subject to local government review (EPA 1984). 
Furthermore, independent of direct authority, local governments will also have a role in bioremediation efforts because local government is a focal point for public reaction to the planned remediation. This point will be discussed more fully in Chapter 7.0. .

\subsection{Identifying Regulatory Issues}

To determine what specific regulatory issues would accompany a bioremediation project, the most straightforward approach is to step methodically through the treatment process and examine the kinds of generic activities that the project might involve (e.g., soil extraction, addition of nutrients) and the kinds of residuals that might be generated (e.g., water discharges, air volatilization of contaminants, waste residuals). These activities and residuals-which can be termed "environmental adjustments"-determine which environmental regulations would apply at each part of the treatment process.

\subsubsection{Description of Major Types of Bioremediation Systems}

Essentially three types of bioremediation treatment exist: in situ treatment, land-based treatment, and reactor-based treatment. Each type of treatment is subject to special kinds of regulatory review, based on its potential for environmental impact.

In situ bioremediation entails treating contaminated soils or groundwater in place (without excavation). In situ treatment can rely on organisms that occur naturally at the site (indigenous organisms) or can involve added organisms (bioaugmentation). Depending on site hydrogeochemical conditions, in situ treatment can either be aerobic or anaerobic. ${ }^{6}$ In situ treatment-by not being separated from the environment-faces special regulatory issues. For example, the addition of nutrients might occur via underground injection, which is covered by general regulations on underground injection.

Land-based and reactor-based bioremediation are both referred to as "ex situ" treatment, since they require the excavation of the contaminated media.

Land-based bioremediation can take a number of forms, including: 1) engineered soil piles, ${ }^{7}$ which involve piling contaminated soil into heaps.on an asphalt or other treatment bed; 2) composting, in which air is moved through soil piles to generate thermophilic microbial activity; and 3) surface treatment ${ }^{8}$ which involves treating soils in a ground-based treatment area designed to serve as an ultimate disposal site. The treatment of sludge and sediments in lagoons is another form of land-based treatment. Land-based bioremediation generally relies on aerobic degradation

\footnotetext{
${ }^{6}$ Aerobic biodegradation relies on the presence of oxygen in air to direct the degradation process (hence the word "aerobic" for air-based). Alternatively, anaerobic (non-air-based) biodegradation occurs only in the absencoxfgen.

7 Engineered soil piles are also referred to as "soil heaping."

8 Surface treatment is also referred to as "solid-phase biotreatment," "land farming," or "landspreading." See Skladany and Metting (1992).
} 
and can use either native or non-native organisms. A general characteristic that distinguishes land-based systems from in situ systems is that they use control techniques such as liner systems to separate them from the general environment. Typically, land-based systems provide control of leachate via leachate collection systems. Similarly, volatilization of contaminants can be controlled by using covers, such as greenhouses.

Reactor-based treatments (often referred to as bioreactors) entail the use of closed tanks that allow for stirring, tumbling, or other means of mixing of the contaminated media. Typically, bioreactors for treating contaminated soil convert the soil into a slurry through mixing with water. These reactors are therefore known as slurry bioreactors. The water used in slurry reactors can be contaminated surface water or groundwater, allowing for simultaneous treatment of both soil and water. In addition, tumble bioreactors can be used to biodegrade soils mixed with bulking agents. Finally, bioreactors can also be used to treat contaminated water alone. Because reactors are closed systems, they can use either aerobic or anaerobic organisms, although aerobic treatment is more common. The organisms used can be either native or non-native. Finally, all aspects of the bioreactors' outputs can be controlled, including air emissions and ultimate disposal of water.

\section{3..2 Bioremediation Activities that Affect the Environment}

Apart from the governing regulatory framework, a series of regulatory requirements arise during bioremediation projects because of the specific activities that the projects involve or because of the kinds of residuals that might be generated. The following discussion will identify the activities and residuals that might occur during a bioremediation project and will address their general regulatory implications. Both in situ and ex situ applications of bioremediation will be considered.

\section{Phytoremediation}

Plants that preferentially take up contaminants from the soil and groundwater (e.g. lead) may be used to remediate terrestrial sites. Uptake of contaminants by the plants lowers concentrations of contaminants in the environmental media, often to levels that bring the site within acceptable regulatory limits for release or reuse. However, when harvested, the plants themselves often contain high concentrations of contaminants that exceed regulatory limits. Under various U.S. environmental laws (e.g., CERCLA, RCRA), the harvested plants themselves may then become regulated substances. Hence, before remediating a site, deployers of phytoremediation technologies must understand and have a strategy for addressing regulatory concerns related to the ultimate disposal of the contaminated plant material.

\section{Use/Release of Microorganisms}

One of the first decisions to make regarding a bioremediation project is what type of microorganisms will be used for the treatment process. From a regulatory standpoint, three types 
of microorganisms to warrant consideration: genetically engineered microorganisms (GEMs), naturally occurring but non-native microorganisms, and indigenous microorganisms. A large majority of cases to date and for the foreseeable future utilize indigenous organisms.

Use/Release of GEMs. The use of GEMs for bioremediation is subject to special U.S. Environmental Protection Agency (EPA) regulation under TSCA. In particular, a premanufacture notice (PMN) review process would have to be followed prior to any commercial use of GEMs for bioremediation.

The PMN review process is required in one of two instances: either when a GEM is first proposed for use or whenever it is proposed for a "significant new use." Theoretically, this means that once a particular GEM has been approved under the PMN process for use in a bioreactor, for example, it could be used in similar bioreactors without requiring EPA review. However, if a GEM has been approved for use in a bioreactor, it could not be used in a land-based system without again being subject to EPA review, since such use would constitute a "significant new use."

The recently proposed EPA regulations goveining GEMs (40 CFR 700, et al.) would exempt the use of GEMs in contained systems such as bioreactors from the PMN process, and would otherwise narrow the definition of which GEMs are subject to PMN review. If approved, these proposed regulations might facilitate the use of GEMs for bioremediation in some cases.

Use/Release of Non-Native Microorganisms. In some instances, a bioremediation project may choose to use naturally occurring (i.e., non-engineered) microorganisms that are not indigenous to the contaminated site.

No permitting or approval from EPA is required before the use of such microorganisms. However, several other regulations might possibly apply. For example, the permit requirements of the Federal Plant Pest Act would apply if the microorganisms to be used were considered plant pests or were in the same genus as identified plant pests. ${ }^{9}$ In addition, the transportation of microorganisms to a site would be covered by U.S. Department of Transportation (DOT) requirements governing biological materials. Current DOT requirements are fairly straightforward, requiring proper packaging and labeling prior to transport. Finally, it is possible that in some instances the use and/or release of non-indigenous microorganisms would be covered by state or local public health regulations. However, because public health regulations are primarily concerned with human pathogens, and because microorganisms being used for bioremediation are unrelated to human pathogens, the likelihood of such regulation is fairly small. Furthermore, such regulation would probably not cover bioreactors because they are closed systems.

9 In the special case of GEMs, the FPPA also applies to microorganisms that have been modified to include any genetic materials from species that are considered plant pests (Giamporcaro 1992). 
Use of Indigenous Microorganisms. The use of indigenous microorganisms is subject to little direct regulation. One possible but remote exception is that the active stimulation of indigenous microorganisms (e.g., through the addition of nutrients) as in the case of non-native microorganisms, might trigger state or local public health regulations if a concern about human pathogens exists.

\section{Application of Chemical Agents to the Environment to Stimulate Bioremediation}

A series of chemical agents may be required by the bioremediation project to ensure optimal conditions for biodegradation. These agents include oxygen sources, nutrients, and carbon sources. In addition, the application of tracer compounds may be required to monitor progress of the bioremediation process, particularly for in situ projects. The application of any of these chemical agents may raise regulatory issues.

Oxygen Sources. If the bioremediation project is using an aerobic process, the microorganisms will require sufficient oxygen to perform metabolism of the contaminants. Oxygen can be added to the treatment area either through aeration (the addition of air) or via application of hydrogen peroxide solutions.

Common methods of aeration range from the simple technique of tilling soils in a land-based system to more involved procedures such as bioventing (forced air injection into the contaminated media) or negative air pressure (drawing air through the contaminated media by vacuum suction). In in situ applications, aeration is performed using wells drilled into the treatment area. For landbased ex situ applications, aeration occurs either via direct tilling or via piping laid down in the treatment area. Finally, for bioreactors, aeration generally occurs by venting the unit as a whole.

Because in situ aeration techniques require construction of wells, such activities come under any existing well construction and maintenance regulations. While the EPA does not regulate well construction, most states do so as a part of their water supply or underground injection regulations. For example, the State of Washington has well construction standards for all types of wells, including "resource protection wells" such as would be used for a remediation project. ${ }^{10}$ Well construction regulation may specify the kinds of drilling techniques that can be used, the kind of maintenance required, and so on. These well construction standards would have to be met prior to in situ air injection activities.

More importantly, another potential regulatory concern posed by all aeration procedures, (both in situ and ex situ) is that aeration might cause contaminants to become volatilized, particularly volatile organic compounds (VOCs). Any volatilization of contaminants would trigger regulation under the Clean Air Act (CAA), especially the regulations governing air toxics (Section 112 of the $\mathrm{CAA}$ ). These regulations require control technology to maintain air emissions

10 Regulation of well construction in Washington State is found in the Washington Administrative Code, Section 173-160. 
below certain threshold levels. In addition, some states regulate air toxics, and such regulations would also have to be addressed. For bioreactors, air emissions controls could be imposed at the point where air is vented outside of the reactor. By contrast, aeration of in situ or land-based systems promotes volatilization throughout the treatment area, so there would be no single air emissions point, making controls more difficult. One strategy to address this problem involves the use of a greenhouse cover over the treatment area, although such an approach may not be feasible for large remediation sites. Regardless of the opportunity for controls, it is likely that the bioremediation project would be required to perform air sampling to ensure that any emissions from the site remain below regulatory thresholds.

Water-based application of oxygen (e.g., hydrogen peroxide solutions) will have regulatory implications similar to aeration. In situ use of water-based oxygen would involved the same well construction standards that would be applicable to in situ aeration. In addition, in situ waterbased oxygen application might also come under state-level underground injection standards related to injecting water. Finally, water-based application of oxygen also has some potential for increasing volatilization of contaminants, although its effect would be much less than that of aeration.

Nutrient and Carbon Source Addition. The addition of nutrients may be necessary when otherwise low concentrations limit microbial activity. Nutrients generally include various compounds containing nitrogen or phosphorus (i.e., "fertilizers"). In some cases, additional carbon sources such as methane or acetate may also be required to stimulate microbial activity. These substances are generally dissolved in water.

Nutrient or carbon addition for in situ treatment is by aqueous injection through wells. In this case, adding nutrients or carbon sources implies meeting both well construction standards (outlined above under oxygen addition) and underground injection standards. In particular, EPA's Safe Drinking Water Act (SDWA) regulations provide numerical limits for a number of chemicals, including nitrates, being injected into underground sources of drinking water. Therefore, nutrients and carbon sources being considered for injection for a bioremediation project must be checked against SDWA requirements. In addition, state standards governing underground injection may also be relevant. For example, some states regulate more compounds than does EPA. States may also set more restrictive injection standards.

While nutrient or carbon addition per se would not be regulated in ex situ treatment (since ex situ treatment is by definition separated from the environment), any nutrients or carbon sources that remain as residuals in the media or in leachate from the treatment system may be regulated when these media are disposed. For example, if treated groundwàter is disposed via surface water discharge, federal CWA discharge regulations may include limits on nutrient or carbon source levels, particularly nitrates and phosphates. Alternatively, if treated groundwater is disposed via underground injection, SDWA standards and state- or local-level underground injection control standards may apply to any residual nutrient or carbon source compounds in the groundwater. 
Injection of Tracer Compounds. To gauge the progress of an in situ bioremediation process, tracers can be used to indicate where biodegradation is active and how completely it has occurred. Tracer compounds can range from inert substances used simply to show direction of groundwater flow to radioactively labeled compounds capable of being biodegraded, which would be used to indicate the degree of degradation that has already occurred. If trace compounds are to be injected into the ground (most likely in a water base), it would raise regulatory issues similar to those detailed above under nutrient addition, including application of well construction standards and underground injection standards. The use of radioactively labeled compounds might prove to be particularly difficult, as injection of such compounds may be prohibited by state standards.

\section{Adjustment of Physical Conditions to Accommodate Bioremediation}

In addition to adding sufficient oxygen and nutrients to encourage bioremediation, other adjustments of the physical environment may be required to accommodate bioremediation. Such adjustments include modifying the $\mathrm{pH}$, redox potential, temperature, and moisture content of contaminated media. Each of these adjustments may have regulatory implications, particularly in the case of in situ applications.

pH. Because pH adjustment of in situ treatment would most likely occur via aqueous injection, this activity would face regulatory issues similar to those detailed above under nutrient addition, including well construction standards and underground injection standards. In particular, the SDWA does provide numerical guidelines for the $\mathrm{pH}$ of waters injected into drinking water sources. (Unlike standards, "guidelines" are not enforceable, but they do represent policy goals.) In addition, state standards governing the $\mathrm{pH}$ of injected waters may be applicable.

As with nutrient addition, $\mathrm{pH}$ adjustment of an ex situ treatment process would not be subject to regulation per se, but $\mathrm{pH}$ levels in treated media or leachate might be subject to regulation when these media are disposed. For example, discharge of treated water to surface waters would be governed by $\mathrm{pH}$ standards under the CWA. However, because $\mathrm{pH}$ adjustment is usually designed to make the treated media close to neutral (rather than to the extremes of high acidity or alkalinity), it is unlikely that any such adjustment would result in treated media or leachate that reached regulatory standards for $\mathrm{pH}$.

Redox Potential. Different groups of bacteria predominate at different oxidation-reduction (redox) potentials. In some cases, manipulation of redox to favor a specific bacterial group, such as sulfate reducers, may be proposed.

Temperature. Heating the treatment area may be required to achieve optimum temperatures for the bioremediation process.

For in situ treatment, heating may require injection of water or air. If the heat carrier is water, this activity would raise regulatory issues similar to those detailed above under nutrient addition; 
if the carrier is air, it would raise issues similar to those detailed above under aeration. In addition, heating of contaminated media will in itself tend to increase the degree of volatilization . of organic contaminants, thereby further increasing the likelihood that federal or state air emissions standards apply.

For ex situ treatment, if heating should prove to be necessary, it is unlikely that the temperature of treated soil or groundwater will be sufficiently high to come under temperature standards upon disposal. However, any heating may increase the likelihood of contaminants in process gas emissions, further increasing the need to monitor, and perhaps treat, gas emissions.

Moisture. If the treatment are is too dry to allow for optimum levels of biodegradation, adjustment of moisture content would be required. For in situ applications, regulatory issues for moisture adjustment would be similar to those for nutrient adjustment, including well construction and underground injection standards. As before, for an ex situ treatment process, the only regulatory coverage would be for leachate.

\subsubsection{Other Activities at a Bioremediation Site That May Trigger Regulatory Requirements}

Well Drilling. For both in situ and ex situ treatment, wells may be required for a series of activities ranging from injection of treatment materials (as detailed above) to extracting contaminated materials. Whenever wells are required for the bioremediation project, any existing well construction and maintenance standards will apply. As mentioned previously, while EPA does not have regulations directly covering well construction, most states do. For example, welldrilling activities involving resource protection wells are regulated in the State of Washington.

Soil Excavation. Land-based or reactor-based remediation of soil (ex situ treatment) entails excavation. Excavation and movement of contaminated soils is governed by standards provided by the regulatory framework for the site (e.g., CERCLA or RCRA Corrective Action). In addition, if the soil qualifies as hazardous waste, RCRA hazardous waste generation, transport, and treatment standards would need to be followed. Finally, any extraction or movement of contaminated soil might cause volatilization of contaminants around the extraction area, possibly making the project subject to air emissions regulations under the air toxics sections of the CAA or under state air standards.

Groundwater Extraction and Reinjection. Ex situ treatment of contaminated groundwater requires extraction and, possibly, reinjection. In situ bioremediation may also involve extraction and/or reinjection of groundwater. For example, it may be desirable to influence groundwater flow direction or speed to optimize the bioremediation process. Any such activities will come under regulatory standards for well construction and groundwater injection. In addition, if the groundwater is contaminated and qualifies as hazardous waste, extraction and/or reinjection of the water will be subject to RCRA hazardous waste treatment and disposal standards. This is the case even if the groundwater is to be extracted or reinjected simply to optimize an in situ 
bioremediation process. Treatment standards are governed primarily by the LDR restrictions. In addition, state standards may also apply to reinjection of contaminated groundwater. The result of these standards is to make the reinjection of groundwater difficult; unless it is completely treated. As a result, simple recirculation of contaminated groundwater for in situ treatment is usually not feasible without some form of aboveground treatment of the water prior to reinjection.

\section{Products of the Bioremediation Process}

Finally, after examining the environmental adjustments required by the bioremediation process and associated activities that may occur at the site, it is also important to examine the results of the bioremediation process. These results (or "outputs") also imply certain regulatory issues. The outputs to consider include residual levels of contaminants, breakdown products, and the resulting treated media.

Residual Contaminants. It is clearly important to account for residual concentrations of contaminants being degraded because these levels determine whether the remediation has met the cleanup standards for the site. In general, cleanup standards are set by the governing regulatory framework for the site (CERCLA, RCRA Corrective Action, etc.), and are often based on the standards otherwise found under the general media-based regulations (e.g., CWA standards, SDWA standards, relevant state standards). For example, SDWA maximum containment levels (MCLs) for groundwater injection are often invoked as cleanup standards for contaminated groundwater. This means that contaminated groundwater must be treated so that residual contaminants are below the threshold levels specified by the SDWA. This may be the case even for in situ treatment of groundwater, where no "injection" actually occurs. ${ }^{11}$

In addition, when the media being remediated are considered hazardous waste, cleanup is -governed by the LDRs. This is particularly relevant to in situ bioremediation and to most forms of land-based ex situ treatment, because they necessarily represent "land disposal" and therefore must guarantee that the treatment of contaminants meets aggressive Best Demonstrated Available Technology (BDAT) treatment standards. However, as detailed in Chapter 2.0, exemptions to the LDRs can be sought for in situ and land-based ex situ treatment. These exemptions include a

- No Migration Variance, which provides exemption to the LDRs based on a demonstration that no migration of contaminants out of the treatment area will occur during or after the bioremediation treatment.

- Treatability.Variance, which provides exemption to the LDRs for treatment of contaminated soils and debris.

1 The EPA has some discretion in selecting cleanup levels. These levels must, at a minimum, address actual health risks, but may be then set more stringently, based on other applicable regulation. There is sometimes the opportunity to negotiate cleanup levels on a site-specific basis. 
If either of these variances can be obtained, the site is exempt from BDAT standards. However, it still must meet other applicable regulatory standards for final contaminant levels, including any state- and local-level standards.

Breakdown Products. In addition to determining the residual level of contaminants, it is also important to identify any partial breakdown products of the degradation process and to determine whether they are covered by regulatory standards or policy. In particular, it must be ascertained that the biodegradation of one contaminant does not result in the accumulation of a significant amount of secondary contaminants. For example, the anaerobic degradation of trichloroethylene (TCE) has the potential to form vinyl chloride, a regulated contaminant. Complete and partial breakdown products are of concern for in situ applications and for.ex situ bioremediation processes, to the extent that they occur in the residuals (e.g., extracted groundwater requiring disposal).

Complete and partial breakdown products must meet the same kinds of cleanup standards as the original contaminants. For example, vinyl chloride that accumulates during bioremediation of TCE-contaminated groundwater must satisfy both SDWA and state standards. In addition, if the medium being remediated is determined to be hazardous waste, RCRA regulations (particularly the LDRs) also apply to any breakdown products "derived from" treatment of the medium. Finally, state and local standards may also be relevant.

Treated Media Resulting from Bioremediation. For both in situ applications and landbased ex situ applications, the media resulting from treatment will in most cases remain at the treatment site. Exceptions include the land-based treatment of soils in engineered soil piles, which are generally removed from the treatment site after treatment.

In cases where the material remains at the site of treatment, the final status of the site depends on the governing regulatory framework (i.e., whether the site is governed by CERCLA, RCRA Corrective Action, or other regulation). Each of these laws details specific requirements for closing a treatment site; in terms of monitoring of the treated media and other activities.

Furthermore, the final status of the site also depends on whether hazardous waste was treated and was, therefore, subject to RCRA TSD standards. In that case, the TSD closure standards also apply.

For bioreactor treatment and those land-based treatments that do not include final disposal, the treated media must be disposed of according to the governing regulatory framework. Most importantly, if the treated medium was contaminated by listed hazardous waste, it requires disposal in a RCRA-approved facility, even if bioremediation destroyed the contaminants. For media that were contaminated by characteristic wastes or were not contaminated by hazardous waste, the residuals would be exempt from RCRA hazardous waste disposal requirements. 


\subsection{Intellectual Property and Patenting}

In 1474, the Venetian Senate passed the first general patent law. The Senate emphasized the importance of conferring "honor" on inventors, which would inspire others to "apply their genius .. to build devices of great utility to [the] commonwealth" (Carroll 1995, p. 2444).

A patent is a form of legal protection awarded to an inventor that enables him or her to profit from the invention for a limited period of time before the invention becomes freely available to the public. General patent statutes perform two functions: they reward an inventor's investment of time and resources, and they ensure that inventions are eventually brought into the public domain through disclosure of the patented material. Patents can cover machines, compositions of matter (like new chemicals or drugs), articles of manufacture, and processes (35 USC Sec. 101 et seq.; Schechter 1986, p. 111).

The United States Constitution provides that "Congress shall have the power ... to promote the progress of science and useful arts, by securing for limited times to authors and inventors the exclusive right to their respective writings and discoveries" (U. S. Constitution, Art. 1, Sec. 8 (8)). Participants in the Constitutional Convention understood that patents create a limited monopoly, allowing inventors to profit from their inventions without participating in the free market for as long as the patent protection lasted. However, Congress determined that the social benefit gained by stimulating and rewarding invention outweighed the value of free market competition during the patent's term (Chiapetta 1994, p. 162).

These legislative justifications for patents reflect the incentive to invent theory, which recognizes that inventors require compensation for investments in research and development $(R \& D)$. Without patent protection, inventions could be copied by an inventor's competitors, destroying that inventor's ability to recover costs in the marketplace. The competition would also drive down the cost of an invention, providing profits to the cheapest manufacturer but denying inventors sufficient profit margins to recover development expenses. Patent protection encourages $R \& D$ by granting inventors the exclusive right to prevent others from using or selling the invention without permission, even if they discovered it independently of the patent holder (Ko 1992, p. 791; Scalise and Nugent 1995, p. 87).

Patent law performs a second important function by bringing inventions into the public domain through disclosure requirements. In order to obtain patent protection, an inventor must clearly explain how other people can replicate the invention. This information is available to the public, and once the patent term is over, others may make and sell the invention without the inventor's permission. While it is possible that some inventors could profit indefinitely if they succeeded in keeping an invention secret, such secrecy could result in inefficient and duplicative research, and stifling of communication which helps inventors develop new ideas (Scalise and Nugent 1995, p. 87). Patent law provides sufficient economic incentive for inventors to disclose their inventions in exchange for a limited monopoly. Recently, the Supreme Court stated that "the ultimate goal of 
the patent system is to bring new designs and technologies into the public domain through disclosure" (Bonito Boats 1989, p. 151).

Historically, patent law has provided inventors with 17 years of protection from the date the patent issues in which to recover their development costs. However, Congress recently changed the patent term to 20 years from the date of filing, to bring United States law into compliance with international standards set out in the General Agreement on Tariffs and Trade (35 USC 154 et seq.; Derzko 1996, p. 9).

Patent protection is especially important to the biotechnology industry, since so many developments require large investments in $R \& D$, and new ideas may require 5 to 10 years to commercialize. The extension of the patent term to twenty years may help biotechnology inventors to recover more of their development and commercialization costs. However, since the term begins running before the patent issues, inventors may not receive as much protection if the Patent and Trademark Office (PTO) delays issuing the patent. The Patent Code contains provisions for extending the patent term if issuing delays jeopardize its value (35 USC 154-155; Hardy 1994, p. 308).

\subsection{Obtaining a Patent}

To obtain a patent, the inventor must file an application with the PTO which discloses a detailed description of the invention and instructions on how to make and use it. While "products of Nature" are not patentable, recent changes in case law have clarified that living material may be patentable, especially when they have been genetically altered. This section will discuss patent requirements and the product of nature doctrine in more detail, and conclude with a discussion of public opposition to the patenting of living organisms.

\subsubsection{The Patent Application Process}

The patent application process is essentially adversarial. The PTO must carefully filter out applications that may duplicate or infringe on material already patented by other inventors, to prevent excessive infringement litigation and to ensure that each patent is actually valid. Patent examiners will also deny patents to applicants who breach the duty of candor in describing the prior art, utility, and operation of the invention. While the patent examiner works to filter out applications that do not meet statutory criteria, the inventor and patent attorney work to persuade the examiner that their application should qualify. The entire process can take several years to complete (Schechter 1986, p. 123). ${ }^{12}$

Usually an inventor will work with a patent agent or attorney to prepare a patent application. The application must disclose the invention in detail sufficient to enable someone skilled in the field to make and use the invention. The patent examiner then determines if the application meets

\footnotetext{
22 Conversation with Steve May, July 16, 1996.
} 
the statutory criteria of novelty, utility, and nonobviousness (35 USC 101 et seg.). The applicants then submit the application and appropriate fees to the PTO. A patent examiner reviews the application, and either grants the patent, or more usually issues an Office Action explaining why it fails to meet statutory criteria. The inventor and attorney work to respond to these objections. The examiner responds with a final Office Action; the applicants can then make one more attempt to persuade the PTO that the invention should receive a patent.

If the examiner fails to grant a patent by this point, the applicant and agent/attorney have three choices:

1. re-file the application or file a continuation to go through the process again, creating more time to provide information to support the arguments or to make other amendments to the claims

2. abandon the application by failing to appeal or refile within six months

3. appeal the Examiner's outstanding rejections.

The appeal process starts with the Board of Patent Appeals and Interferences, a review board internal to the PTO. If applicants lose the appeal, they can either file suit against the Commissioner of Patents in the U.S. District Court for the District of Columbia, or appeal to the Court of Appeals for the Federal Circuit Court (CAFC). If the Circuit Court rules against the applicants, they can make one final appeal to the United States Supreme Court (Schechter 1986, p. 123).

\subsubsection{Statutory Requirements for Patentability}

To obtain a patent, an applicant must fully disclose the details of the subject matter, and the Patent Examiners must issue a patent unless they can demonstrate that an invention or discovery fails to meet criteria laid out in the United States Patent Code (35 USC 100 et seq.). There are three types of patents: utility patents (most common), plant patents, and design patents. This section will focus on utility patents, which are most relevant to biotechnology inventors. Plant patents will be discussed briefly in a later section. Design patents are not relevant to the field of biotechnology (OTA 1991, p. 203).

To qualify for a utility patent, the invention must be patentable subject matter and it must be novel, non-obvious, and useful. It must also be fully disclosed (35 USC 101, 102, 103, and 112). While these patenting requirements are simple, case law and detailed statutory provisions complicate this area of law. The applicant must devote major portions of the patent application to the specification (describing the invention in detail) and to the claims. The claims are particularly important, since they determine the patent's scope, which defines the extent to which the patent holder can prevent others from researching or commercializing variations or improvements on the patented subject matter.(Ko 1992, p. 781). 


\section{Patentable Subject Matter: Utility}

The Patent Code states that "[w]hoever invents or discovers any new and useful process, machine, manufacture, or composition of matter, or any new and useful improvement thereof, may obtain a patent therefor .. " (35 USC 101). This provision requires that patentable material must be useful (the "newness" requirement is elaborated in Sec. 102).

\section{Novelty Requirements}

Novelty requirements are defined in 35 USC Sec. 102, which states that a person is entitled to a patent unless:

(a) the invention was known or used by others in this country, or patented or described in a printed publication in this or a foreign country, before the invention thereof by the applicant for patent, or

(b) the invention was patented or described in a printed publication in this or a foreign country or in public use or on sale in this country, more than one year prior to the date of the application for patent in the United States, or

(c) [the inventor] has abandoned the invention, or ...

(e) the invention was described in a patent granted on an application for patent by another filed in the United States before the invention thereof by the applicant . . . or on an international application by another who has fulfilled the requirements . . of this title before the invention thereof by applicant for patent, or

(f) [the inventor] did not ... invent the subject matter sought to be patented, or

(g) before the applicant's invention thereof the invention was made in this country by another who had not abandoned, suppressed, or concealed it.

Scientists and inventors facing pressure to publish their findings run the risk of jeopardizing their patents if they publish before they file the application. If the publication occurs more than a year before the application is filed, the PTO will reject the application for lack of novelty. Researchers should also consult patent experts to determine whether field testing of an invention or process constitutes "use" which could trigger the requirement to file for U.S. patents within one year.

In cases where inventors want to obtain foreign patents, publication can pose a more significant problem. While U.S. law requires inventors to show that the subject matter is novel, and that it has not been used or published for more than a year before the patent application is made, foreign laws often require applicants to demonstrate "absolute novelty." Absolute novelty 
means that any evidence of use or publication of an invention can invalidate the patent (Patents Throughout the World 1995).

\section{Non-Obviousness}

The patent code directs patent examiners to reject any subject matter that would be obvious to a person having ordinary skill in the technical field related to the invention. While early versions of patent law required a "flash of genius" for an invention to qualify for a patent, Congress changed the statute to make it easier for inventors to qualify through exhaustive experimental methods that might not reflect any single moment of inspiration. Current law suggests that the subject matter must advance the state of tèchnology by a "significant step" (Jones Knitting 1966).

The inventiveness requirement assures that the public only awards the privileges of a patent to an inventor who substantially improves on previous inventions. Courts have held that inventions that were likely to occur without the inducement of patent protection should remain in the public domain (Griffith Rubber Mills 1963).

An applicant can use evidence of long felt need for the invention, commercial success, approval from other professionals in the field, or widespread licensing agreements to demonstrate the non-obviousness of an invention (Graham 1966).

\section{Specifications and Disclosure}

U.S. patent law requires applications to include "a written description of the invention, and of the manner and process of making and using it, in such full, clear, concise and exact terms as to enable any person [experienced in the field] . . to make and use [the subject matter of the patent]. . . " (35 USC 112). In addition to making a comprehensive disclosure of how to make and use the product or process, patent law requires inventors to disclose the "best mode . . . of carrying out [the] invention" (35 USC 112).

Describing an invented product or process in sufficient detail can pose major challenges to an inventor seeking a patent. The description must be thorough to ensure that the patent examiner can determine whether it infringes on other patents.

In the case of genetically engineered organisms, and other genetically engineered substances that are not easily described in a way that enables another person to reproduce them, the PTO may require inventors to deposit a sample of their organisms with the PTO (and may deny a patent if a sample is not provided). The PTO makes the sample (stored in appropriate cryogenic or refrigerated facilities) available to the public as soon as a patent issues. Patent laws of many foreign countries also require deposits of patented organisms (Hardy 1994, p. 309).

Even though depositing samples of genetically engineered organisms may assist potential infringers, the biotechnology community requires maximal exchange of information for research 
efforts to progress. Many products and processes cannot be discerned through reverse engineering, and disclosure permits researchers to build on each others' discoveries. Disclosure also assists regulators in making informed decisions about appropriate regulations (Chiapetta 1994, p. 169).

While the deposit requirement may make an organism available to researchers working in competition with an inventor, patent applicants cannot refuse to deposit an organism in order to prevent others from using it (Eisenberg 1987, p. 215). If inventors suspect that others are using a patented organism without permission, they must bring a patent infringement suit in court.

A narrow exception to the enforceability may exist in the "experimental use" defense to infringement suits (Hardy 1994, p. 311). A few patent cases have permitted the use without royalties of patented material to determine if the invention worked. However, few courts have allowed this defense when the infringement related to "philosophical experiments" or commercial activities (Eisenberg 1987, p. 219). The most significant exceptions to patent protection exist in the Plant Variety Protection Act, discussed in Section 3.2.5.

The CAFC abolished the experimental use defense to infringements of the Patent Act in 1984, holding that a pharmaceutical company's use of a patented drug for testing related to FDA drug approval constituted infringement (Roche Products 1984). In response, Congress amended the Patent Act to permit infringement "necessary to obtain regulatory approval" under federal law regulating the manufacture, use, or sale of drugs (35 USC 271(e)(1)). This statutory exemption is narrow enough that it should not significantly threaten an inventor's ability to commercialize and profit from bioremediation technologies.

The details of patent applications, including disclosure statements, have traditionally remained confidential until the time the PTO issues a patent and the inventor can exercise control over the published information through infringement proceedings. Many other countries routinely publish patent applications 18 months after they are filed, regardless of whether a patent has issued by that time. The United States has recently approved new legislation to permit the publication of patent applications after 18 months, in order to bring U.S. patent law into greater harmony with international practices (Sabatelli and Rasser 1995, p. 600).

\subsubsection{Product of Nature Doctrine and the Patentability of Living Matter}

A naturally occurring substance is not patentable (in the form found in nature), since it is not an "invent[ion of a] process, machine, manufacture, or composition of matter" that is "new" (35 USC 101). If an inventor sought to obtain a monopoly over a naturally occurring substance, the patent would deprive citizens from making use of something "which nature has produced and which nature has intended to be equally for the use of all men" (ex parte Latimer 1889).

The patent code states that the PTO will issue a patent to anyone who "invents or discovers" patentable subject matter (35 USC 101). To make a discovery patentable, a discoverer must take 
an "inventive step" which changes the discovery from its natural form in some way that complies with the requirements of patent law (Scalise and Nugent 1995, p. 89). Just how significant this step has to be is unclear in light of patent case law.

\section{American Fruit Growers, Inc. v. Brogdex Co.}

In an early and controversial case, the Supreme Court reversed a circuit court opinion upholding the patentability of a process for protecting citrus fruit from blue mold by impregnating the fruit rind with a borax solution (American Fruit 1931). While the Supreme Court acknowledged that the process was useful, novel, and non-obvious, the Court asserted that even after being treated with borax, the fruit remained a "product of nature" (American Fruit 1931, p. 12). Apparently the now mold-resistant fruit did not qualify as a "manufacture" despite the new qualities added by the inventor.

Subsequent commentators have criticized the case for setting impossibly high standards for inventors working with living material, claiming "there was little logic in the decision" (Sease 1989, p. 555).

\section{Funk Brothers Seed Co. v. Kalo Inoculant Co.}

In this 1948 case, the Supreme Court denied a patent to an inventor who combined several strains of bacteria which were capable of fixing nitrogen in the roots of legumous plants (Funk 1948, p. 127). While farmers had used individual strains of bacteria for inoculating crops for a long time, no one had successfully combined bacteria strains which did not inhibit each other's effectiveness. By experimentally determining which bacteria were not mutually inhibitory, the inventor produced a popular and profitable multi-purpose inoculant, which could be used on a wide variety of crops (Funk 1948, p. 127).

While Justice Douglas's majority opinion acknowledged that the product was both "new" and "useful," it declared that the inoculant mixture did not meet the inventiveness requirement for patentability. While the inventor had discovered a useful natural property in the bacteria, the act of mixing the non-inhibitory strains did not qualify as a sufficiently "inventive step" for patenting purposes. The Court stated the following:

The qualities of these bacteria, like the heat of the sun, electricity, or the qualities of metals, are part of the storehouse of knowledge of all men. They are manifestations of laws of nature, free to all men and reserved exclusively to none. He who discovers a hitherto unknown phenomenon of nature has no claim to a monopoly of it which the law recognizes. (Funk 1948, p. 127)

Justice Frankfurter's concurring opinion challenged this logic: "Everything that happens may be deemed 'the work of nature' .... Arguments drawn from such terms for ascertaining 
patentability could fairly be employed to challenge almost every patent" (Funk 1948, p. 133; Cooper 1989, p. 3-4).

After the American Fruit Growers and Funk Brothers decisions, few inventors successfully obtained patents on inventions involving living material, since living matter was interpreted as a "product of nature" by the courts. While modern courts may have become more sensitive to the application of invention to living matter, it is still unclear where courts draw the line between patentable living material and products of nature.

\section{Diamond v. Chakrabarty: Patentability of Genetically Engineered Organisms}

However, the courts have redefined certain living material as patentable. In 1980 the Supreme Court acknowledged the patentability of a strain of genetically engineered bacteria (Chakrabarty 1980). Chakrabarty applied for a patent on "a bacterium from the genus Pseudomonas containing therein at least two stable energy-generating plasmids, each of said plasmids providing a separate hydrocarbon degradative pathway" (Chakrabarty 1980, p. 305). The Court stated that the human-made, genetically engineered bacterium was capable of breaking down multiple components of crude oil. Because of that property, possessed by no naturally occurring bacteria, experts believed that Chakrabarty's invention would have significant value in treating oil spills (Chakrabarty 1980, p. 303).

The Court emphasized that Congress intended that the Patent Code should be read broadly, to include "anything under the sun that is made by man" (Chakrabarty 1980, p. 309). Instead of defining living material as a."product of nature", the Court declared that nothing in the Patent Code prevents living material from qualifying as a "manufacture" or "composition of matter" under 35 USC Sec. 101. The Court stated "Congress . . recognized that the releyant distinction was not between living and inanimate things, but between products of nature, whether living or not, and human-made inventions" (Chakrabarty 1980, p. 313).

\section{In re Bergy: Patentability of Processes Using Naturally Occurring Bacteria and Purified Cultures}

In In re Bergy, decided at the same time as Chakrabarty, the CAFC declared that a process using natural bacteria for producing a naturally occurring pharmaceutical substance could qualify for patent protection. In addition, the researchers could obtain a patent for a purified culture of the bacteria. The purified strain qualified for patent protection since the bacteria never occurred naturally in that form.

The court noted that the PTO had issued a patent for a purified living organism more than 100 years earlier, when Louis Pasteur in 1873 obtained United States patent 141,072 containing this claim: "'2. Yeast, free from organic germs of disease, as an article of manufacture."' (In re Bergy 1979 , p. 985). The court also noted that the PTO had issued patents for various processes 
employing naturally occurring yeasts and other organisms for fermentation and degradation of organic material in septic systems (See also Cameron Septic Tank Co. 1908).

In its decision, the court stated:

In Bergy's case, all of his allowed claims define processes in which a living organism is the active force which causes the process to proceed... [W] do not see the logic of allowing claims to processes which depend for their operation on a living organism while denying claims to the organism or a pure culture of it merely because it is alive (In re Bergy 1979, p. 986).

While the PTO appealed the Bergy decision to the Supreme Court, the office decided to withdraw its appeal and issue the patent once the Supreme Court clarified the patentability of living material in Chakrabarty (Eisenberg 1987, p. 189).

\section{Consequences of Chakrabarty}

After the Chakrabarty decision signaled that living material could now qualify for patent protection, the biotechnology industry initially suspected that Congress might respond to the decision by legislatively denying patent protection to the living products of genetic manipulation. When it became clear that Congress would not nullify the Chakrabarty decision, the industry responded with an explosion of research and patent applications (Scalise and Nugent 1995, p. 97).

While Chakrabarty clarified that human-made microorganisms could qualify for patent protection, the PTOs policy regarding multicellular organisms remained unclear until the office issued its renowned capitulatory Notice of April 7, 1987 (Official Gazette 1987). In this notice, the PTO stated in part that

The Board relied upon the opinion of the Supreme Court in Diamond v. Chakrabarty ... as controlling authority that Congress intended statutory subject matter to 'include anything under the sun that is made by man.' The Patent and Trademark Office now considers non-naturally occurring non-human multi-cellular living organisms, including animals, to be patentable subject matter within the scope of 35 USC 101. . (Official Gazette 1987).

A year after this notice of the PTO's new liberal patenting policy concerning living inventions, the PTO issued a patent for the Harvard "Oncomouse," a mammal genetically engineered to be susceptible to cancer. Due to its oncogenes, the mouse provided researchers with an effective tool for examining the genetics and development of cancer (Scalise and Nugent 1995, p. 108). 


\subsubsection{Public Opposition to Patenting of Living Organisms}

While legal protection for inventions involving living matter and organisms solidified, some segments of the public organized in opposition to these developments. Four major forces oppose the patentability of living organisms in the United States: animal rights groups argue that such patents are immoral; environmentalists object that the risks of manipulated genetic material to ecosystems are inadequately understood; clergy speculate that patenting of living matter may eventually lead to the commodification of humans; and small scale farmers believe that patenting agricultural species may threaten their economic well-being (Hecht 1992, p. 1040; Hettinger 1995, p. 300). Each of these groups is discussed below.

Animal rights activists believe that allowing patent protection for animals will lead to increases in animal suffering. Many of these activists believe that scientists already neglect animal welfare in research on naturally occurring species. In addition, genetic engineering may produce animals with painful abnormalities, like those suffered by the pigs created by the USDA, which contained human genes for producing growth hormones. The pigs produced larger quantities of lean meat than typical pigs, but they had skeletal abnormalities, arthritis, and susceptibility to pneumonia (Hettinger 1995, p. 297). Some animal rights activists also offer moral objections to patenting, arguing that permitting humans to "own" the rights to animals is objectionable. They assert that even organisms produced through genetic manipulation deserve respect as living beings, which should not be defined as "mere instruments for human benefit" (Hettinger 1995, p. 302). While all opposition to patenting of living subject matter may impact legislation affecting bioremediation technologies, it is unlikely that animal rights activists would specifically target the use of natural microbes or GEMs for bioremediation.

Some environmentalists object to patenting of genetically engineered organisms because patent protection creates incentives for scientists to develop new species that may threaten ecosystems into which they are released. Biologists have documented the serious harm naturally occurring exotic species can do if released into a new ecosystem (Bright 1995, p. 10). While biotechnology inventors argue that genetically engineered organisms are more predictable and controllable than their natural counterparts, others argue that the risk of genetically engineered genes spreading into wild populations is insufficiently understood (Bright 1995, p. 16). Some researchers have discovered that even if the genetic material of transgenic organisms is not exchanged, the novel metabolic products of some organisms can threaten ecosystems, making it difficult for native and cultivated species to survive (Bright 1995, p. 16). Some philosophers argue that the intrinsic value of "wilderness" and natural habitat could be compromised by the introduction of organisms created through human intervention (Hettinger 1995, p. 300). Since the risk models for evaluating whether manipulated genes can migrate into wild populations and how exotic or engineered microbes affect local ecosystems are poorly developed, environmentalists may raise valid objections to the deployment of GEMs for bioremediation.

However, these objections should be addressed to regulatory agencies, since the PTO does not consider the danger of patentable material in its evaluations. 
Religious organizations and clergy argue that permitting patents on transgenic organisms exploits animal life and threatens the integrity and distinctiveness of species (Dresser 1988, p. 405). Others contend that biotechnologists are "playing God," and raise concerns that the PTO will eventually issue patents on transgenic human beings (Hecht 1992, p. 1041).

Small farmers challenge patenting of genetically engineered farm animals and crop varieties, claiming that the increased cost of patented species would prevent them from investing in new technology. Without access to new super-productive strains, farmers assert they would be unable to compete against large agricultural businesses (Hecht 1992, p. 1042). Many foreign patent statutes and U.S. plant patent statutes include exemptions for farmers, permitting them to use the offspring and seeds of patented strains without paying additional royalties. However, the biotechnology industry objects to the farmer's exemption, since it reduces the 20 year term of patent protection to the length of time it takes a farmer to replicate a patented species (Scalise and Nugent' 1995, p. 94) (farmer's exemptions will be discussed further in Section 3.3). Since bioremediation technologies are not related to agricultural commodity species, farmers' lobbies should not object in theory to the deployment of microbes for bioremediation (in fact they could become consumers of bioremediation technology).

\section{Legislation}

The PTO notice inviting patent applications for multicellular transgenic species, and the patent issued to Harvard for the Oncomouse angered animal rights activists and worried small farmers. Political pressure from alliances of these organizations caused Congress to introduce the Transgenic Patent Reform Act of 1988, which would have provided exemptions from patent protection for farmers who used patented species on a single farm. This legislation failed to pass, as did an almost identical bill in 1989 (Scalise and Nugent 1995, p. 1009). However, no legislation has attracted comparable amounts of support since the failure of these measures, and little momentum seems to exist in Congress for other legislation limiting the patentability of living organisms.

\section{Litigation}

After Congressional failure to limit animal patenting, several animal rights groups including the Animal Legal Defense Fund filed suit challenging the PTOs authority to issue the 1987 Notice declaring the patentability of animals $(A L D F 1991)$. The plaintiffs sought an injunction preventing the PTO from issuing any patents for animals, asserting that the PTO violated procedural requirements for issuing its Notice, and that the Notice constituted a substantive violation of animal protection laws (Scalise and Nugent 1995, p. 1009). Both the District court and the CAFC dismissed the case, stating that the plaintiffs lacked standing to bring suit since they had suffered no legally recognizable harm. In addition, the court reiterated that patent law required only that patentable subject matter be "made by man," and that the PTO could issue patents on living material (Scalise and Nugent 1995, p. 1010). 
Supporters of biotechnology patents argue that the PTO is not intended to regulate the safety or morality of new inventions. Congress and state legislatures are responsible for regulating the implementation of new technology, and these bodies are able to respond to voters' concerns in a democratic fashion. The Supreme Court also stated that denying patents to new inventions is unlikely to prevent scientists from pursuing research in biotechnology:

The large amount of research that has already occurred when no researcher had sure knowledge that patent protection would be available suggests that legislative or judicial fiat as to patentability will not deter the scientific mind from probing into the unknown any more than Canute could command the tides. Whether respondent's claims are patentable may determine whether research efforts are accelerated by the hope of reward or slowed by want of incentives, but that is all. (Chakrabarty 1980, p. 317)

\subsubsection{Plant Patent Statutes}

Prior to the Chakrabarty decision, the Plant Patent Act and the Plant Variety Protection Act provided the only reliable protection for living subject matter (35 USC 161 et seq.). The Plant Patent Act (PPA) provides patent protection for a narrowly defined category of asexually reproducing plants, which may result from grafting, budding, air layering and reproduction through the use of tissue cultures (Scalise and Nugent 1995, p. 88). Congress passed this law in 1930 to respond to the needs of plant breeders, who often spent a decade or more developing a new hybrid strain only to lose their research investments as soon as the plants were marketed.

The Plant Patent Act requires an applicant to demonstrate that the variety is distinct, new, and does not occur in nature. These requirements are analogous to the utility patent requirements of utility, novelty, and nonobviousness, but the Plant Patent Act contains more lenient requirements regarding the description of the patentable material. To obtain protection, a breeder must demonstrate that the variety possesses at least one characteristic, either physiological or anatomical, that differs significantly from existing varieties (Scalise and Nugent 1995, p. 92).

The bulk of plants used in the U.S. agricultural industry are sexually reproducing, making them ineligible for protection under the PPA. In 1970, Congress passed the Plant Variety Protection Act (PVPA), which extended patent protection to certain sexually reproducing varieties (PVPA 1970).

Neither the PPA nor the PVPA provide patent protection for bacteria. In 1940, the PTO declared that the PPA cannot be used to obtain patent protection for bacteria (In re Arzberger 1940). In 1988 Congress amended the PVPA to specifically deny coverage to fungi and bacteria (7 USC 2402).

However, it is unlikely that many inventors would prefer to obtain patent protection under the PPA or the PVPA, since they include exceptions to patent coverage which undermine the economic advantages offered by patent protection. The PVPA includes a "farmer's exemption" 
which permits farmers to reproduce patented plant species and sell their crop or produce their own seed without paying royalties on the patented material after it is first obtained. In essence, this exemption reduces the 20 year term of patent protection to the length of time a farmer needs to reproduce a patented species. Since farmers are the primary market for many patented plant species, this exemption significantly reduces the value of a plant patent to the inventor (Sease 1989, p. 567).

In addition, the PVPA includes an "experimental use" exemption, which prevents a patent holder from enforcing a patent against an infringer using the plant for bona fide research purposes. While this exemption does not jeopardize a plant patent holder's profits very much, a similar exemption could prove significantly more problematic in the context of transgenic biotechnology research, where researchers may be the primary users of patented organisms (Scalise and Nugent 1993, p. 1002).

Now that the PTO Notice of 1987 has clarified that living material may qualify for utility patent protection, creators of genetically engineered plants can obtain more comprehensive protection under 35 USC 100 et seq. While utility patent protection requirements are stringent, prudent inventors should seek utility patent protection whenever possible. Inventors may also obtain patent protection for processes involving plants (Scalise and Nugent 1995, p. 100).

\subsection{International Intellectual Property Law}

The United States has the most liberal policies toward the patenting of living matter in the world (Scalise and Nugent 1993, p. 1011). The U.S. courts provide stringent patent protection, and the U.S. biotechnology industry is currently one of the most active in commercializing and licensing biotechnology patents (Carroll 1995, p. 2439). However, industry forecasters fear that the United States may lose its competitive advantage in biotechnology if inventions are sold too cheaply and if international patent protection is not strengthened (Hardy 1994, p. 301).

In support of this claim, some cite evidence that the United States developed most of the semiconductor and microprocessor technology needed in the videocassette recorder, but that only $2 \%$ of those components are now manufactured domestically. While inventors were able to obtain U.S. patents, it proved far more difficult to obtain patent protection overseas. Since off shore manufacturers could produce technology more cheaply without paying royalty fees to U.S. patent holders, much of the production in the semiconductor industry moved to Asia (Hardy 1994, p. 300).

Biotechnology industry analysts fear that without strengthened international patent protection for processes, lucrative products that are not in themselves patentable (like naturally occurring pharmaceuticals) could be produced overseas and imported for sale without paying royalties to the U.S. patent holder. While section 1337 of the Tariff Act of 1930 makes it unlawful to import into the United States products made from a process patented in the United States, the CAFC. held that "obvious" processes are not patentable, even if the starting products may be (Hardy 
1994, p. 312; In re Durden 1985). This "Durden Dilemma" had prevented many U.S. inventors from obtaining process patents for biotechnology, allowing foreign competitors to use the processes to make products for export back to the United States (Hardy 1994, p. 315).

In 1988 and 1995, Congress amended the patent act to resolve the "Durden Dilemma" by changing 35 USC Sec. 103 to provide patent protection for processes producing non-patentable natural products (35 USC 103; S 1111, 104th Congress 1995). However, bioremediation technology does not result in a "product" other than the absence of contaminants in the remediated medium; therefore, these legislative changes should not change the patentability of bioremediation processes. Inventors of bioremediation technologies will be able to enforce patents on genetically engineered microbes as long as the patent applies in the country where the organism is deployed. Process patents will similarly receive protection as long as the process is used in a country where the patent is in force.

Patent rights are granted and enforced by each foreign country independently. Each country only enforces patents granted under its own jurisdiction, and an inventor must apply for separate patents to protect an invention in every country where the inventor wishes to enforce intellectual property rights to the invention (Carroll 1995, p. 2441). The United States, Canada, Japan, and many other developed nations have historically granted stringent patent protection to inventions, while many less developed countries have weaker patent systems with sketchy enforcement (Carroll 1995, p. 2440). As a consequence of patent piracy in less developed countries, the United States and other industrial nations have promoted various treaties and plans to promote more stringent patent protection worldwide (Carroll 1995; p. 2444).

However, in order to pass treaties implementing comprehensive patenting arrangements on the international level, countries must reconcile different national patenting practices and the conflicting demands of industrial countries for stringent enforcement and of developing countries for economic leverage. The U.S. patent code differs from patent laws in many countries, and it may be necessary for Congress to approve significant changes in U.S. law to achieve international harmonization. The need for these changes grows more pressing as the global market for products and intellectual property develops, and U.S. businesses increasingly depend on global patents to protect their investments (Sabatelli and Rasser 1995, p. 585).

While a U.S. patent provides protection to the first person to invent patentable subject matter, virtually all foreign patent jurisdictions award protection to the first person to file for the patent (the Philippines is the only other country with a first-to-invent system) (Carroll 1995, p. 2447). Many Americans believe awarding patents on a first-to-file basis is unfair, since this system disadvantages small inventors in favor of large enterprises with streamlined patent application procedures (Carroll 1995, p. 2447). However, most American companies doing international business already operate on a first-to-file basis in order to protect their ability to obtain patent protection worldwide. The first-to-invent system is actually very expensive to administer, since the PTO must search for any publication or use of the subject matter before the patent application was made (Sabatelli and Rasser 1995, p. 620). 
Many foreign patent laws contain non-disclosure requirements (absolute novelty requirements) which deny patents to inventors who published or otherwise publicized the invention before filing for patent protection. While a few countries provide a grace period, within which an inventor must file for a patent on published subject matter, in other countries, including Germany, any prior publication will render an invention unpatentable (Carroll 1995, p. 2447). These policies exacerbate the conflict many more academically oriented inventors face between the need to publish findings to ensure funding and the need to file for patents before the publication destroys the "novelty" of the inventions. When inventors wish to file for foreign patents, the need to file before publication is more acute, and the time and expense involved in preparing the application may be greater, further delaying publication.

In addition, U.S. law differs from many other countries in permitting a wider variety of patentable subject matter, in requiring that the inventor, rather than the owner of an invention, must file for patents, and in requiring that the inventor disclose the "best mode" of using the invention (Czmus 1994, p. 445; Sabatelli and Rasser 1995, p. 587).

\subsubsection{International Patent Treaties}

International law is largely composed of treaties that, once signed by participating countries, are supposed to carry the force of law in each nation. However, treaties do not have legal force in non-signing countries, and they depend on fragmented international organizations for enforcement. While enforcement measures can force some poorer or smaller nations to comply with treaty terms, countries with enough resources like the United States comply voluntarily, since no other entity has the legal and economic power to enforce treaty provisions against them.

The United States has attempted to unilaterally impose some of its intellectual property laws in the international context through import limitations on products produced in violation of U.S. patent law (even if the production was legal in the country in which it occurred). In addition, some U.S. laws impose trade sanctions on foreign countries that do not assure adequate patent protection according to U.S. standards. Many foreign countries view these strategies as barriers to global trade (Sabatelli and Rasser 1995, p. 586).

\section{The Paris Convention}

The first global discussion of international patent law took place in 1883 at the Paris - International Convention for the Protection of Industrial Property (Paris Convention). The meeting generated an international agreement on patent law, also known as the Paris Convention, which sets out common principles governing each member country's patent system. The principle of national treatment ensures that each member country will consider applications from foreign inventors in the same way that they consider applications from citizens (Czmus 1994, p. 454). The right of priority assures that once an inventor has filed a patent application in a signatory country, all subsequent applications in other member countries will receive the same filing date for purposes of determining filing priority. The right of priority assures that an inventor can obtain 
patent protection in different countries without having to file all applications simultaneously (Carroll 1994, p. 2456). The Convention also requires member states to implement legislation protecting patent holders from unfair competition (Scalise and Nugent 1995, p. 105). As of 1992, 108 different countries had signed the Convention. However, each member country continues to define its own scope of patentable subject matter and enforcement mechanisms (Sabatelli and Rasser 1995, p. 591). While the Paris Convention establishes principles that continue to impact international patent law today, for over 80 years no enforcement organization existed to implement and police the principles (Carroll 1994, p. 2456).

\section{The World Intellectual Property Organization}

In 1967, the United Nations created the World Intellectual Property Organization (WIPO), with 139 member countries, to administer the Paris Convention and other international intellectual property agreements (Sabatelli and Rasser 1995, p. 594). WIPO receives applications after inventors file national patent applications, publicizes what patents have been awarded by different nations, and initiates patent registration procedures in other countries (Carroll 1994, p. 2457). In addition, the WIPO engages in harmonizing patent laws, and encouraging countries to make their

patent application procedures, patenting criteria, and enforcement more compatible. While WiPO has had some success in harmonizing procedures (like the term of patent protection, and the firstto-invent/first-to-file priority disparity), international differences in the enforcement of intellectual property rights have proven more intractable (Carroll 1994, p. 2457).

While many industrialized countries support stringent enforcement of patent rights, less developed countries have resisted WIPO's efforts to tighten international patent regulations. Some argue that the Paris Convention principles already favor developed countries, since the requirements that all countries treat domestic and foreign applicants equally and honor foreign filing dates for priority purposes favor inventors in industrial nations where most patents are filed. In addition, many less developed countries rely to some extent on piracy of patented goods to sustain their economies (Oddi 1987, p. 856).

Since WIPO is a special agency of the United Nations, it is more responsive to developing nations, who constitute a majority of U.N. membership. Private industry in industrial countries distrusts WIPO's efforts at patent harmonization, since it is not able to influence this forum as completely as others like GATT (Scalise and Nugent 1995, p. 106). While WIPO initiated procedures to ratify a Patent Harmonization Treaty in 1987, the United States has requested postponement of ratification conventions and has failed to approve the treaty in the U.S. Congress (Sabatelli and Rasser 1995, p. 599).

\section{The General Agreement on Tariffs and Trade (GATT)}

GATT is an international commercial treaty first signed in 1947 as a mechanism to remove barriers to global trade and technology transfer. Since its inception, there have been eight major conferences, or rounds, in which member states resolve pressing trade, tariff, and other concerns 
(Sabatelli and Rasser 1995, p. 602). By the 1987 Tokyo round of GATT, industry leaders in member countries of the World Trade Organization realized that they needed to address the enforcement and coordination of international intellectual property rights among developed nations. American industry forces (endorsed by The President's Commission on Industrial Competitiveness) were instrumental in focussing the 1993 Uruguay round of GATT on international intellectual property protection (Carroll 1995, p. 2460). The portion of GATT addressing intellectual property issues is called the agreement on Trade Related Intellectual Property Rights (TRIPs) (Scalise and Nugent 1995, p. 114).

While the GATT negotiations concluded before a U.S.-imposed deadline, disagreements regarding intellectual property protection for biotechnology almost derailed the convention. Developing nations objected to patenting living organisms and processes for producing patentable plants and animals. These countries argued that the proliferation of genetically engineered crops and livestock would threaten their agriculturally based economies and the diversity of world crop and indigenous species (Scalise and Nugent 1995, p. 84). To obtain the support needed to pass the TRIPS, supporters conceded to a definition of patentable subject matter that excluded microorganisms, genetically engineered organisms, and certain microbiological processes. Only organisms and processes involved in traditional breeding practices received protection, reflecting the patent laws of many World Trade Organization member countries (Scalise and Nugent 1995, p. 114).

President Clinton signed the GATT, including TRIPs into U.S. law in December, 1994. While the treaty failed to enact significant protection for biotechnology, it still contains global standards for patent processes and provisions for stringent enforcement considered necessary by U.S. industry (Carroll 1994, p. 2460).

\section{The Convention on Biological Diversity}

The United Nations Conference on Environment and Development (UNCED) also considered intellectual property protection during the 1992 meeting in Rio de Janeiro, Brazil. The conference focussed on the introduction and signing of the Convention on Biological Diversity, which included these major provisions: 1) the conservation of biological diversity; 2) the sustainable use of biological resources; and 3) the equitable sharing of benefits derived from genetic resources (Scalise and Nugent 1995, p. 110).

U.S. representatives and industrial participants objected to the concept of "equitable share," which they believed would hinder U.S. efforts to use genetic material derived from organisms native to less developed countries. The Convention included this provision to ensure that countries with vast biological resources would not continue to be exploited by developed nations with the technology to convert these resources into lucrative pharmaceuticals and other patented products. Less developed countries lack both the infrastructure to develop these products domestically and the economic resources to benefit from products once marketed internationally. Through the Convention, less developed countries hoped to leverage their natural biological 
resources to obtain some access to technology and profits derived from them (Scalise and Nugent 1995, p. 110).

Provisions in the treaty appeared to require developers of biotechnology to provide access to and transfer of technology to countries where raw materials for the products were obtained (Scalise and Nugent 1995, p. 111). In addition to technology transfer, treaty language provided that innovators must share "the benefits arising from commercial and other utilization of genetic resources with the ... country ... providing such resources" (United Nations Draft Convention on Biological Diversity 1992, at art. 15, para. 7). Industrial biotechnologists in developed countries feared that these provisions would require them to surrender proprietary technology without compensation, and require companies to share profits from technology sales with countries that contributed biological material. The ambiguity of treaty language created the potential for widespread forfeiture of intellectual property rights (Scalise and Nugent 1995, p. 111).

Such fears motivated President Bush, supported by trade organizations such as the Association of Biotechnology Companies, to refuse to sign the Convention on Biological Diversity at the Earth Summit (Hardy 1994, p. 299). However, President Clinton agreed that conservation of global biological diversity should remain a global priority. To obtain support from the biotechnology industry, Clinton involved industry representatives in drafting a letter of interpretation which unilaterally renegotiated the Convention's terms (Scalise and Nugent 1995, p. 112). When the U.S. representative to the United Nations, Madeline Albright, signed the Biodiversity Treaty in 1993, these interpretive statements were appended to the document. They stated that patent protection is necessary for biotechnology companies to afford research and development costs associated with new innovations (Hardy 1994, p. 318).

As it now stands, the Convention on Biological Diversity can encourage but not mandate biotechnology companies to share profits and technology with the countries providing raw materials for these innovations. The Clinton administration has agreed in principle that developing countries should derive some benefits from the commercialization of their natural resources, reflecting industry interpretations that the treaty may encourage royalty payments, not technology transfer, to developing countries (Hardy 1994, p. 321).

However, the non-binding nature of the treaty leaves developing nations with little recourse for protecting their resources from "genetic prospectors" who find new genetic material in these countries and then develop new patented products, ensuring that the prospector companies derive all the profits. Few other treaties concerning intellectual property and biotechnology include developing countries as signatories. It seems clear that industrialized countries are in the process of "locking up" patents for biotechnology in such a way that few countries providing raw materials will ever be able to share in the profits or industrial development linked to the biotechnology industry (Hardy 1994, p. 319). 


\section{Other International Treaties}

The Budapest Treaty on the International Recognition of the Deposit of Microorganisms for the Purposes of Patent Procedure, signed in 1977, establishes an international repository for patented microorganisms and other products requiring a deposit to complete the description required to receive patent protection. This treaty allows inventors to make a single deposit when applying for patent protection in many different countries. The treaty does not specify who has access to deposited material. If signatory countries, biotechnology companies, or others request samples, the laws of the country where they are located governs access to deposited samples. While some inventors have speculated that providing international access to patented material may encourage infringement, it is unclear whether this problem has actually developed (Hardy 1994, p. 311; See Budapest Treaty, Apr. 28, 1977, 32 U.S.T.

1241).

The Patent Cooperation Treaty of 1970 simplifies procedures for filing for international patent protection by unifying application procedures and preparing search reports on existing international patents (Cooper 1989, p. 10-2; Sabatelli and Rasser 1995, p. 595). The International Convention for the Protection of New Varieties of Plants protects breeders of new species in a similar way to the U.S. PPA and the PVPA (Hardy 1994, p. 319).

In addition, the United States has successfully negotiated several bilateral treaties protecting U.S. biotechnology in return for providing signatory countries with access to U.S. markets and investment capital. While these treaties only bind the few signatory countries, U.S. wealth and the force of United States trade sanctions make these agreements very effective in guaranteeing intellectual property rights for U.S. inventors (Scalise and Nugent 1995, p. 115).

\subsubsection{European Patents and Biotechnology}

European patent law is currently governed by the statutes of each member nation and by the agreements of the 1973 European Patent Convention (EPC), administered by the Administrative Council and the European Patent Office (EPO). Patent laws in Germany and the United Kingdom parallel those of the United States and Japan in assuring stringent protection for patentable subject matter, including living organisms (Scalise and Nugent 1993, p. 1016). However, only three European countries expressly permit inventors to patent living material (Scalise and Nugent 1993, p. 1016). European nations have engaged in a prolonged debate about the patentability of biotechnology, reflected in provisions in the EPC and in the debate and demise of the EU Draft Directive on the Legal Protection of Biotechnological Inventions (Draft Directive 1989).

The European Patent Convention is comprised of 18 nations, including member states of the European Union (EU) plus several non-member nations in the region. The EPC serves primarily as a registration system for patents, not as a legislative body. While it provides a single registration system for patents enforceable in member countries, each country interprets the patent scope and enforces patent projections according to national, not international law. Therefore the 
EPC has had little impact in harmonizing patent provisions within Europe, and a holder of a European patent may have to cope with as many as 18 varying sets of laws when pursuing enforcement actions (Scalise and Nugent 1993, p. 1011).

The Convention asserts that inventions that are contrary to "ordre public" or morality, plant or animal varieties, or processes for producing plants and animals are not entitled to patent protection (Scalise and Nugent 1993, p. 1013). While EPC interpretations of restrictions on plant and animal patenting parallel U.S. patent law requiring novelty and prohibiting the patenting of products of nature, the prohibition on patents contrary to the "ordre public" are unique to the EPC (Scalise and Nugent 1993, p. 1013). In 1990, the EPC Technical Board of Appeals held that the EPC does not categorically exclude the patenting of animals per se, and that innovators may obtain protection for new and distinct organisms engineered through biotechnological processes (In re Harvard 1990).

However, the provision for denying patents contrary to the "ordre public" provides an opportunity for citizens to challenge EPC patent awards, either during the time the patent is under consideration or after issue. By giving citizens standing to challenge patent awards in the courts, the EPC system poses increased risk and delay for biotechnology innovators whose inventions face public opposition.

Beginning in 1988, the European Council considered the Draft Directive on Biotechnological Inventions, which created a scope of biotechnological patent protection as stringent as protection provided in the United States and Japan. While original language reflected the priorities of the biotechnology industry in Europe, which was eager to win patent protection akin to competitors abroad, the European Parliament quickly polarized. Opponents sought amendments to prohibit the patenting of human materials, enhance animal rights projections, and provide farmer's . exemptions from patent laws (Scalise and Nugent 1993, p. 1026). The debate was exacerbated when the EPC considered patenting the Harvard Oncomouse in 1990, and eventually the directive failed to win approval (Reuters European Community Report 1995). Under pressure from European biotechnology companies, the draft has been revived for further consideration of new proposals (Reuters Chemical Business News Base 1996).

\subsubsection{European Opposition to Animal Patents}

As demonstrated by the demise of the Draft Directive, organizations opposing animal patenting in Europe wield considerable power. Opposition crystallized in the late 1980s when the EPC considered awarding patent protection to the genetically engineered Harvard Oncomouse. The European Patent Organization provided a period for public comment when considering Harvard's patent application, and animal welfare activists and the Green party launched a campaign to convince the organization that granting animal patents would lead to further exploitation of animals. Since the EPC allows concerned citizens to challenge the validity of patents both at the level of the EU and at the level of individual nations, the Green party and others may prove powerful opponents to biotechnology patents. The expense of litigating in 18 
different countries to defend patent validity almost negates the value a controversial patent confers on the holder (Scalise and Nugent 1993, p. 1016).

\subsection{Alternatives to Patent Protection: Trade Secret Law}

Trade secrecy is an alternative to patent protection which innovators may use when a patent is pending, to protect peripheral information surrounding a patent, or to protect commercially viable but unpatentable techniques, information, or other subject matter (Cooper 1989, p. 11-2; Burk 1993, p. 127). Trade secret law is usually more relevant in an industrial or business context than in an environment where basic R\&D is the goal. Most trade secret protection is derived from state common law, although some states have adopted statutory protection. While the scope of protection and definitions of protectable subject matter vary somewhat between jurisdictions, most common law on the subject is relatively uniform.

The Restatement of Torts defines the common law of trade secrets, defining them as "any formula, pattern, device, or compilation of information which is used in one's business, and which gives ... an advantage over competitors who do not know or use it. . . . a process or device for continuous use in the operation of the business" (Restatement of Torts 1939). This definition could be interpreted to exclude information related to ongoing research, since it has not been applied to the operation of a business (McDaniel 1994, p. 571; Eisenberg 1987, p. 192).

The Uniform Trade Secrets Act, adopted by at least ten states including Washington, defines trade secrets more broadly to include subject matter that derives economic value from not being generally known. This definition might cover research discoveries that promise to result in lucrative processes or products that are not patentable, or research at too early a-stage to receive patent protection (Eisenberg 1987, p. 192).

However, in order to receive trade secret protection, the owner of the subject matter must demonstrate actual secrecy, efforts to maintain secrecy, and proof that someone using the trade secret obtained the information through misconduct. Many biotechnology innovations cannot be adequately protected as trade secrets, especially since the need to prove wrongdoing prevents enforcement against any innovator who discovered the subject matter independently through research or reverse engineering (Ko 1992, p. 794; Eisenberg 1987, p. 193).

Trade secret protection is likely to impede scientific communication between colleagues, unless efforts at signing and enforcing confidentiality agreements and other security measures are routinely taken. Material protected as a trade secret cannot be published or presented, posing further problems for innovators in the scientific community. It can even complicate the commercialization of technology, since negotiators cannot fully disclose trade secrets until parties have reached an agreement regarding how to share and pay for the information (McDaniel 1994, p. 575; Burk 1993, p. 142; Cooper 1989, p. 11-7). 
With a few limited exceptions, trade secret protection is not available for information generated with government funding. The Freedom of Information Act and other federal statutes guarantee that the public has access to information generated through government contracts, except when disclosure would jeopardize a pending patent or cooperative research agreement. ${ }^{13}$

13 Stephen May and Doug McKinley. Personal Communication, July 1996. 


\subsection{Technology Transfer}

During the twentieth century, most patentable inventions have been developed through organized R\&D efforts. During and after World War II, the U.S. government fundamentally changed the R\&D process by taking on the responsibility for extensively funding both industrial and academic research (Walterscheid 1990, p. 103). Currently, the United States spends about $\$ 150$ billion each year on R\&D. The government $R \& D$ budget totals $\$ 70$ billion, divided between military and civilian projects performed by private industry, universities, government laboratories, and non-profit organizations. Private industry contributes the remaining $R \& D$ funds (Chandler 1993, p. 3).

While these investments have produced large quantities of basic research information, they have not historically resulted in significant commercial product development. Many basic research projects focus on producing new knowledge rather than new marketable products. Taking the results of basic research through the stages of implementation and commercial development can cost up to 100 times the initial research investments. While the U.S: government and industry have failed to exploit the market potential of the basic research produced through their investments, foreign companies have developed this technology into profitable industries. Much of the basic research into techniques to make microtransistors for video recording technology and liquid crystal display technologies was done in the United States. However, Japanese industry invested in developing commercial products from the technology, and Japanese companies receive the majority of profits from the marketing of this technology (Chandler 1993, p. 5).

Before 1980, many government policies regarding the ownership of patents produced through government-funded research exacerbated this problem. By retaining title to patents produced through $R \& D$, the government stifled private industry efforts to develop commercial markets for the new technology. Since commercial developers could not protect their investment by retaining patent rights, they directed little private sector activity at commercializing technology derived from government research (Walterscheid 1990, p. 133).

Since 1980, U.S. policy makers have addressed this problem by creating legislative mandates for the transfer of intellectual property rights produced through basic research from the government to commercial partners who can then invest in commercialization efforts and profit from the results. Some argue that these policy changes are inadequate, since they do not change the fact that the majority of government research is directed at non-commercial military technology and the fact that civilian research is rarely focused upon commercially viable results (Chandler 1993, p. 4, 7). While Congress has regularly refined technology transfer policy since 1980, no policy initiatives consider such drastic changes in the structure of U.S. R\&D at this time.

- Current technology transfer policy, described in the National Technology Transfer and Advancement Act of 1995, is driven by Congressional findings that 
- citizens will benefit from the commercialization of technology

- the government can encourage product development by making funding and national laboratory facilities available to the private sector through Cooperative Research and Development Agreements (CRADAs)

- industrial innovation will be enhanced if the private sector partners can obtain licenses or title to the inventions developed in cooperation with governmental entities.

\subsection{History of Technology Transfer Policy in the United States}

From its inception the Atomic Energy Commission (AEC), which later became the Department of Energy, implemented a policy under which it retained title to inventions developed under its R\&D contracts. This policy was implemented through the AEC's use of the "short form" clause in agreements with AEC contractors, which established that the government-owned the products of government-funded research. While the clause theoretically permitted the government to grant title to itself or to anyone else, in practice the AEC (and later the DOE) retained exclusive rights to all inventions developed under its auspices (Walterscheid 1990, p. 110).

AEC policy differed from government contracting policy implemented at the Department of Defense, where the military departments habitually granted title or patent licenses to their private sector contractors. The DOD justified its "title granting" approach by stating that this was the most effective way to obtain R\&D work from the most competent contractors. Since contractors retained the rights to commercialize technology developed through government-funded research, more military industrial partners competed for government contracts (Walterscheid 1990, p. 112).

Before 1980, various pieces of legislation and presidential statements encouraged government agencies to transfer title to the private sector in order to stimulate commercialization of U.S. basic research investments. However, during its existence from 1947 to 1974, the AEC never waived government rights to inventions created through its $R \& D$ contracts (Waltersheid 1990, p. 121).

While technology transfer is now widely accepted, in the 1950s and 1960s some members of Congress objected to the trend towards granting title to government-funded inventions: Many shared a populist view that since the research was funded by the taxpayers, the products of that research should also belong to the taxpayer and remain in the public domain. While some proponents articulated this objection as late as 1980 , other policy makers prevailed by arguing that taxpayer-funded inventions were useless to the public unless industry had incentive to develop them into commercial products (Walterscheid 1990, pp. 123, 131).

In 1974, when the AEC became the Energy Research and Development Administration (ERDA), the Federal Nonnuclear Energy Research and Development Act established criteria for granting patent waivers to contractors doing government-funded research. The Act gave the 
ERDA Administrator the power to "waive" government title to inventions when this action complied with Congressional objectives. These objectives included making the benefits of government $R \& D$ available to the public promptly, promoting commercialization of inventions, and fostering competition among technology developers (Walterscheid 1990, p. 125). While the waiver process opened up the possibility for contractors to obtain title to inventions, it was plagued with implementation problems, including "inordinate" delays in completing the waiver process (Walterscheid 1990, p. 128).

\subsection{Modern Technology Transfer Policy}

In 1980, Congress reversed the presumption of government ownership by passing the BayhDole and Stevenson-Wilder Acts (35 USC 200 et seq.; 15 USC 3701 et seq.). In Bayh-Dole, Congress set up provisions for small business and nonprofit government contractors to "elect to retain title" to inventions developed with government funding. Bayh-Dole also permitted government-owned, government-operated laboratories (GOGOs) to grant exclusive licenses to private sector partners.

In Stevenson-Wilder, Congress established procedures for for-profit contractors to retain title and established policies to promote cooperation between government laboratories and private industry. The Act also created Offices of Research and Technology Application at federal laboratories, and established the Center for the Utilization of Federal Technology.

\section{Contractor Obligations}

While different government contractors are governed by policies resulting either from BayhDole or Stevenson-Wilder, depending on their nonprofit or small business status, the basic rights and obligations established by the legislation are similar. In exchange for the power to elect title, a contractor must fulfil several responsibilities to the government (35 USC 202, 204; 48 CFR. 970.2703; Wisner 1994, p. 194). The contractor must

- disclose new inventions to the funding agency

- file for patent protection before international laws bar applications (due to publication or announcements before filing)

- acknowledge the government's support in the patent application

- grant the government an irrevocable license to practice the invention for U.S. government purposes

- elect to retain title within two years of invention 
- ensure that wherever possible, private sector licensees manufacture products using the invention within the United States in a manner which promotes U.S. industrial competitiveness.

Inventors are obligated to disclose inventions to laboratory intellectual property offices promptly, to ensure that applications can be filed before publication or presentations render the subject matter unpatentable. However, laboratory patent officials must select which inventions to patent based on their potential for commercial development and profit. While many inventions are patentable, few promise to be profitable, and many inventions will not end up receiving patents due to these constraints. Once an invention is patented, laboratories can pursue cooperative relationships with private industry to develop and commercialize the invention.

\section{Government Rights}

While under current laws both GOGOs and government-owned, contractor-operated facilities (GOCOs) may retain title to inventions and grant licenses to private sector partners to commercialize them, the government retains certain rights over the inventions. The government can retain title to inventions when needed to protect national security interests ( $48 \mathrm{CFR}$ 970.2702). The government also retains a license to use inventions developed through government funding to meet government needs throughout the world (35 USC 202 (c)).

If a laboratory licenses an invention to a commercial developer, the government retains "march-in rights" which allow the government to grant additional licenses if the contractor fails to ensure practical application. of the subject, or if the contractor fails to make the invention available to meet public health and safety needs (35 USC 203). While these provisions may appear daunting to potential commercial partners, who may worry whether their license to commercialize a product is likely to be usurped by the government, the government has never exercised march-in rights in the context of technology transfer from government-funded research. ${ }^{14}$

\section{Cooperative Research and Development Agreements}

Through the 1986 amendments to the Stevenson-Wilder Act, Congress encouraged federal laboratories to enter into cooperative research and development agreements (CRADAs) with private-sector development partners. In these agreements to develop commercial products from existing basic research, the laboratory may contribute personnel, property, and services (but no funding), and the private partner may contribute personnel, property, services, and funding (15 USC 3710). Government laboratory directors have the power to negotiate the terms of CRADAs without obtaining approval from the government agency funding the basic research, streamlining the agreement process (48 CFR 970.5204-40 (b); Wisner 1994, p. 195). Laboratory directors may negotiate licensing agreements for the final products, subject to government rights to use the technology for government purposes (15 USC 3710 (a)).

\footnotetext{
14 Stephen May. Personal communication, July 1996.
} 
In implementing technology transfer legislation, DOE has created regulations declaring that technology transfer is a primary mission for federal laboratories and laboratory employees (48 CFR 970.5204-40). Later legislation makes employee responsibility for enacting technology transfer a factor in performance evaluations. Legislation amending Stevenson-Wilder extended the technology transfer mission and the power to enter into CRADAs and grant licenses to both GOGOs and to GOCOs (15 USC 3710 (a)).

While Bayh-Dole and Stevenson-Wilder permit contractors to elect title to patents resulting from basic research funded by the government, CRADA legislation suggests that laboratories must give private-sector partners the option to obtain an exclusive license to practice the commercial products resulting from further investment. Even if government laboratory employees perform the work and develop the commercial products, the commercial partner must still have the option of obtaining an exclusive license from the contractor (15 USC 3710(e)(7)). While this policy certainly encourages private sector cooperation and investment in developing basic research, it leaves laboratories with little leverage to negotiate profitable terms for the licensing agreements. Some comment that this policy will lead to technology transfer without appropriate compensation to government laboratories who invested the most resources into product development (Wisner 1994, p. 198).

Since its inception, federal technology transfer policy has produced significant successes. Over 2000 CRADAs have been signed since Congress authorized them in 1986; and total patent applications from government laboratories and universities have increased significantly (Report of the Senate Committee on Commerce, Science, and Transportation, 12/20/95 [Science Committee]; Wisner 1994, p. 196).

\section{Royalties and Inventor Reward Programs}

In the CRADA guidelines Congress established an inventor reward program to encourage individual inventors to patent their creations. The Federal Technology Transfer Act of 1986 established principles for royalty sharing, stating that federal inventors should receive $15 \%$ of royalties derived from their inventions. This reward system encourages inventors to disclose of inventions and participate in CRADA projects, and encourages managers to recognize the centrality of technology transfer to the laboratories' mission (Science Committee 12/20/95). Contractor-operated laboratories are encouraged to develop inventor reward programs similar to the federal one.

In most government laboratories, inventors produce large quantities of patentable material but few inventions that promise to generate profits. Laboratory intellectual property offices must select a small number of inventions for patenting due to budget constraints. Despite this filtering process, few of the patented inventions result in profitable commercial products. Thus few inventors have received large rewards since the royalty stream produced from licensed technology is typically small. From the inventor's perspective, patenting an invention is like entering a lottery: 
it is unlikely that the invention will generate significant royalties, but the more inventions patented, the greater the odds that one of them will succeed commercially. ${ }^{15}$

Royalties not awarded to inventors may be spent on further R\&D, technology transfer, education at the laboratory, and other projects consistent with the laboratory mission. Laboratories that are not wholly government owned may have more flexibility in determining how to spend royalties from inventions commercialized without government funding (15 USC 3710 (C); 48 CFR $970.5204-40(\mathrm{~h})$ ).

Congress has passed at least 19 pieces of legislation altering and refining technology transfer policy since the passage of Bayh-Dole and Stevenson-Wilder. Appendix E provides a chart describing the major legislative themes in technology transfer outlines these provisions in more detail.

\subsection{Issues for Bioremediation Technology}

Typically government agencies only invest in developing inventions to meet agency needs that cannot be met through commercially available technology. In the case of bioremediation, many businesses have already developed processes for remediating common soil contaminants. Since the government would purchase commercial technologies if they met agency needs, government$\mathrm{R} \& \mathrm{D}$ investments are likely to focus on problems unique to federal sites, or on problems that are not unique and for which acceptable technologies do not exist.

While government-funded research may result in technologies that effectively address remediation problems on federal sites, these technologies will have the potential to generate large profits in the private sector only when the government-funded technologies fill a commercial need. Researchers should also be aware that because many microbial remediation technologies are site-specific, commercial partners may not want to invest in marketing the technology, especially when the field is already populated with private sector competitors.

National laboratories and other contractors developing bioremediation technology may elect to retain title to patentable inventions. However, the government retains the right to use these technologies wherever they meet government remediation needs. The non-federal market for the technology may be small, so inventors should expect their rewards in the form of professional recognition and publication rather than patent royalties. ${ }^{16}$

\footnotetext{
15 Stephen May. Personal communication, July 1996.

16 Stephen May. Personal communication, July 1996.
} 


\subsection{Stakeholder Perceptions and Acceptance of Bioremediation Technologies}

About two-thirds of the public thinks that biotechnology will improve human quality of life (Zechendorf 1994). Because the public's degree of acceptance increases with knowledge and understanding, public education and involvement are essential to successful deployment of environmental biotechnologies, including bioremediation technologies. Bioremediation technologies are yet in their infancy. As a result, numerous concerns have been raised that will require researchers to engage and work with the public toward their eventual resolution. Some of the more important issues and concerns are related to ecological effects, the risks associated with those effects, and their management.

Because bioremediation is a very new discipline, the ecological effects of releasing genetically engineered microorganisms and non-native, naturally occurring microorganisms into the environment are poorly known for most organisms - rhizobia, soil microalgae, and some fungi being three exceptions (Kohler et al. 1992; Rehmann 1993; Fox 1994; Melting 1988; Minshull 1995). The limited number and scope of bioremediation test applications conducted to date is not sufficient to determine the range of, or optimal conditions for, the use of bioremediation technologies. In addition, the present state of knowledge includes little information on the largescale implications of introducing non-native and genetically engineered organisms into the field, including persistence of the introduced organisms, their ecology, and their ability to compete with (or even outcompete), naturally occurring fauna and flora.

The next five years will be crucial to the formulation of the public's image of environmental biotechnology as it moves from laboratory research to field testing (McCabe and. Fitzgerald . 1991). The scientific and technical community will face greater public scrutiny concerning the safety and desirability of applying environmental biotechnology to a variety of problems. Successful technology application will depend on how well biotechnologists are prepared to deal with public scrutiny. For biotechnologies to be assured of success, those concerned with moving them from the flask into the field must to be concerned with the public's image of environmental biotechnology. If those who fear biotechnology dominate its image formation and transmission through the mass communication process, and if the public lacks a basis for rejecting or modifying that image in a positive way, environmental biotechnology will be brought to a standstill.

The scientific community must undertake several, interrelated activities to ensure the successful deployment of environmental biotechnologies (McCabe and Fitzgerald 1991). It must first heighten its image awareness (i.e., image as portrayed by various mass media outlets) and improve its internal communication processes. Concurrently, public education in basic science and technology must then be enhanced to effectively filter and interpret the biotechnology "reality" that the mass communications process delivers to us all. Public acceptance is based on trust that must be earned over time. Hence, no replacement exists for successful demonstrations, good science, ethical conduct, and unflagging commitment to the public interest (as opposed to corporate profit in some cases). Commitment to the public interest must be based in the third 
major concurrent activity: active, appropriate engagement of the public by researchers across the spectrum of government biotechnology R\&D programs. During the education, awareness, and engagement processes, the regulatory process must be perceived by the public as credible and protective, and the regulations must be sufficiently stringent to mitigate potential risks associated with field testing. Finally, the environmental biotechnology community must manage its failures in an open, rational, and safe manner if public perceptions about biotechnologies are to be positive.

This chapter provides an evaluation of in situ bioremediation from the stakeholder perspective. It summarizes issues that technology developers should consider, as identified by a diverse group of stakeholders. It also summarizes those stakeholders' evaluations of the process designed to elicit their comments. The evaluation of the acceptability of bioremediation is based on the findings of the VOC Arid Site Integrated Demonstration (VOC-Arid ID) Program and follow-up interviews conducted in 1996. The VOC-Arid ID Program was a three-year program funded by the DOE's Office of Technology Development. It included focus groups, workshops, and interviews with over 100 individuals at Hanford and four other arid DOE sites. Because the in situ bioremediation project under the VOC-Arid $\mathrm{D}$ Program focused on enhancement of native, naturally-occurring organisms, additional interviews were conducted in 1996 on stakeholders' evaluations of non-native, naturally-occurring and genetically engineered microorganisms. Additionally, both the VOC-Arid ID Program and the follow-up interviews collected information on processes to stimulate organisms.

This chapter is divided into four sections. First, the history and goals of the stakeholder involvement process are presented. Second is a summary of the findings from the stakeholder involvement process on issues relevant to use of micro-organisms. A description of the issues specific to each of the three types of micro-organisms and to stimulation processes included in the proposed scope of the NABIR program is third. Recommendations for involving stakeholders in designing, conducting, and evaluating the results from NABIR are included last.

\subsection{Stakeholder Involvement Process}

The VOC-Arid Site Integrated Demonstration involved stakeholders extensively in the evaluation of six innovative technologies to remediate VOC contamination:

- resonant Sonic Drilling

- in-well Vapor Stripping

- membrane Separation

- in situ Bioremediation 
- passive Soil Vapor Extraction Using Borehole Flux

- tunable Hybrid Plasma.

The stakeholder involvement program identified data requirements and issues at many arid sites, so that those concerns could be included in technology test plans and demonstrations. Ultimately, the process was designed to expedite deployment of effective and acceptable remedial technologies by determining what stakeholders required of these technologies. The goal was to design the technology demonstration comprehensively such that it addressed issues important to all of DOE's sites potentially interested in using bioremediation technology. ${ }^{17}$

Stakeholders included regulators, technology users, public interest groups representatives, elected officials, and tribal and Hispanic community representatives. The program identified 100 stakeholders at five DOE arid sites: Hanford, Sandia, Los Alamos, Rocky Flats, and the Idaho National Engineering Laboratory. The stakeholder involvement process had several components. First, through individual interviews and focus groups, Hanford Site stakeholders contributed to the development of criteria by which technologies would be evaluated. These criteria are presented in Table 6.1. Through additional individual interviews, stakeholders from the other arid sites worked toward two goals. First, they validated and further refined the data requirements, issues, and concerns identified by the Hanford stakeholders. Second, they described the requirements specific to their site and region.

In addition to identifying concerns, Hanford stakeholders participated in an integrated workshop that provided input to demonstration test plans for groundwater remediation technologies, the first four of the six technologies listed above. The workshop included all of the Hanford stakeholders and the scientists and engineers who are developing and testing the technologies. In the fall of 1995, the Hanford stakeholders were interviewed for their final evaluations on three of the technologies that had completed demonstrations: Passive Soil Vapor Extraction, Tunable Hybrid Plasma, and Sonic Drilling.

In addition to the VOC-Arid ID activities, NABIR stakeholder concerns were elicited in 1996. First, the DOE Site Technology Coordination Group Subcommittee for Plumes and Landfills was briefed on the proposed NABIR program. Second, additional interviews were conducted with specific stakeholders to validate VOC-Arid ID findings and to enhance those findings with stakeholder issues and concerns related to non-native, naturally occurring micro-organisms and genetically engineered micro-organisms. (A copy of the protocol is included as Appendix A.) Stakeholders issues and concerns on the use of enzymes that cross-cut all types of organisms were also solicited. These comments were analyzed and are reported here as a necessary precursor to designing an appropriate stakeholder involvement plan for NABIR.

17 For more information on the VOC Arid Integrated Demonstration see Peterson 1995 and Peterson et al. 1995. 


\subsection{Overview of Stakeholder Comments Related to Bioremediation Technologies}

An analysis of stakeholders' comments collected during focus group meetings and individual interviews as part of the VOC-ARID ID Program revealed issues that need to be considered in technology design. NABIR interviews further validated the findings and addressed the additional types of micro-organisms. Comments are sorted into the categories shown in Table 6.1.

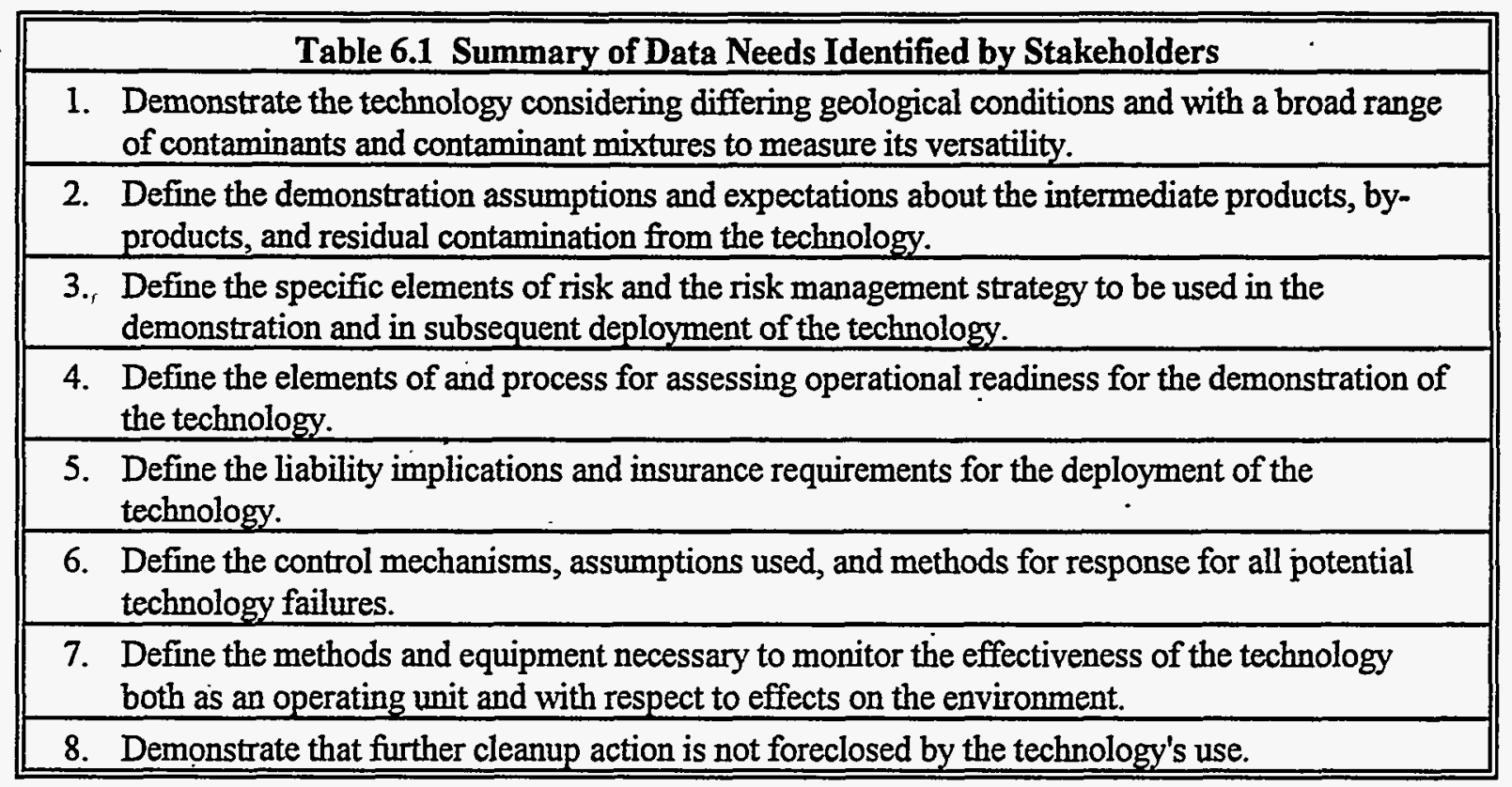

performance, cost, environmental health and safety, regulatory issues, and socio-political issues. A summary of stakeholder data needs is presented in Table 6.1. Factors that are likely to be of particular interest to stakeholders (e.g., sub-surface injection) are noted. These issues are relevant to the full scope of micro-organisms included in the NABIR program. In the next section, issues that technology developers should consider are addressed. The last section discusses how bioremediation is viewed by stakeholders with respect to the remaining criteria.

\subsubsection{Issues for Technology Developer to Consider}

Stakeholders presented ideas about both the development and demonstration of in situ bioremediation technologies. Stakeholders believed that several steps were necessary to have confidence in the demonstration process. The sequential steps recommended were 
1. Conduct laboratory experiments.

2. Scale up the technology following good scientific principles from bench scale, to pilot scale, to preparation for field demonstration.

3. Move to an enclosed field experiment where a barrier is placed on all sides of the demonstration site to control any problem encountered.

4. Move to open use in field once failure scenarios are identified and assessed, with both the assumptions understood and the mechanisms in place to handle them. The failure control issue is addressed fully in the section below.

5. Peer reviews of both design and evaluation should be solicited at each step, as was conducted under the VOC-Arid ID Program, and the results should be published.

Issues that stakeholders believe should be addressed during the demonstration of a bioremediation technology include performance, environmental health and safety, regulatory issues, and socio-political issues. Each is discussed below.

\section{Performance}

Ability to Deal with Co-Contaminants. Stakeholders are very interested in a technology's ability to remediate all of the contaminants it is likely to encounter. They are concerned about technologies that do not take care of the entire problem-either leaving other contaminants behind or mobilizing contaminants that subsequently escape the treatment zone. This concern is particularly relevant for sites with mixed radioactive and hazardous contaminants, and is important for in situ bioremediation techniques that face the challenge of residual cocontaminants. (As most DOE sites that are contaminated contain mixed wastes, technologies that have the ability to remediate mixed waste are a major theme of the NABIR Program.)

Versatility. In a related issue, stakeholders prefer technologies that are able to address a broad range of contaminants, and that can be used in diverse soil, groundwater, chemical, temperature, and other site conditions.

Timeliness. Insitu bioremediation methods may have significant benefits in terms of - effectiveness, cost, or other attributes, but are anticipated to operate more slowly or to be slower to reach objectives than a baseline technology. In evaluating technologies, stakeholders take into account both the rate of performance and the time required to complete the job. Therefore, bioremediation technology is likely to be inappropriate for high-risk sites that need immediate attention. 


\section{Environmental Health and Safety}

Failure. Stakeholders are concerned about the potential effects that any new technology may have on the health and safety of workers and the public. The major specific issue is failure. The more catastrophic the potential failure scenario, the greater the likelihood that stakeholders will have an issue in this area. The potential failure scenario will vary with the microorganism, as will the importance of this issue. Effects on the environment or on public health from the unexpected failure of an innovative technology must be carefully considered. Stakeholders want to be informed about the assumptions associated in determining failure scenarios and the controls planned to address any problems.

\section{Regulatory Issues}

Track Record. Insitu bioremediation has a limited history of regulatory approval at radioactive sites. Regulatory precedence refers to the regulations and regulatory guidance needed to evaluate a technology's compliance. Obviously, regulators' familiarity with a technology reduces regulatory uncertainty. Insitu bioremediation's subsurface injection may raise issues related to regulatory requirements (e.g., Washington State's non-degradation standards for groundwater). Additionally, technology developers should address the perception that in situ bioremediation techniques face complex regulatory hurdles because they require many regulatory approvals.

Case studies of successful in situ bioremediation projects at non-radioactive sites have shown that cleanup standards and permitting procedures are the primary barriers to their deployment (Interstate Technology and Regulatory Cooperation Working Group and Colorado Center for Environmental Management 1996). These barriers were most successfully navigated when state regulators maintained a flexible approach to compliance with environmental protection requirements.

\section{Socio-Political Issues}

Impacts to Resources. Stakeholders are very concerned about potential impacts natural and cultural resources. Any potential impact to natural or cultural resources that are valued by a particular community or region should be addressed for stakeholders. These resources include drinking water/groundwater supplies, tribal resources, and traditional land uses.

\subsubsection{General Issues of Concern to Stakeholders}

More general issues of concern to stakeholders regarding in situ bioremediation may be divided into the categories of performance, cost, and socio-political issues. These issues were generally seen as favorable or neutral toward in situ bioremediation. Hence, technology developers should consider these criteria somewhat differently from the issues addressed above. 


\section{Performance}

Complexity. On the one hand, in situ bioremediation's use of microorganisms to remove contaminants alleviates issues that stakeholders may have with a technology's complexity of operation. However, on the other hand, the science behind the technology is viewed as complex, particularly for genetically engineered microorganisms. With complex technologies, there is a common belief that the more complex a technology, the more expensive it is, the more likely it is to fail, and the more costly and difficult it is to repair the damage the technology could cause.

Maintenance and Operation. Insitu bioremediation is viewed as having an advantage over other technologies because of low operation and maintenance needs.

Off-Site Treatment/Transport. Technology developers should note that in situ bioremediation does not require off-site transport, treatment, or disposal of contaminants. These attributes minimize issues dealing with varying jurisdictional authorities, possible environmental and health exposure, accidents, and issues associated with treatment and disposal facilities.

\section{Cost}

Cost-Effectiveness. Cost is an important evaluation criterion to stakeholders, but does not take precedence over other considerations, especially health and safety. Existing insitu bioremediation methods are perceived to incur lower costs than baseline alternatives.

Stakeholders are interested to know if the cost to develop, operate, and decommission a new technology is less than for the baseline technology. Their preferred basis for such comparisons is life-cycle cost, including startup, operations, maintenance, and decommissioning. However, stakeholders point out that many decisions about technology development and deployment now have to be made in light of reduced budgets. As the cost of developing the new technology is unknown, this may impact stakeholders willingness to support new technology development efforts.

\section{Socio-Political Issues}

Stakeholders prefer methods that promote unrestricted future use of currently contaminated sites, including spiritual, traditional, and practical uses. Technology developers should emphasize that insitu bioremediation does not foreclose future options for remediation or land use.

\subsection{Stakeholder Comments Related to Specific Types of Microorganisms and Stimulant Use}

Comments related to natural, native organisms; natural, non-native organisms; genetically engineered organisms; and stimulants are summarized below. 


\subsubsection{Natural, Native Organisms}

Overall, the use of native, naturally-occurring organisms is acceptable to stakeholders. In the 1996 follow-up interviews, stakeholders were comfortable with progressing to use this type of microorganism to remediate contaminated soils. The VOC-ARID ID Program included a demonstration of insitu bioremediation using natural, native organisms.

\section{Hanford Focused Considerations}

Hanford stakeholder issues relevant to designing the VOC-Arid ID are summarized in Appendix B. A full compilation of issues raised by Hanford stakeholders is presented in Appendix C. Issues highlighted by the Hanford stakeholders, including interviews conducted for the NABIR Program, are discussed below.

Effectiveness. Stakeholder's questions regarding effectiveness focus around four traditional stakeholder issues: "works as intended," versatility, ability to address co-contaminants, and speed. The demonstration test plan under the VOC-Arid ID Program was modified to include these issues as data requirements. Based on the success of that program, NABIR's technology demonstration efforts may benefit by including data requirements relevant to these issues in its test plans. Inclusion of these issues implies that the technology developers must

- demonstrate that the technology "works as intended" (i.e., that it is capable of remediating contaminants). This can be done through a carefully designed monitoring system that demonstrates the technology's progress toward reducing the levels of targeted contaminants.

- determine the overall site conditions including aquifer characteristics and geological conditions, permeability ranges, and plume size. Stakeholders raised questions about the technology's ability to work in changing aquifer characteristics and transmissivity characteristics, as well as its ability to address subsurface aquifer discontinuities. Demonstrations under NABIR, therefore, may define the hydrogeologic conditions for which the technology is appropriate.

- determine the radius of influence of the technology. Stakeholders will want to know how large an area can be remediated by a given size demonstration.

- identify temperature limits under which the technology will be effective.

- predict and measure potential effects on co-contaminant mobility and possible chemical changes to the co-contaminant. 
- determine the range and associated concentrations of contamination for which the technology is applicable.

- predict and measure the technology's destruction efficiency, its rate of action, and the limits of its effectiveness.

Failure Control. Incomplete information about both performance and risks leads to concern about the unknown and unpredictable consequences of a potential failure impact. Interest group representatives at Hanford are emphatic that proven failure-control methods be in place prior to the start of any demonstration. One identified failure control need is the ability to stop microbial growth.

Applicability. Whereas the effectiveness criterion focuses on how the technology works, the applicability criterion examines where the technology could be applied. Stakeholders are interested in knowing when it is appropriate to use the technology. Questions raised include

- When should it be applied as an interception method versus as a source treatment?

- In what cases should the technology be used at the edge of the plume to contain its movement?

- Should the technology be used to remediate low-priority or small plumes?

Interviewed technology users found the technology to be appropriate as a good polishing method to follow after a more active remediation approach.

Environmental Effects. Related to effectiveness, Hanford stakeholders stressed the importance of understanding how the microbes would work during and after stimulation, so that any effect on human health and on the biota could be detected. Stakeholders consider monitoring to be critical both during and after the demonstration. They want to know what happens to micro-organisms after the withdrawal of nutrients. Short- and long-term effects on aquifer permeability are a concern as well. The concern is whether the growth of microorganisms induced by the technique can plug the aquifer. Hanford stakeholders want demonstrations to prove that bioremediation processes do not harm the biota in the Columbia River and that the action of the stimulated microorganisms on contaminants does not produce harmful by-products.

\section{Additional National Considerations}

The complete stakeholder comments from the four other arid DOE sites are provided in Appendix D. The following comments are highlights from these other arid sites.

Effectiveness. Overall, stakeholders like the ease of use of insitu bioremediation. However, stakeholders at different sites have raised different questions. At INEL, they question the 
effectiveness of delivering nutrients to the microorganisms through INEL's porous rocks and the fast-moving water in the aquifer. New Mexico stakeholders focus on the effectiveness of microbes in field conditions where there are extreme temperature shifts. In areas where high levels of nitrates occur in the water, questions arise about whether bioremediation can work on nitrate fertilizer problems. Some stakeholders from the four other DOE arid sites question the ability of bioremediation to remove contaminants to levels that are necessary to clean the groundwater.

Stakeholders also question whether bioremediation technologies can be controlled, and whether specific or all microbes are stimulated. One tribal representative in the 1996 interviews recommended that stimulants be tested on all microbes to ascertain and measure potential impacts. A Rocky Flats technology user asked that demonstrations assess whether microbes could further spread contamination, a major concern at the site. A range of stakeholders requested determinations of secondary products that bioremediation technologies can create insitu, and whether any harmful intermediate products such as chlorides, chlorine gas, and vinyl chloride could be produced. Stakeholders also wanted an analysis of the groundwater oxidation chain.

Regulatory. Stakeholders are more comfortable with a given technology if it has a regulatory track record. In the case of insitu bioremediation, stakeholders want assurances that the technology complies with relevant regulations, including groundwater quality and permitting requirements. Injection can cause direct conflict with groundwater quality standards and antidegradation policies in the short term. Even though bioremediation may facilitate source removal and aquifer restoration in the long term, the technology may not be approved in states where any and all injection is prohibited. ${ }^{18}$. For instance, New Mexico prohibits the injection of any materials into the subsurface.

Environment. At INEL, interest group representatives and technology users viewed bioremediation as an attractive technology with regard to its impact on the environment. A tribal representative at INEL feels that there is an advantage in using a natural process that appears to be protective of the natural environment. Groundwater impacts are a significant concern at all arid sites included in the VOC-Arid study. On the other hand, some stakeholders question the technology's potential to negatively impact drinking water sources. The suggested measuring stick is that the technology be able to comply with drinking water standards.

\subsubsection{Natural, Non-Native Organisms}

Issues that technology developers should address with natural, native organisms also apply to natural, non-native organisms. Additionally, new issues such as the transportation of the

\footnotetext{
${ }^{18}$ Case Studies Task Group of the Interstate Technology and Regulatory Cooperation Working Group and Colorado Center for Environmental Management, "Case Studies of Regulatory Acceptance In Situ Bioremediation Technologies" Feb. 1996, p. 10.
} 
organisms to the site and demonstrations that the organism will not damage the local biota are important to stakeholders.

Again, the importance of careful scale-up of the technology has been emphasized by most stakeholders. While most stakeholders believe it is possible to use non-native species, others believe that non-native species have the potential to be harmful. They cite examples such as rabbits in Australia and the kudzu plant in the southern United States, both of which permanently altered local natural ecosystems. The burden of proof is demonstrating that there is not even a remote possibility of damage to the ecosystem using an introduced microorganism.

\subsubsection{Genetically Engineered Organisms}

In general, stakeholders are only slightly more concerned about the use of genetically engineered microorganisms than they are about the use of native, natural organisms. Their main requirement is that the same scrupulous scientific principles are used to scale up the technology from laboratory experiments to bench-scale, pilot-scale, closed-cell field, and finally full-scale field experiments with failure scenarios identified and mechanisms in place to mitigate potential problems. When designing and evaluating the results of each step, they request that a peer review process be used to validate the overall developmental effort. One stakeholder who voiced his concern about non-native introduced species has similar concerns about the use of GEMs. Genetic alternations raise the specter of science-fiction movies with organisms growing out of control and harming people or the environment. Stakeholders believe that more risk and uncertainty about public health and safety is associated with the use of GEMs than with naturally occurring organisms. Stakeholders want proof that the GEM is not a human pathogen before a demonstration proceeds. As with natural, non-native species, the burden of proof for some stakeholders is very high.

\subsubsection{Stimulants}

The stimulation of organisms through the addition of chemical agents or changes to the environment is generally acceptable to stakeholders if the same good science protocols are used including having peer-reviewed, scale-up mechanisms in place.

Chemical agents and tracers used with bioremediation include oxygen, inorganic nutrients, and carbon sources. Oxygen is used when the treatment area is aerated through drilled wells. Stakeholders want two issues addressed when demonstrations use oxygen sources to stimulate the organisms. First, technology developers must demonstrate that the they can comply with water supply regulations and underground injection regulations. Second, developers must demonstrate that forcing oxygen into the environment will not contribute to the volatilization or mobility of the contaminant. Insitu aeration may promote the volatilization throughout the treatment area, such that no single air emissions point would exist. Consequently, monitoring systems must be able to detect the broad release of fugitive emissions. 
Nutrients (e.g., nitrogen and phosphorus compounds) and carbon sources (e.g., methane and acetate) are used to increase microbial activity. Generally, these additions are dissolved in water for application. All issues relevant to the addition of oxygen apply to the addition of nutrient and carbon sources. In particular, stakeholders want to be assured that the addition of the chemicals meets provisions of the SDWA that has specify upper limits on substances, including nitrates. Some stakeholders, both at Hanford and at INEL, have expressed concerns that unwanted byproducts could be produced, and that acetate and nitrate may combine to make and leave something more hazardous. The products of concern include chlorides, chlorine gas, and vinyl chloride. Lastly, stakeholders are interested in information about potential impacts of residual substances from nutrients or carbon sources that could be left in the groundwater.

Changes to the environment could include modifying $\mathrm{pH}$, temperature, or moisture levels. Modifying the $\mathrm{pH}$ level to stimulate the organisms may raise issues with stakeholders regarding regulatory requirements. For example, stakeholders may want demonstrations that the $\mathrm{pH}$ of waters injected into the drinking waters sources meet the SDWA guidelines. Changes in temperature and moisture levels are done to create optimum conditions for biodegradation. Heating may require the injection of air or water. If the heating is conducted through air, the issues would be the same as for oxygen, while if the heating is carried through water, the issues would be the same as for nutrient addition. The issues related to moisture adjustment are detailed in nutrient addition as well.

In Washington State, the Department of Ecology critically reviews the injection of anything but oxygen to stimulate microbial growth because of the state's non-degradation standard for groundwater. To be acceptable in the state, the technology must satisfy regulators' requirements for the safety of anything added to the subsurface.

\subsection{Recommendations on How to Involve Stakeholders}

The following are recommendations made by stakeholders concerning their involvement in the developing NABIR Program. While the comments are focused on the Hanford Site, the recommendations are most likely broadly applicable to other DOE sites.

Recommendation 1: Use existing forums to disseminate information on the progress of the technologies. Provide bi-annual updates on the project to the DOE Site Technology Coordination Group's Subcommittee on Plumes and Landfill and the Hanford Advisory Panel Committee on Hazardous and Solid Waste Management with bi-annual updates on the project, or provide timely briefings if new developments occur or new program activities are being planned. Allow the subcommittees to respond with questions or provide recommendations on how they would like to be involved.

Recommendation 2: Conduct peer reviews of test plans and performance reports for the demonstrations at each stage of the development process. Share the results of the peer reviews with citizen advisory committees. 
Recommendation 3: Make project reports and backup references available to citizen advisory committees. 


\subsection{Conclusions}

While microbial bioremediation technologies offer the promise of more effective cleanup technologies at lower cost, the legal and social issues that surround them have the potential to inhibit their research, development, and deployment. Technology developers must develop an understanding of the policy and regulatory environment which may affect the feasibility of alternative methods of microbial remediation. They must decide how to invest in acquiring intellectual property protection for the processes and technologies they develop, and evaluate whether and how to collaborate with private sector investors to commercialize the research. Finally, technology developers must establish effective stakeholder involvement processes to ensure that obstacles do not result from misinformation or public resentment.

\subsection{Policy, Legal, and Regulatory Issues}

The United States relies on the Coordinated Framework for regulating Biotechnology developments. Instead of coordinating policy under one set of statutes and one regulatory agency, the Coordinated Framework instructs many different government agencies to apply existing law to the unique problems posed by genetically altered organisms and technologies employing gene-splicing techniques. As a result, technology developers face difficulties in determining which overlapping regulations and agencies apply to particular projects, if any regulations apply at all.

The EPA currently regulates the field release of many GEMs under TSCA, which only permits the agency to restrict releases if it can show they pose a danger to human health or the environment within the 90-day review period. While the structure of the statute favors industry interests in obtaining permits efficiently, very little information exists regarding the possible threat genetically altered or exotic organisms pose when introduced into native ecosystems. This may cause technology developers to face uncertain liability and public opposition. Citizens aware of the damage caused by exotic species worry that underregulation of field releases of genetically altered organisms may result in similarly severe and unforeseeable problems.

Bioremediation efforts must also proceed according to statutes and regulations governing hazardous waste cleanup procedures. While regulators are beginning to move to risk-based cleanup standards, most laws still impose a command and control structure on cleanup efforts. While these regulations evolved to ensure the speedy and effective cleanup of hazardous waste, they may not provide needed flexibility to permit bioremediation, which may take more time and eliminate less waste than more drastic conventional remediation methods. However, some exceptions within existing frameworks provide opportunities for biotechnology developers to implement bioremediation without an excessively burdensome permitting process. 


\subsection{Intellectual Property and Patenting Issues}

Biotechnology developers may obtain intellectual property protection in the form of utility patents for processes involving microbes, for genetically altered organisms, or for purified forms of natural microbes. Researchers must work closely with intellectual property professionals to ensure that protection can be obtained: technology that is revealed through publication may not be eligible for patent protection abroad, and publication limits the time inventors can take before filing for U.S. patent protection. The patent application process can be lengthy and expensive, and technology developers must assess whether obtaining patent protection is a worthwhile investment.

\subsection{Technology Transfer}

Current U.S. technology transfer policy encourages contractors receiving government funding to take title to the resulting inventions. Once laboratories own the patents on the products of basic research, they can form cooperative $R \& D$ agreements with private industry to develop the inventions into a marketable form. National laboratories and research organizations must try to evaluate the commercial potential of patented inventions, since the commercialization process can be lengthy and expensive. Attempts to commercialize bioremediation technology from DOEfunded research may not prove as successful as other technologies, since many private competitors already address common hazardous wastes, the toughest DOE remediation problems may not commonly occur on private sites, and the effectiveness of microbial technology depends on soil, nutrient, and other environmental factors specific to the contaminated site.

\subsection{Stakeholder Considerations}

Discussions with stakeholders at Hanford and other DOE sites reveal that the public harbors concerns about the performance, environmental health and safety, and regulațory compliance of bioremediation technologies. Stakeholders want bioremediation technologies that are able to remediate all of the contaminants that are encountered. They prefer simple technologies which seem to be less expensive, more reliable, and easier to fix if problems occur. While stakeholders recognize that bioremediation may be cost-effective, they believe that safety and environmental protection priorities must be emphasized in designing a remediation plan. Stakeholders revealed that they need more information about the versatility, safety, operational readiness, liability implications, control mechanisms, and monitoring of proposed technologies.

\subsection{Recommendations for Involving Stakeholders}

In order to ensure that stakeholders are involved in a productive manner, technology developers must involve them at the initial stages of research specific to the contaminated site. Existing fora permit stakeholders to obtain periodic updates on the progress of research. Sharing the results of peer reviews of research help stakeholders understand the quality of research. Providing citizen committees with reports and evaluations helps keep stakeholders informed and involved. 


\subsection{References}

1077 Official Gaz. Pat. Office 24, 31 (April 21, 1987).

7 CFR 340. Introduction of Organisms and Products Altered or Produced Through Genetic Engineering Which are Plant Pests or Which There is Reason to Believe are Plant Pests.

7 USC $\S \S 150$ et seq. Governmental Policy for Protection of Potatoes and Tomatoes from Golden Nematode.

7 USC 2402. Plant Variety Protection Act (PVPA).

15 USC §§ 2604(a) et seq. Toxic Substances Control Act (TSCA), P.L. 94-469 (as amended).

15 USC 3710. Federal Technology Transfer Act of 1986.

15 USC 3701 et seq. Stevenson-Wydler Technology Innovation Act of 1980.

29 CFR 1910. Occupational Safety and Health Standards, Occupational Safety and Health Administration, Department of Labor.

29 USC §§ 651 et seq. Occupational Safety and Health Act of 1970.

33 USC $\S \S 1251$ et seq. Clean Water Act of 1977.

35 USC 1-376. U.S. Patent Act (1994) (as amended).

35 USC 100. Defenitions.

35 USC 101. Inventions Patentable.

35 USC 102. Conditions for Patentability; Novelty and Loss of Right to Patent.

35 USC 103. Conditions for Patentability; Non-Obvious Subject Matter.

35 USC 112. Specification.

35 USC 154. Contents and Term of Patent.

35 USC 161. Patents for Plants.

35 USC 200. Policy and Objective. 
35 USC 202. Disposition of Rights.

35 USC 203. March-in Rights.

35 USC 204. Preference for United States Industry.

35 USC 271. Infringement of Patent.

40 CFR Parts 260 through 272. Hazardous Waste Regulations.

40 CFR 300. National Oil and Hazardous Substances Pollution Contingency Plan.

40 CFR Part 700, et al. 1994. Microbial Products of Biotechnology; Proposed Regulation Under the Toxic Substances Control Act; Proposed Rule. U.S. Code of Federal Regulations.

42 USC $\S 6921$ et seq. Identification and Listing of Hazardous Waste.

42 USC $\S 4321$. National Environmental Protection Act of 1969.

42 USC $\S \S 7401$. Clean Air Act.

42 USC $\S \S 300$. Safe Drinking Water Act.

48 CFR 970 et seq. DOE Management and Operating Contracts.

51 FR 23313. June 26, 1986. U.S. Environmental Protection Agency, "Statement of Policy; Microbial Products Subject to the Federal Insecticide, Fungicide, and Rodenticide Act and the Toxic Substances Control Act." Federal Register.

51 FR 23349. June 26, 1986. National Institutes of Health, "Statement of Policy Describing the Role of NIH in Relation to Biotechnology." Federal Register.

51 FR 23347. June 26, 1986. Occupational Safety and Health Administration. "Agency Guidelines on Biotechnology." Federal Register.

51 FR 23302. June 26, 1986. Office of Science and Technology Policy, "Coordinated Framework for Regulation of Biotechnology." Federal Register.

51 FR 23309. June 26, 1986. U.S. Food and Drug Administration, "Statement of Policy for Regulating Biotechnology Products." Federal Register. 
59 FR 45526. September 1, 1994. U.S. Environmental Protection Agency, "Microbial Products of Biotechnology; Proposed Regulation Under the Toxic Substances Control Act." Federal Register.

American Fruit Growers, Inc. v. Brogdex Co. 283 U.S. 1 (1931).

Animal Legal Defense Fund v. Quigg. 932 F.2d 920 (Fed. Cir. 1991). (Cited as ALDF).

Auchincloss, S. 1993. "Does Genetic Engineering Need Genetic Engineers?: Should the Regulation of Genetic Engineering Include a New Professional Discipline?" Boston College Environmental Affairs Law Review. 20:37-63.

Bakst, J.S. 1991. "Impact of Present and Future Regulations on Bioremediation." Journal of Industrial Microbiology 8:13-22.

Biotechnological Inventions: Proposal for a Council Directive on the Legal Protection of Biotechnological Inventions. Oct. 20, 1988, O.J. C 10/3 (1989).

Bonito Boats Inc. v. Thunder Craft Boats, Inc. 489 U.S. 141 (1989).

Bright, C. July/August 1995. "Bio-Invasions: The Spread of Exotic Species.". World Watch 8(4):10-20.

Burk, D. L. 1993. "Misappropriation of Trade Secrets in Biotechnology Licensing." Albany Low Journal of Science \& Technology 4:121-154.

Cameron Septic Tank Co. v. Village of Saratoga Springs 159 Fed. 453 (2nd Cir. 1908).

Carroll, A. E. 1995. "Not Always the Best Medicine: Biotechnology and the Global Impact of U.S. Patent Law." American University Law Review 44:2433-2493.

Chadwick, R.A. 1995. "Regulating Genetically Engineered Microorganisms Under the Toxic Substances Control Act." Hofstra Law Review 24:223-251.

Chakrabarty (see Diamond v. Chakrabarty).

Chandler, J. P. 1993. "Wealth Accumulation for the United States." In Intellectual Property and the Production of New.Technology for the Future. National Intellectual Property Law Institute, Washington, D.C.

Chiapetta, J. R. 1994. "Of Mice and Machine: A Paradigmatic Challenge to Interpretation of the Patent Statute." William Mitchell Law Review 20:155-190. 
Cooper, I. 1989. Biotechnology and the Law. Clark Boardman Callahan, New York.

Czmus, A. F. 1994. "Biotechnology Protection in Japan, the European Community, and the United States." Temple International and Comparative Law Journal 8:435-463.

Dentler, J.L. 1993. "Noah's Farce: The Regulation and Control of Exotic Fish and Wildlife." University of Puget Sound Law Review. 17:191-242.

Derzko, N. 1996. "Using Intellectual Property Law and Regulatory Processes to Foster the Innovation and Diffusion of Environmental Technologies." Harvard Environmental Law Review 20:3-58.

Diamond v. Chakrabarty. 447 U.S. 303 (1980).

Draft Directive (see Biotechnological Inventions).

Dresser, R. 1988. "Ethical and Legal Issues in Patenting New Animal Life:" JURIMETRICS J. 28:399.

Eisenberg, R. 1987. "Proprietary Rights and the Norms of Science in Biotechnology Research." Yale Law Journal 97:177-230.

Ex parte Latimer 1889. 1889 Dec. Comm'r Pat. 123.

Fox, J. L. 1994. "Field Testing for Bioremediation Called Logical Next Step." ASM News 60(6):319-322.

Funk Brothers Seed Co. v. Kalo Innoculant Co. 333 U.S. 127 (1948).

Giamporcaro, D.E. 1992. Law and Policy on the Frontier: The Regulation of Bioremediation of Hazardous Waste (Draft). U.S. Environmental Protection Agency, Office of Pollution Prevention and Toxics, Biotechnology Program.

Gore, A. 1991. "Planning a New Biotechnology Policy." Harvard Journal of Law and Technology 5:19-30.

Graham v. John Deere Co. 383 U.S. 1 (1966).

Graziano, K. M. 1996. "Biosafety Protocol: Recommendations to Ensure the Safety of the Environment." Colorado Journal of International Law and Policy: 7:179-211.

Griffith Rubber Mills v. Hoffar, 313 F.2d 1 (Or. 1963). 
Hardy, C. 1994. "Patent Protection and Raw Materials: The Convention on Biological Diversity and Its Implications for U.S. Policy on the Development and Commercialization of Biotechnology." University of Pensylvania Journal of International Business Law 15:299-325.

Hecht, E. J. 1992. "Beyond Animal Legal Defense Fund v. Quigg: The Controversy Over Transgenic Animal Patents Continues." American University Law Review 41:1023-1074.

Hettinger, N. 1995. "Patenting Life: Biotechnology, Intellectual Property, and Environmental Ethics," Boston College Environmental Affairs Law Review 22:267-305.

In re Arzberger. 46 U.S.P.Q. 32 (1940).

In re Bergy. 596 F.2d 952 (1979).

In re Harvard, 5 Eur. Pat. Off. Rep. 501 (Tech. Bd. App. 1990).

In re Durden, $763^{\circ}$ F.2d 1406 (Fed. Cir. 1985).

Interstate Technology and Regulatory Cooperation Working Group and Colorado Center for Environmental Management (CCEM). 1996. Case Studies of Regulatory Acceptance: In Situ Bioremediation Technologies. CCEM, Denver, Colorado.

Jones Knitting Corp. v. Morgan, 361 F.2d 451 (Pa. 1966).

Kaiser, J. 1996. “U.S. Frets Over Global Diosafety Rules.” Science 273:423.

Kim, J. J. 1993. "Out of the Lab and Into the Field: Harmonization of Deliberate Release Regulations for Genetically Modified Organisms." Fordham International Law Journal 16:11601207.

Ko, Y. 1992. "An Economic Analysis of Biotechnology Patent Protection." Yale Law Journal 102:777-804.

Kohler, C. C., W. L. Muhlach, P. C. Philips, and G. A. Paleudis. 1992. "Environmental and Ethical Concerns Associated with Transgenic Fishes." Journal of the World Aquaculture Society 23(2):27.

Kovalick, W. W., Jr. 1992. "Innovative Site Remediation Technologies: Barriers and Opportunities." Bioremediation News 2(5).

Kurdila, J. 1988. "The Introduction of Exotic Species into the United States: There Goes the Neighborhood!" Boston College Environmental Affairs Low Review 16:95-118. 
McCabe, A.S., and M.R. Fitzgerald. 1991: "Media Images of Environmental Biotechnology: What Does the Public See?" In Environmental Biotechnology for Waste Treatment., eds. G.S. Sayler et al., Plenum Press, New York.

McDaniel, C. S. 1994. "Protecting Biotechnology Trade Secrets in University and Industrial Research." Houston Journal of International Law 16:565-589.

Metting, F. B. 1988. "Microalgae in Agriculture." In Micro-Algal Biotechnology, M.A. and C. J. Borowitzka (eds), pp. 288-304, Cambridge University Press.

Miller, H. I. August 4, 1996. "Eco-Battiness: A New Tenet of United States Foreign Policy." Genetic Engineering News.

Minshull, J. 1995. "Cleaning Up Our Own Backyard: Developing New Catabolic Pathways to Degrade Pollutants." Chemistry and Biology 2(12):775-780.

National Technology Transfer and Advancement Act of 1995. $104 \mathrm{HR} 2196$, signed into law 28/2/96.

Oddi, A. S. 1987. "The International Patent System and Third World Development: Reality or Myth?" Duke Law Journal. 1987:831.

OTA (see U.S. Congress, Office of Technology Assessment).

Patents Throughout The World, 4th Ed. 1995. Clark, Boardman, Callaghan, New York.

Powell, D. 1991. "Canadian Biotech Regs Under Fire." Science 254:1720

PVPA. 1970. Plant Variety Protection Act. 7 USC 2402, PL 91-577.

Rehmann, S.C. 1993. "Nature in the Laboratory - Nature as a Laboratory: Considerations About the Ethics of Release Experiments." Experiential 49:190 -199 (Birkhauser Verlag. CH 4010 Basel, Switzerland).

Report of the Senate Committee on Commerce, Science, and Transportation (Science Committee), 12/20/95 on S 1164 (companion to HR 2196).

Restatement of Torts, Sec. 757 comment b (1939).

Reuter Textline: Chemicals Business News Base. March 14, 1996. "EU: New Moves to Clear . Up EU Biotechnology Patent Laws." 
Roche Products. v. Bolar Pharmaceutical Co. 733 R.2d 858 (Fed. Cir.) cert. denied, 469 U.S. 586 (1984).

Sabatelli, A. D., and J. C. Rasser. 1995. "Impediments to Global Patent Law Harmonization." Northern Kentucky University Law Review 22:579-620.

Saperstein, R. 1991. "The Monkey's Paw: Regulating the Deliberate Environmental Release of Genetically Engineered Organisms." Washington Law Review 66:247-265.

Scalise, D., and D.' Nugent. 1993. "Patenting Living Matter in the European Community: Diriment of the Draft Directive." , Fordham International Law Journal 16:990-1031.

Scalise, D., and D. Nugent. 1995. "International Intellectual Property Protections for Living Matter: Biotechnology, Multinational Conventions and the Exception for Agriculture." Case Western Reserve Journal of International Law 27:83-118.

Schechter, R. 1986. Unfair Trade Practices and Intellectual Property. West Publishing Co. St. Paul, Minnesota.

Science Committee (see Report of the Senate Committee on Commerce, Science, and Transportation).

Sease, E. J. 1989. "From Microbes, To Corn Seeds, To Oysters, To Mice:

Patentability of New Life Forms." Drake Law Review 38:551.

Skladany, G.J., and F.B. Metting, Jr. 1992. "Bioremediation of Contaminated Soil." In Soil Microbial Ecology: Applications in Agricultural and Environmental Management, pp. 483-513. F. B. Metting, Jr. (Ed.). Marcel Dekker, New York.

Testimony of David G. Davis, Deputy Director, Office of Wetlands, Oceans, and Watersheds, Office of Water, U.S. Environmental Protection Agency, before the Subcommittee on Water Resources and Environment and the Subcommittee on Coast Guard and Maritime Transportation of the Committee on Transportation and Infrastructure, U.S. House of Representatives, July 17, 1996.

- The Budapest Treaty on the International Recognition of the Deposit of Microorganisms for the Purposes of Patent Procedure 1977. 32 U.S.T. 1241.

The Reuter European Community Report. March 1, 1995. "Europarliament Skills Biotech Patent Directive." 
Tiedje, J.M., R.R. Colwell, Y.L Grossman, R.E. Hodson, R.E. Lenski, R.N. Mack, and P.J. Regal. 1989. "The Release of Genetically Engineered Organisms: A Perspective from the Ecological Society of America." Ecology 70: 298-315.

U.S. Congress, Office of Technology Assessment (OTA).' 1991. Biotechnology in a Global Economy. OTA-BA-494, U.S. Government Printing Office, Washington, D.C.

U.S. Environmental Protection Agency (EPA). 1984. Ground-Water Protection Strategy. U.S. Environmental Protection Agency Office of Ground-Water Protection, Washington, D.C.

United Nations Draft Convention on Biological Diversity. May 22, 1992. Reprinted in International Environmental Report (BNA) 15:11, at 372 (June 3, 1992).

Vandenbergh, M. P. 1986. "The Rutabega That Ate Pittsburgh: Federal Regulation of Free Release Biotechnology." Virginia Law Review 72:1529-1568.

Vito, C. C. 1993. "State Biotechnology Oversight: The Juncture of Technology, Law, and Public Policy." Maine Law Review 45:329-383.

Walterscheid, E. C. 1990. "The Need for a Uniform Government Patent Policy: The DOE Example." Harvard Journal of Law \& Technology 3:103-166.

Wisner, M. R. 1994. "Proposed Changes to the Laws Governing Ownership of Inventions Made with Federal Funding." Texas Intellectual Property Law Journal 2:193-198.

Zechendorf, B. 1994. "What the Public Thinks About Biotechnology." BioTechnology 12:870875. 


\section{Appendix A}

\section{Legal and Social Issues Protocol}




\section{Appendix A: Legal and Social Issues Protocol}

I. Introduction

to interviewers,

Did you receive the half page description we faxed on NABIR? (If not - describe NABIR)

The NABIR project is a potential program for Hanford to undertake doing research and development in bioremediation. This program involves technologies that are very early in the development phase so the opportunity for public involvement at such an early stage is unprecedented. One of the things we need to know is how you would like to be involved. We're sensitive to the time commitment you have made in the past and would like to know what the most beneficial way is to involve you.

\section{Comment on inclusion in loop}

We are interested in learning about how stakeholders view various bioremediation techniques. It is our belief that if we can accurately describe the issues and concerns to the technology developers that the resulting technologies will be both better designed and more deployable. We're going to talk about three types of organisms as well as microbially produced enzymes and we'll ask a set of questions for each group.

Before we begin with questions specific to the types of microorganisms, we're going to summarize our findings on stakeholders' views of bioremediation during the VOC-ARID ID and ask you to comment on your perception. In the VOC-ARID ID, there was a demonstration of bioremediation using native, naturally occurring microorganisms. Stakeholders raised four issues that they felt should be addressed in preparing for that demonstration.

1) Overall effectiveness of the technology: Having confidence in the monitoring system to know that the technology is working and, similarly, having the ability to detect a failure?

2) If a failure is detected, having the ability to manage the situation and measure and control the impact.

3) The effect on groundwater.

-- plugging of the aquifer from the growth of microorganisms.

4) Under what applications is the technology appropriate?

-- edge of plume, center of plume, small plume, low priority plume.

(co-contaminants)

Comment. Is this your perception of the general bioremediation issues? 
II. Native, naturally occurring. Let's begin with the simplest microorganisms, the enhancement of those that currently exist at Hanford.

1. What risks do you envision being associated with this type of microorganism? --the science itself, or the newness of the technique?

--that it operates subsurface, and therefore out of sight?

--the potential impact on the aquifer? biota? human health?

--the monitoring system functioning correctly?

How do you see these risks playing out as real problems? Which ones do you see as the greatest?

2. Under what conditions would you feel comfortable seeing these organisms tested? lab only? closed soil cells in the ground? normal, natural insitu conditions? other conditions of the test?

3. Under what conditions would you feel comfortable having these organisms deployed?

II. Microbially produced enzymes. We're going to move on to enzymes. These are additives such as nutrients, oxygen, and carbon sources that stimulate microorganisms.

4. What risks do you envision being associated with this addition of enzymes?

--the science itself, or the newness of the technique?

--that it operates subsurface, and therefore out of sight?

--the potential impact on the aquifer? biota? human health?

--the monitoring system functioning correctly?

How do you see these risks playing out as real problems? Which ones do you see as the greatest?

5. Under what conditions would you feel comfortable seeing these organisms tested? lab only? closed soil cells in the ground? normal, natural insitu conditions? other conditions of the test?

6. Under what conditions would you feel comfortable having enzymes deployed?

IV. Non-native naturally occurring. Now, we'll move on to organisms that are natural, but come from somewhere else. 
7. What risks do you envision being associated with this type of microorganism?

--the science itself, or the newness of the technique?

--that it operates subsurface, and therefore out of sight?

-the potential impact on the aquifer? biota? human health?

--the monitoring system functioning correctly?

How do you see these risks playing out as real problems? Which ones do you see as the greatest?

8. Under what conditions would you feel comfortable seeing these organisms tested? lab only? closed soil cells in the ground? normal, natural insitu conditions? other conditions of the test?

9. Under what conditions would you feel comfortable having these organisms deployed?

V. Genetically Engineered Microorganisms. Lastly, we're going to ask some questions about GEMs. These microorganisms are human designed to maximize the desirable attributes of microorganisms, such as eating more contaminants.

10. What risks do you envision being associated with this type of microorganism? --the science itself, or the newness of the technique?

--that it operates subsurface, and therefore out of sight?

--the potential impact on the aquifer? biota? human health?

--the monitoring system functioning correctly?

How do you see these risks playing out as real problems? Which ones do you see as the greatest?

11. Under what conditions would you feel comfortable seeing these organisms tested? lab only? closed soil cells in the ground? normal, natural insitu conditions? other conditions of the test?

V. Conclusion. Thinking about your answers to the questions above, we have two closing questions.

12. In what cases, if any, is intrinsic bioremediation an acceptable alternative to a more aggressive remediation strategy? 
13. Has your view of the level you'd like to keep involved on this project changed? What are your ideas on how stakeholders should be involved?

--newsletters

--new HAB subcommittee

--STGC subgroup

That's all the questions we have, do you have any for us? 
Appendix B

Issues - Design of VOC-Arid ID 


\begin{tabular}{|c|c|c|c|c|c|}
\hline \multicolumn{6}{|c|}{ IN-SITU HIOREMLIIIATION } \\
\hline & $\begin{array}{l}\text { FOCUS GROUB } \\
\text { DATA REQUIREMLNTS }\end{array}$ & & $\begin{array}{l}\text { WORKSHOP } \\
\text { COMMENTS }\end{array}$ & $\begin{array}{l}\text { TLST PLAN ELEMENTS TO } \\
\text { ADIDESS DATA } \\
\text { REQUIREMEN'S }\end{array}$ & $\begin{array}{l}\text { DEMONSTRATION } \\
\text { RESULTS }\end{array}$ \\
\hline 1. & $\begin{array}{l}\text { Define how the aquifer } \\
\text { charucteristics will be measured } \\
\text { prior to flie use of the feclinoliogy. } \\
\text { Charucteristics inusi include } \\
\text { chensicul, rudiulogital. } \\
\text { geoteclunical, and water quality } \\
\text { parumelers. }\end{array}$ & & 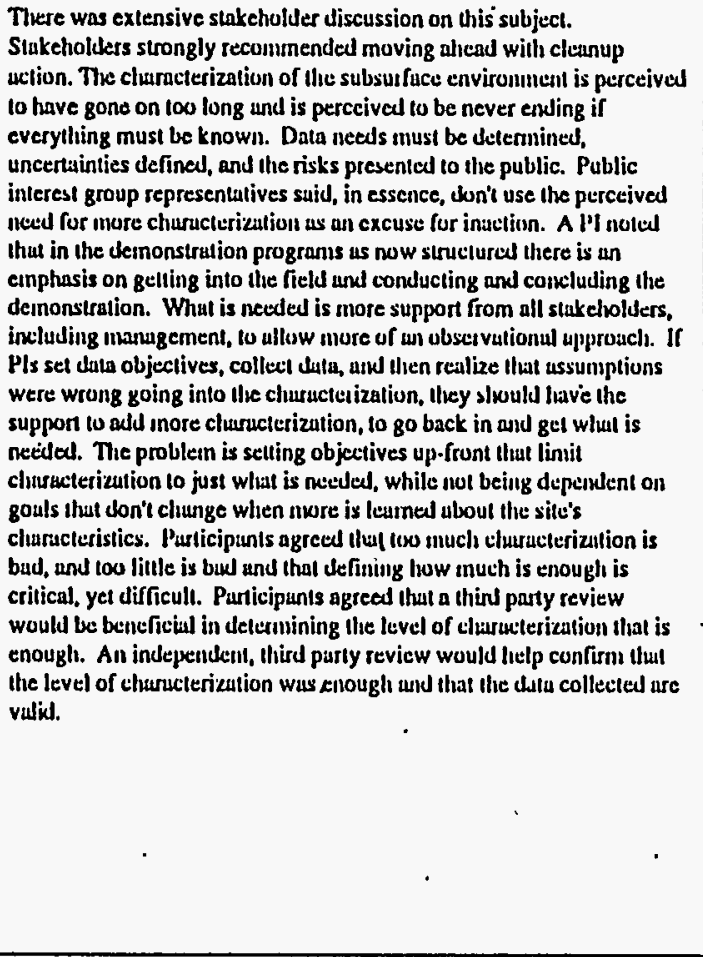 & 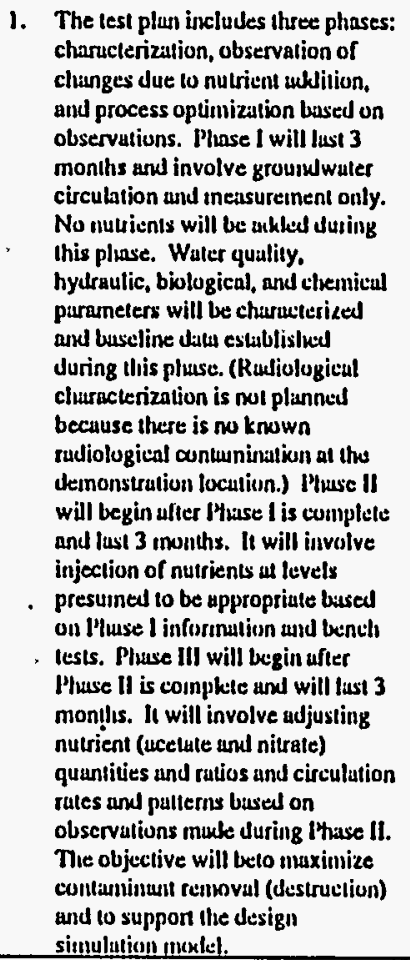 & $\cdot$ \\
\hline
\end{tabular}




\begin{tabular}{|c|c|c|c|c|}
\hline & 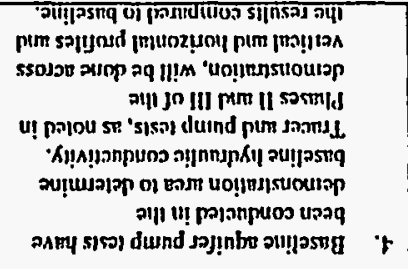 & 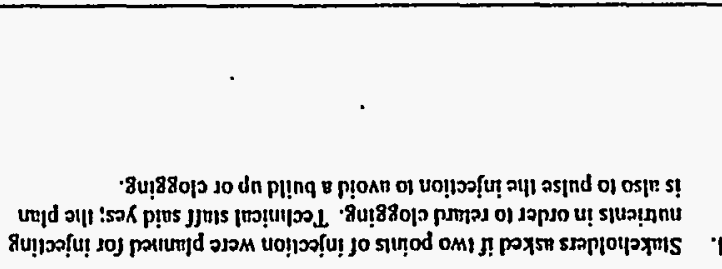 & $r$ & 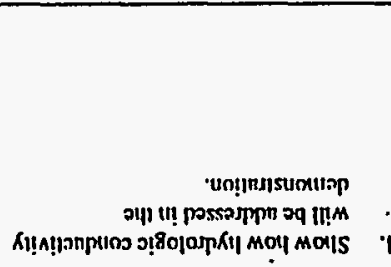 \\
\hline & 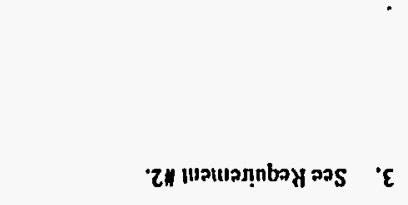 & 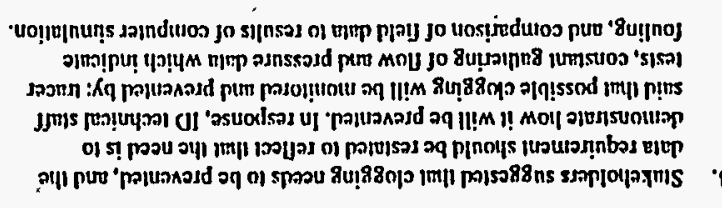 & $\cdot \mathbf{\varepsilon}$ & 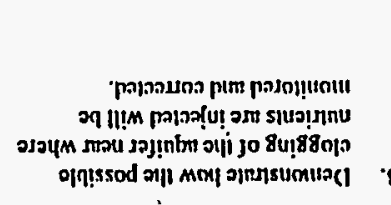 \\
\hline . & 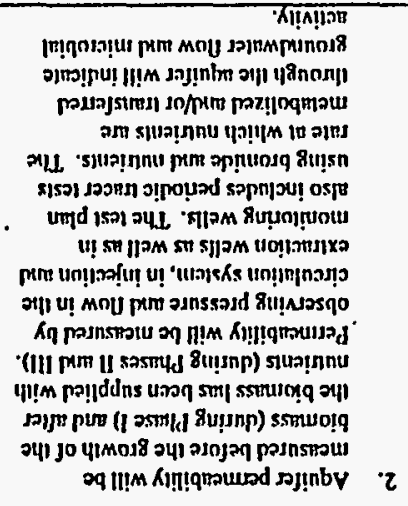 & 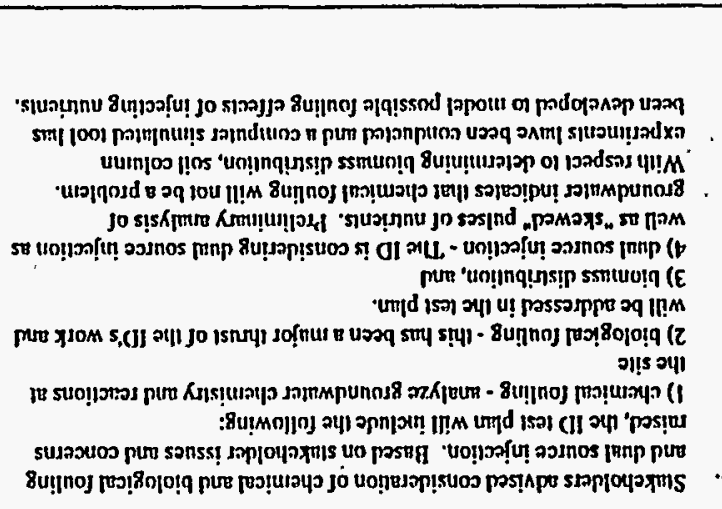 & $\tau$ & 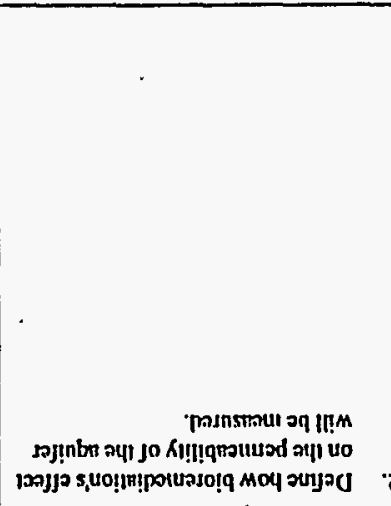 \\
\hline $\begin{array}{c}\text { S.l.Insay } \\
\text { No1.I.YY.ISNotvat }\end{array}$ & 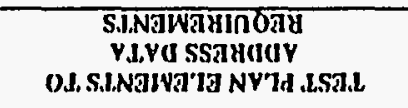 & $\begin{array}{l}\text { S.JNawWOS } \\
\text { JOHSYHOM }\end{array}$ & & 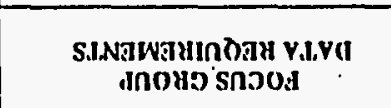 \\
\hline
\end{tabular}




\begin{tabular}{|c|c|c|c|c|c|}
\hline \multicolumn{6}{|c|}{ IN-SITU BIOREMEDIATION } \\
\hline & $\begin{array}{l}\text { FOCUS GROUP } \\
\text { DATA REQUIHLMLNTS }\end{array}$ & & $\begin{array}{l}\text { WORKSHOP } \\
\text { COMMEN'S }\end{array}$ & $\begin{array}{c}\text { TEST PLAN EI.EMENTS TO } \\
\text { ADDRESS DATA } \\
\text { REQUIREALNTS } \\
\end{array}$ & $\begin{array}{l}\text { DEMONSTRATION } \\
\text { RESUI.TS }\end{array}$ \\
\hline & 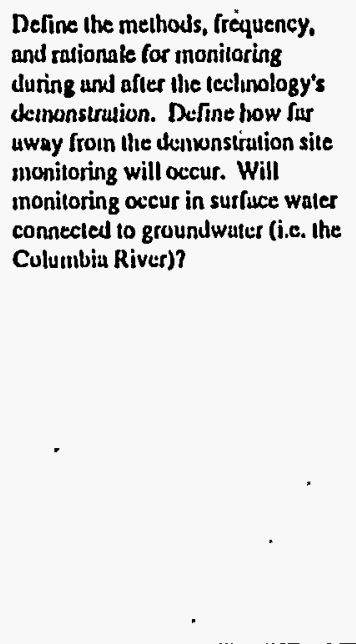 & & 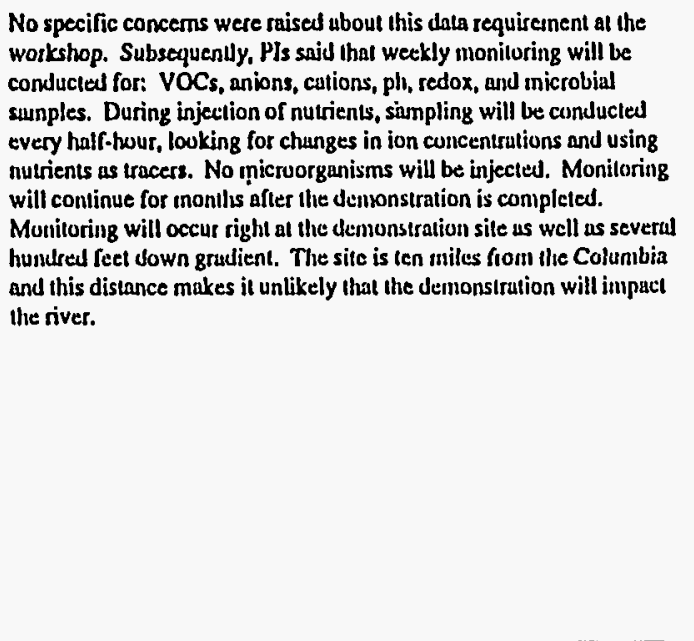 & 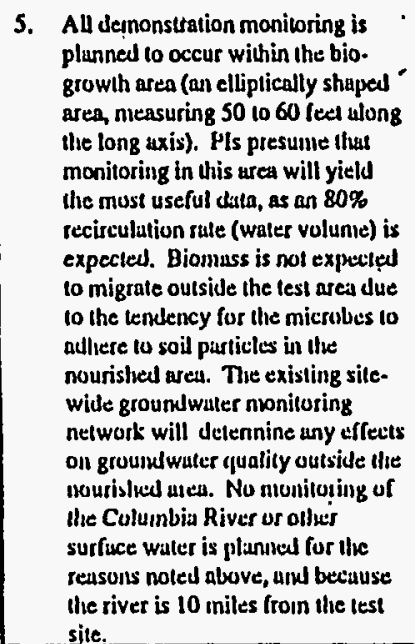 & \\
\hline
\end{tabular}




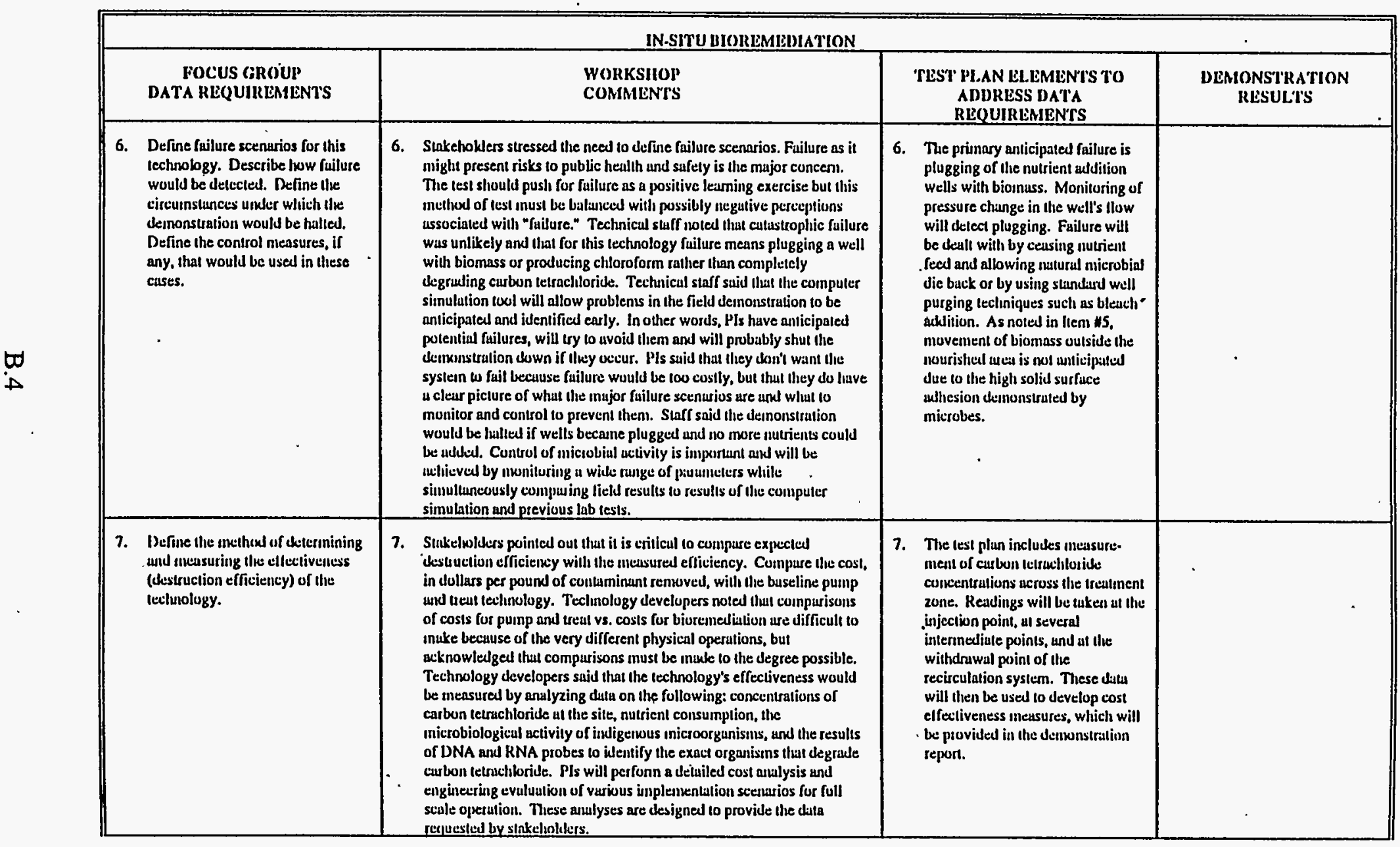




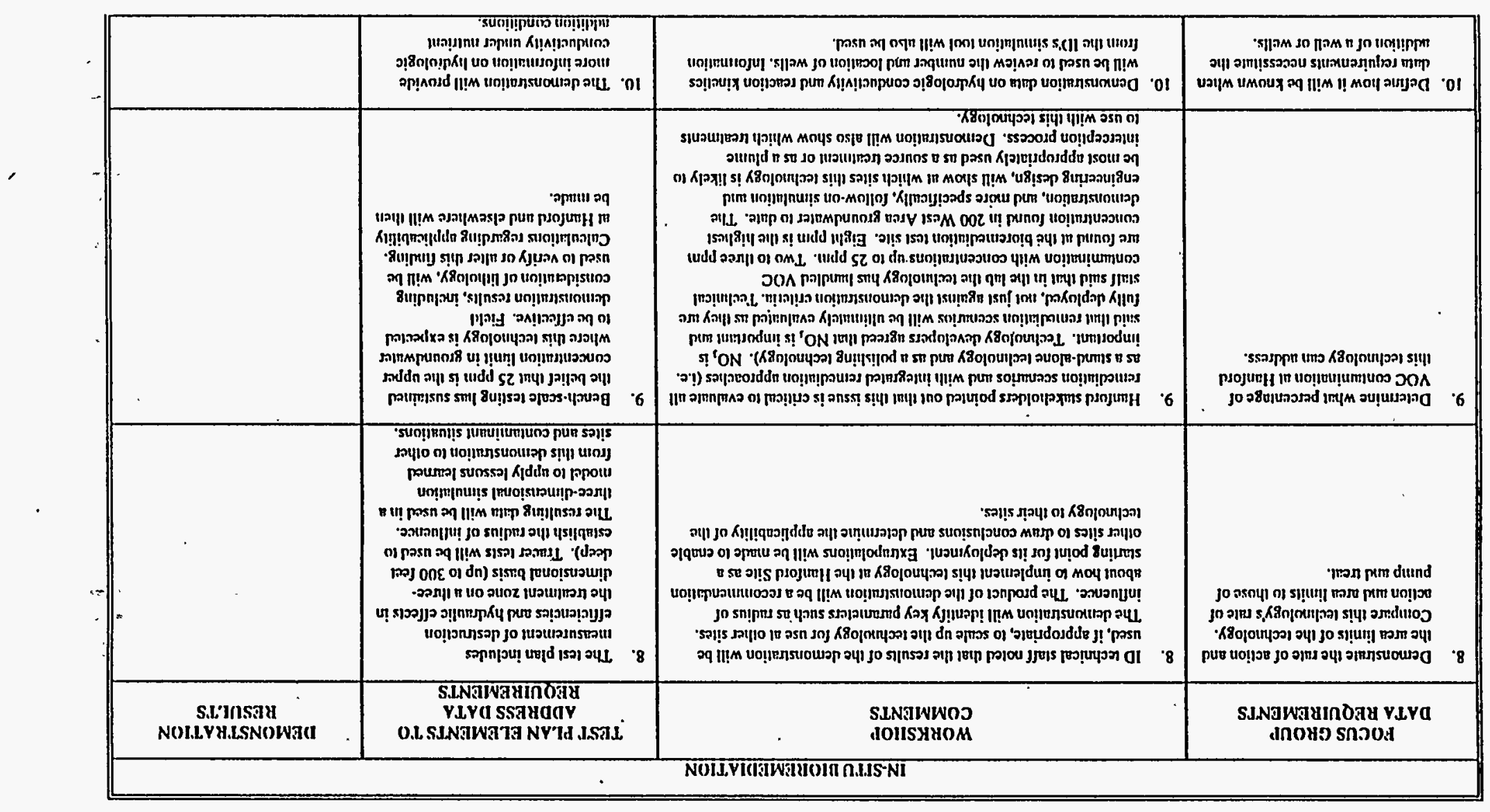




\begin{tabular}{|c|c|c|c|c|}
\hline \multicolumn{5}{|c|}{ IN-SITU DIORIEMBDIATION } \\
\hline & $\begin{array}{c}\text { POCUS GROUP } \\
\text { DATA RLQUIREMIENTS }\end{array}$ & $\begin{array}{l}\text { WORKSIIOP } \\
\text { COMMENTS }\end{array}$ & $\begin{array}{c}\text { TEST PI.AN ELLMENTS'TO } \\
\text { ADIORLSS IIATA } \\
\text { REQUIREMENTS } \\
\end{array}$ & $\begin{array}{l}\text { DEMONSTKATION } \\
\text { RESULTS }\end{array}$ \\
\hline & $\begin{array}{l}\text { Define how the deinonsuation will } \\
\text { detennine if the lechnology would } \\
\text { be effective in working from the } \\
\text { outside of a contaninunt plume } \\
\text { toward the sourte. Conversely, } \\
\text { define if the tectinology would be } \\
\text { effective at contuminant source } \\
\text { reduction or eliminution. }\end{array}$ & $\begin{array}{l}\text { 11. Performance data from the dentonstration will indicate under which } \\
\text { conditions the technulogy is best used as a source trealinent and under } \\
\text { which conditions it is best used as an interception treattuent. Computur } \\
\text { simulutions will be used to evaluate alternative approaches to full scule } \\
\text { implementation based on results from the fietd demonstration that } \\
\text { helped to calibrate the simulation tool. }\end{array}$ & $\begin{array}{l}\text { 11. The effectiveness of this } \\
\text { lechnology for different } \\
\text { applicutions will be evalualed using } \\
\text { the design model after the } \\
\text { deinonstration hus be conducted. }\end{array}$ & $\because$ \\
\hline 12. & 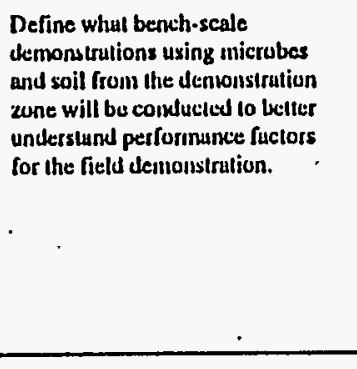 & 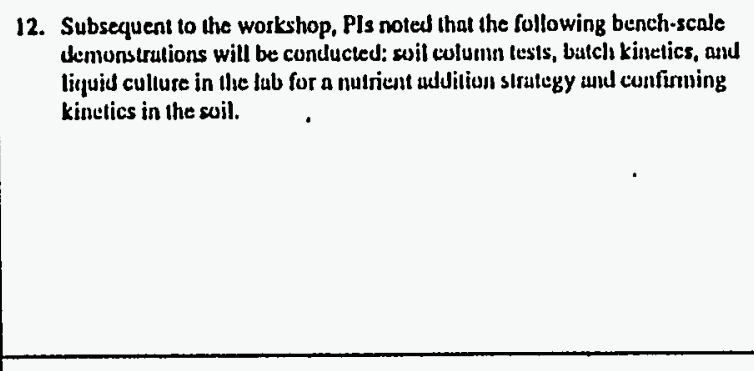 & 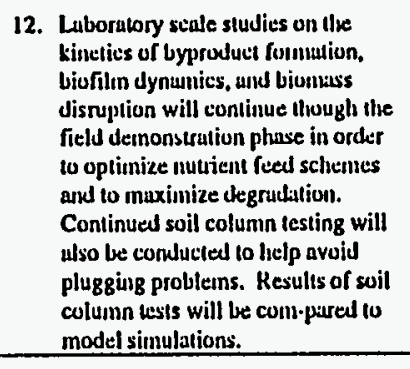 & \\
\hline 13. & 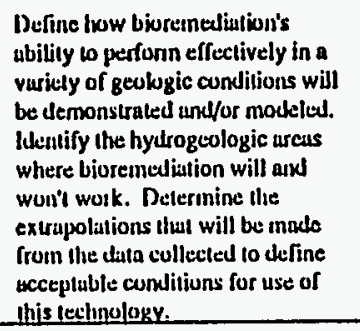 & 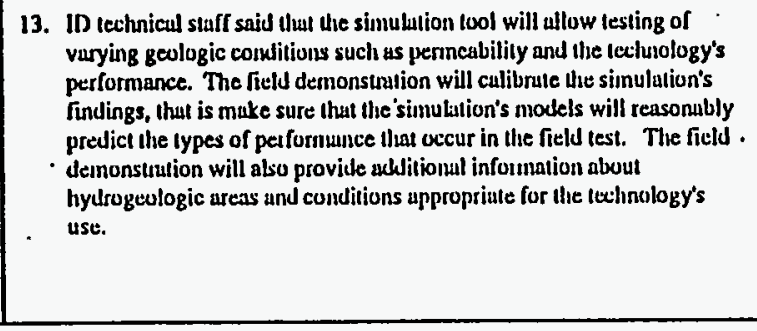 & 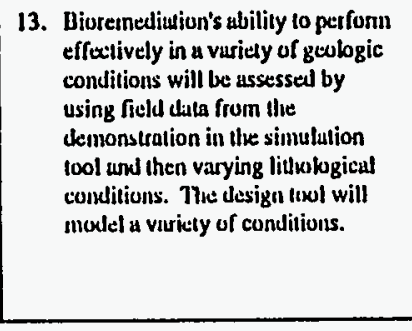 & \\
\hline
\end{tabular}




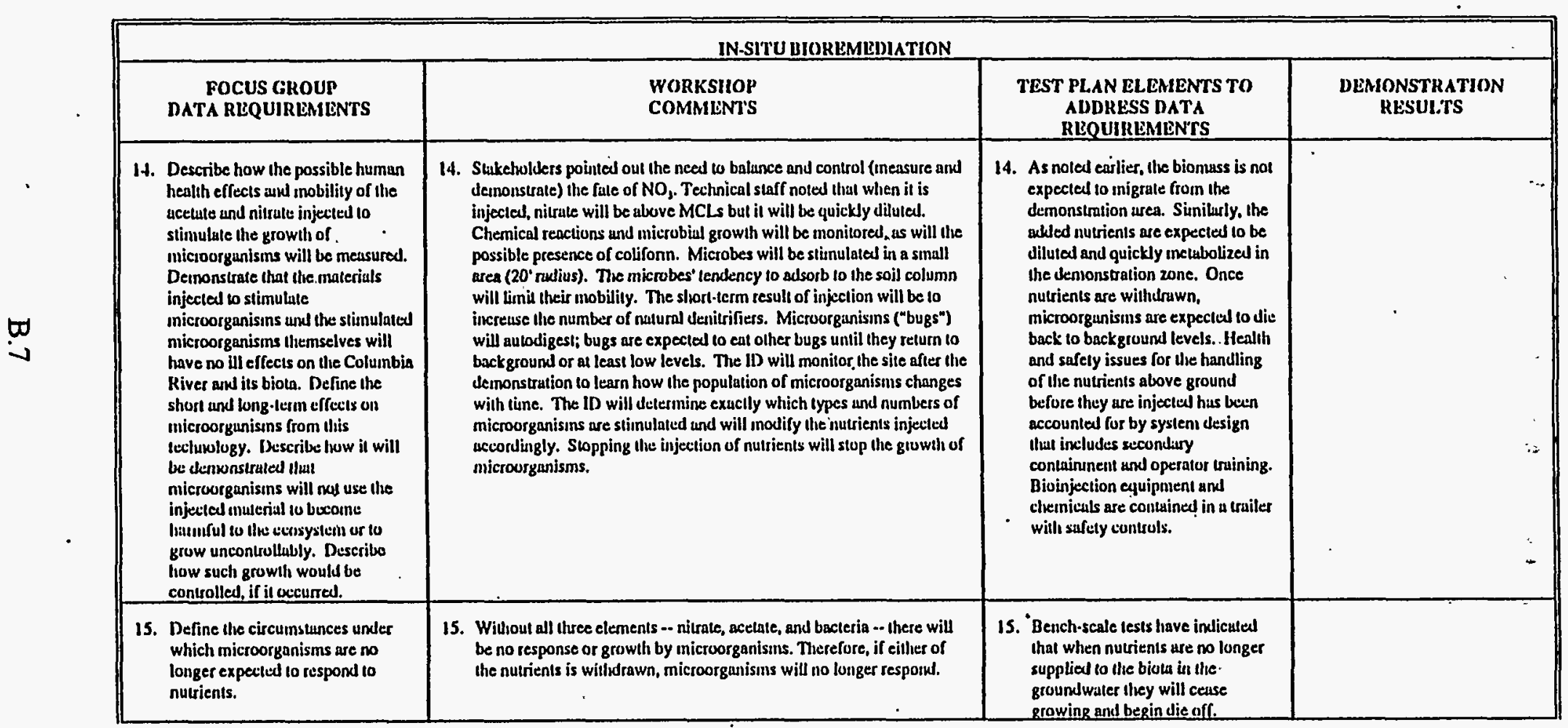




\begin{tabular}{|c|c|c|c|c|}
\hline \multicolumn{5}{|c|}{ IN-STIUUHIOREMLIIATION } \\
\hline & $\begin{array}{c}\text { FOCUS GROUP } \\
\text { DATA REQUIREMENTS }\end{array}$ & $\begin{array}{l}\text { WORKSIIOP } \\
\text { COMMENTS }\end{array}$ & $\begin{array}{c}\text { TEST PLAN DIEMENTS TO } \\
\text { ADIDEESS DATA } \\
\text { REQUIREMENTS } \\
\end{array}$ & $\begin{array}{l}\text { DEMONSTRATION } \\
\text { IESUI.'TS }\end{array}$ \\
\hline 16. & $\begin{array}{l}\text { Demonsitule and measure the } \\
\text { effects of the technology on co. } \\
\text { contuminunts. }\end{array}$ & 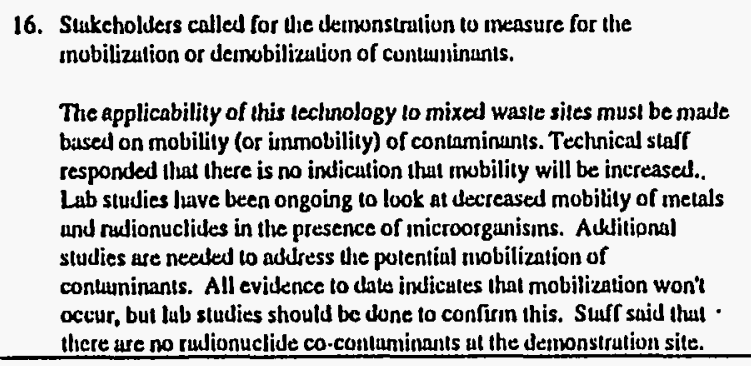 & 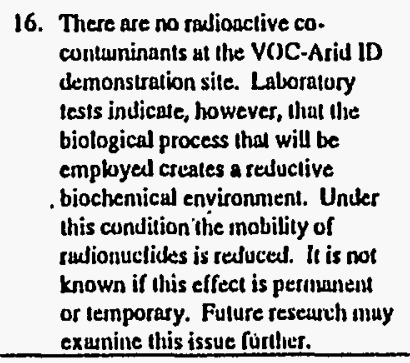 & \\
\hline 17. & 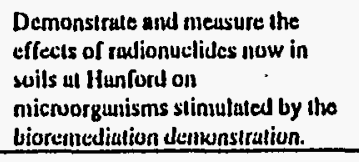 & 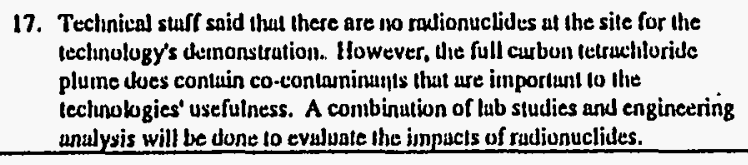 & $\begin{array}{l}\text { 17. As discussed earlier, the test plan } \\
\text { tues not incilude achlocssing this } \\
\text { issue in the voC-Arid it). }\end{array}$ & \\
\hline 18. & $\begin{array}{l}\text { Define the costs of bioremediation } \\
\text { in light of the possible continued } \\
\text { use of pump and treut technology } \\
\text { to bring contuminated } \\
\text { givundwater to the surface. } \\
\text { Detine cuses in which it might be } \\
\text { clieuper to undertiale remediation } \\
\text { above ground. }\end{array}$ & 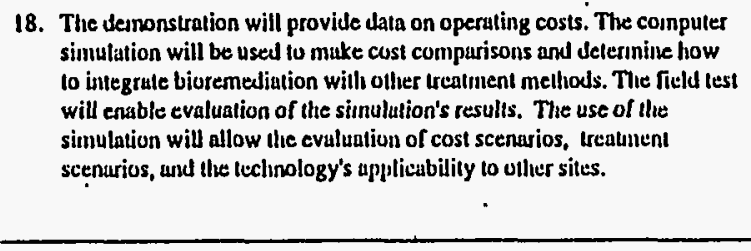 & 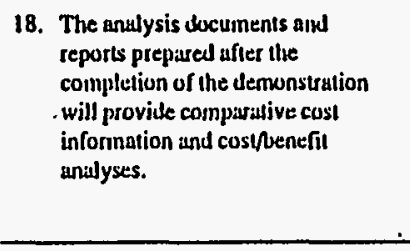 & . \\
\hline 19. & $\begin{array}{l}\text { Show how the denonstrution has } \\
\text { taken into actount iisurunce } \\
\text { requirements. }\end{array}$ & $\begin{array}{l}\text { 19. The demnonstration has not had to take insurance requirennents into } \\
\text { account becuuse of DOE indernsification. Al this time the } \\
\text { demonswation is not acquiring duta on, insurante sequisetnents. }\end{array}$ & 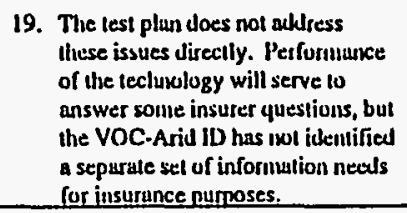 & \\
\hline
\end{tabular}




\begin{tabular}{|c|c|c|c|c|}
\hline \multicolumn{5}{|c|}{ IN.SITU DIOREMEDIATION } \\
\hline & $\begin{array}{c}\text { FOCUS GROUP } \\
\text { DATA KEQUIREMENTS }\end{array}$ & $\begin{array}{l}\text { WORKSIIOP } \\
\text { COMMENIS }\end{array}$ & $\begin{array}{c}\text { TEST PI.AN EL.LMENTSS TO } \\
\text { ADURESS DATA } \\
\text { REQUUREMENTS } \\
\end{array}$ & $\begin{array}{l}\text { DEMONSTRATION } \\
\text { MESUIIS }\end{array}$ \\
\hline & $\begin{array}{l}\text { Identify regulatory constraints on } \\
\text { ithe demonstration of in-situ } \\
\text { biureinaliation, for exumple the } \\
\text { injection of material into } \\
\text { gruundwater. }\end{array}$ & $\begin{array}{l}\text { 20. Technical seaff said that the ID is al this time workjog through } \\
\text { constraints and requirements willt regulators. The purge water } \\
\text { exernption clause buill into NEPA planting alluws for extraction and } \\
\text { reinjuction. }\end{array}$ & 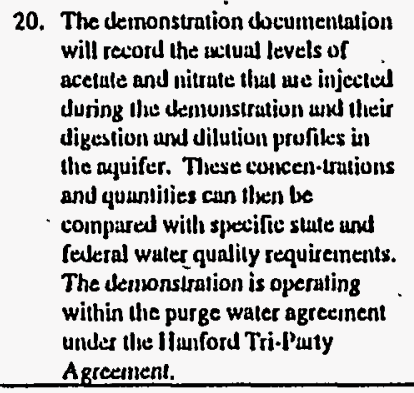 & \\
\hline & 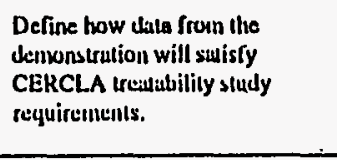 & $\begin{array}{l}\text { 21. Integrated lest plans for the dennonstrution will be modeled after } \\
\text { CERCLA treatability studics und will be at least as compreliensive, if } \\
\text { not trore so. }\end{array}$ & 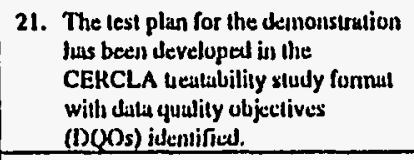 & \\
\hline 22. & $\begin{array}{l}\text { Define how bioremedijution's } \\
\text { ability to ineci regututory } \\
\text { milestones will be theusured. }\end{array}$ & 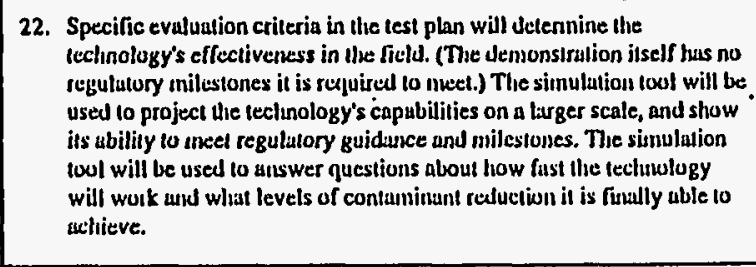 & 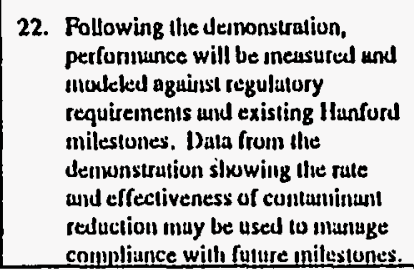 & \\
\hline
\end{tabular}




\begin{tabular}{|c|c|c|c|}
\hline \multicolumn{4}{|c|}{ IN-SITU BIOREMLDIATION } \\
\hline $\begin{array}{c}\text { FOCUS GROUP } \\
\text { DATA REQUIREMENTS }\end{array}$ & $\begin{array}{l}\text { WORKSHOP } \\
\text { COMMEN'TS }\end{array}$ & $\begin{array}{c}\text { TEST PLAN ELEMENTS TO } \\
\text { ADDRESS DATA } \\
\text { REQUIREMENTS } \\
\end{array}$ & $\begin{array}{l}\text { DEEMONSTRATION } \\
\text { RESULTSS }\end{array}$ \\
\hline $\begin{array}{l}\text { 23. Deline which independent pary, if } \\
\text { any, will review the results of the } \\
\text { demonstraion. }\end{array}$ & 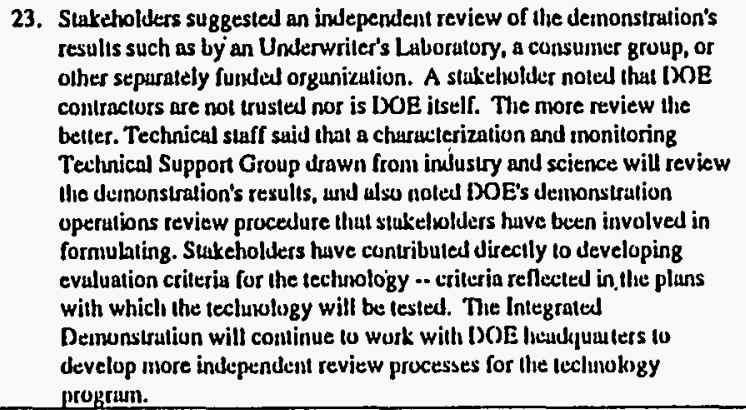 & 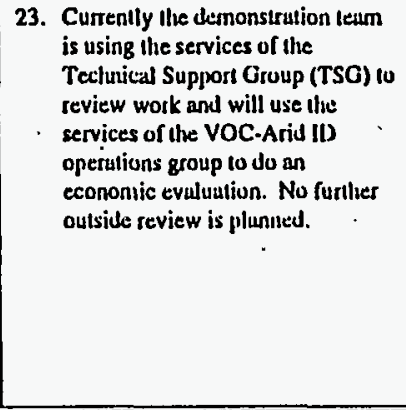 & . \\
\hline
\end{tabular}


Appendix C

Compilation of Hanford Stakeholders Issues 


\section{Appendix C: Compilation of Hanford Stakeholders Issues}

\begin{tabular}{|c|c|}
\hline $\begin{array}{l}\text { FOCUS GROUP } \\
\text { DATAREQULREMENTS }\end{array}$ & 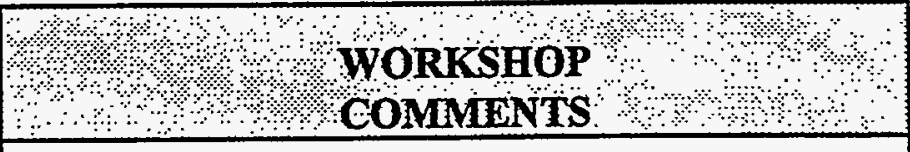 \\
\hline $\begin{array}{l}\text { 1. Define how the aquifer } \\
\text { characteristics will be measured } \\
\text { prior to the use of the technology. } \\
\text { Characteristics must include. } \\
\text { chemical, radiological, } \\
\text { geotechnical, and water quality } \\
\text { parameters. }\end{array}$ & $\begin{array}{l}\text { 1. There was extensive stakeholder discussion on } \\
\text { this subject. Stakeholders strongly } \\
\text { recommended moving ahead with cleanup } \\
\text { action. The characterization of the subsurface } \\
\text { environment is perceived to have gone on too } \\
\text { long and is perceived to be never ending if } \\
\text { everything must be known. Data needs must } \\
\text { be determined, uncertainties defined, and the } \\
\text { risks presented to the public. Public interest } \\
\text { group representatives said, in essence, don't } \\
\text { use the perceived need for more } \\
\text { characterization as.an excuse for inaction. A } \\
\text { PI noted that in the demonstration programs as } \\
\text { now structured there is an emphasis on getting } \\
\text { into the field and conducting and concluding } \\
\text { the demonstration. What is needed is more } \\
\text { support from all stakeholders, including } \\
\text { management, to allow more of an } \\
\text { observational approach. If PIs set data } \\
\text { objectives, collect data, and then realize that } \\
\text { assumptions were wrong going into the } \\
\text { characterization, they should have the support } \\
\text { to add more characterization, to go back in } \\
\text { and get what is needed. The problem is setting } \\
\text { objectives up-front that limit characterization } \\
\text { to just what is needed, while not being } \\
\text { dependent on goals that don't change when } \\
\text { more is learned about the site's characteristics. } \\
\text { Participants agreed that too much } \\
\text { characterization is bad, and too little is bad and } \\
\text { that defining how much is enough is critical, } \\
\text { yet difficult. Participants agreed that a third } \\
\text { party review would be beneficial in } \\
\text { determining the level of characterization that is } \\
\text { enough. An independent, third party review } \\
\text { would help confirm that the level of } \\
\text { characterization was enough and that the data } \\
\text { collected are valid. }\end{array}$ \\
\hline
\end{tabular}

C. 1 


\section{Appendix C: Compilation of Hanford Stakeholders Issues}

\begin{tabular}{|c|c|}
\hline $\begin{array}{l}\text { FOCUS GROUP } \\
\text { DATAREOUREMENTS }\end{array}$ & $\begin{array}{l}\text { - WORKSHOP } \\
\text { COMMENTS }\end{array}$ \\
\hline $\begin{array}{l}\text { 1. Define how the aquifer } \\
\text { characteristics will be measured } \\
\text { prior to the use of the technology. } \\
\text { Characteristics must include. } \\
\text { chemical, radiological, } \\
\text { geotechnical, and water quality } \\
\text { parameters. }\end{array}$ & $\begin{array}{l}\text { 1. There was extensive stakeholder discussion on } \\
\text { this subject. Stakeholders strongly } \\
\text { recommended moving ahead with cleanup } \\
\text { action. The characterization of the subsurface } \\
\text { environment is perceived to have gone on too } \\
\text { long and is perceived to be never ending if } \\
\text { everything must be known. Data needs must } \\
\text { be determined, uncertainties defined, and the } \\
\text { risks presented to the public. Public interest } \\
\text { group representatives said, in essence, don't } \\
\text { use the perceived need for more } \\
\text { characterization as an excuse for inaction. A } \\
\text { PI noted that in the demonstration programs as } \\
\text { now structured there is an emphasis on getting } \\
\text { into the field and conducting and concluding } \\
\text { the demonstration. What is needed is more } \\
\text { support from all stakeholders, including } \\
\text { management, to allow more of an } \\
\text { observational approach. If PIs set data } \\
\text { objectives, collect data, and then realize that } \\
\text { assumptions were wrong going into the } \\
\text { characterization, they should have the support } \\
\text { to add more characterization, to go back in } \\
\text { and get what is needed. The problem is setting } \\
\text { objectives up-front that limit characterization } \\
\text { to just what is needed, while not being } \\
\text { dependent on goals that don't change when } \\
\text { more is learned about the site's characteristics. } \\
\text { Participants agreed that too much } \\
\text { characterization is bad, and too little is bad and } \\
\text { that defining how much is enough is critical, } \\
\text { yet difficult. Participants agreed that a third } \\
\text { party review would be beneficial in } \\
\text { determining the level of characterization that is } \\
\text { enough. An independent, third party review } \\
\text { would help confirm that the level of } \\
\text { characterization was enough and that the data } \\
\text { collected are valid. }\end{array}$ \\
\hline
\end{tabular}

C.1 


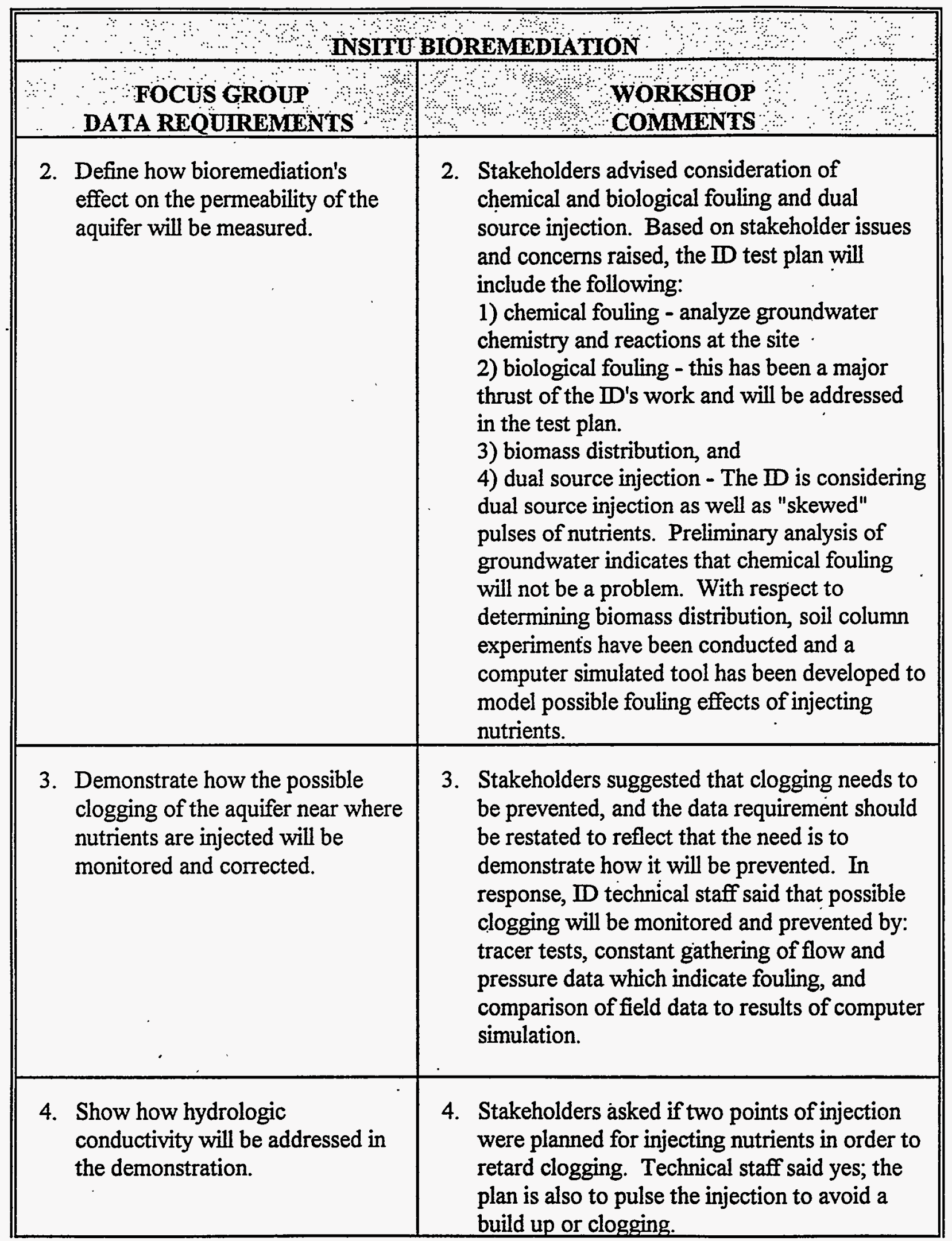

C. 2 


\begin{tabular}{|c|c|}
\hline $\begin{array}{l}\text { FOCUS GROUP } \\
\text { DATA REQUIREMENTS }\end{array}$ & क WORKSHOP \\
\hline $\begin{array}{l}\text { Define the methods, frequency, } \\
\text { and rationale for monitoring } \\
\text { during and after the technology's } \\
\text { demonstration. Define how far } \\
\text { away from the demonstration site } \\
\text { monitoring will occur. Will } \\
\text { monitoring occur in surface water } \\
\text { connected to groundwater (i.e. } \\
\text { the Columbia River)? }\end{array}$ & $\begin{array}{l}\text { 5. No specific concerns were raised about this } \\
\text { data requirement at the workshop. } \\
\text { Subsequently, PIs said that weekly monitoring } \\
\text { will be conducted for: VOCs, anions, cations, } \\
\text { ph, redox, and microbial samples. During } \\
\text { injection of nutrients, sampling will be } \\
\text { conducted every half-hour, looking for } \\
\text { changes in ion concentrations and using } \\
\text { nutrients as tracers. No microorganisms will } \\
\text {,be injected. Monitoring will continue for } \\
\text { months after the demonstration is completed. } \\
\text { Monitoring will occur right at the } \\
\text { demonstration site as well as several hundred } \\
\text { feet down gradient. The site is ten miles from } \\
\text { the Columbia and this distance makes it } \\
\text { unlikely that the demonstration will impact the } \\
\text { river. }\end{array}$ \\
\hline
\end{tabular}




\begin{tabular}{|c|c|}
\hline \multicolumn{2}{|c|}{ aNSITUEIOREMEDIATION } \\
\hline $\begin{array}{l}\text { FOCUS GROUP } \\
\text { DATA REOULREMENTS }\end{array}$ & 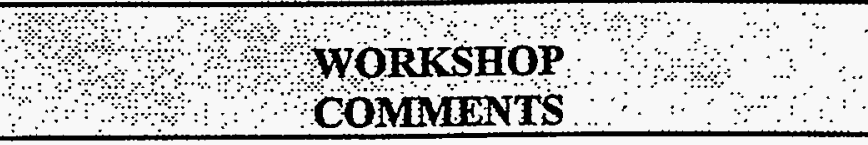 \\
\hline $\begin{array}{l}\text { 6. Define failure scenarios for this } \\
\text { technology. Describe how failure } \\
\text { would be detected. Define the } \\
\text { circumstances under which the } \\
\text { demonstration would be halted. } \\
\text { Define the control measures, if } \\
\text { any, that would be used in these } \\
\text { cases. }\end{array}$ & $\begin{array}{l}\text { 6. Stakeholders stressed the need to define failure } \\
\text { scenarios. Failure as it might present risks to } \\
\text { public health and safety is the major concern. } \\
\text { The test should push for failure as a positive } \\
\text { learning exercise but this method of test must } \\
\text { be balanced with possibly negative perceptions } \\
\text { associated with "failure." Technical staff noted } \\
\text { that catastrophic failure was unlikely and that } \\
\text { for this technology failure means plugging a } \\
\text { well with biomass or producing chloroform } \\
\text { rather than completely degrading carbon } \\
\text { tetrachloride. Technical staff said that the } \\
\text { computer simulation tool will allow problems } \\
\text { in the field demonstration to be anticipated and } \\
\text { identified early. In other words, PIs have } \\
\text { anticipated potential failures, will try to avoid } \\
\text { them and will probably shut the demonstration } \\
\text { down if they occur. PIs said that they don't } \\
\text { want the system to fail because failure would } \\
\text { be too costly, but that they do have a clear } \\
\text { picture of what the major failure scenarios are } \\
\text { and what to monitor and control to prevent } \\
\text { them. Staff said the demonstration would be } \\
\text { halted if wells became plugged and no more } \\
\text { nutrients could be added. Control of microbial } \\
\text { activity is important and will be achieved by } \\
\text { monitoring a wide range of parameters while } \\
\text { simultaneously comparing field results to } \\
\text { results of the computer simulation and } \\
\text { previous lab tests. }\end{array}$ \\
\hline
\end{tabular}

C. 4 


\begin{tabular}{|c|c|}
\hline $\begin{array}{l}\text { FOCUS GROUP } \\
\text { DATA REQUIREMENTS }\end{array}$ & $\begin{array}{l}\text { WORKSHOP } \\
\text { COMMENTS }\end{array}$ \\
\hline $\begin{array}{l}\text { 7. Define the method of determining } \\
\text { and measuring the effectiveness } \\
\text { (destruction efficiency) of the } \\
\text { technology. }\end{array}$ & $\begin{array}{l}\text { 7. Stakeholders pointed out that it is critical to } \\
\text { compare expected destruction efficiency with } \\
\text { the measured efficiency. Compare the cost, in } \\
\text { dollars per pound of contaminant removed, } \\
\text { with the baseline pump and treat technology. } \\
\text { Technology developers noted that } \\
\text { comparisons of costs for pump. and treat vs. } \\
\text { costs for bioremediation are difficult to make } \\
\text { because of the very different physical } \\
\text { operations, but acknowledged that } \\
\text { comparisons must be made to the degree } \\
\text { possible. Technology developers said that the } \\
\text { technology's effectiveness would be measured } \\
\text { by analyzing data on the following: } \\
\text { concentrations of carbon tetrachloride at the } \\
\text { site, nutrient consumption, the microbiological } \\
\text { activity of indigenous microorganisms, and the } \\
\text { results of DNA and RNA probes to identify } \\
\text { the exact organisms that degrade carbon } \\
\text { tetrachloride. PIs will perform a detailed cost } \\
\text { analysis and engineering evaluation of various } \\
\text { implementation scenarios for full scale } \\
\text { operation. These analyses are designed to } \\
\text { provide the data requested by stakeholders. }\end{array}$ \\
\hline $\begin{array}{l}\text { 8. Demonstrate the rate of action } \\
\text { and the area limits of the } \\
\text { technology. Compare this } \\
\text { technology's rate of action and } \\
\text { area limits to those of pump and } \\
\text { treat. }\end{array}$ & $\begin{array}{l}\text { 8. I technical staff noted that the results of the } \\
\text { demonstration will be used, if appropriate, to } \\
\text { scale up the technology for use at other sites. } \\
\text { The demonstration will identify key parameters } \\
\text { such as radius of influence. The product of the } \\
\text { demonstration will be a recommendation about } \\
\text { how to implement this technology at the } \\
\text { Hanford Site as a starting point for its } \\
\text { deployment. Extrapolations will be made to } \\
\text { enable other sites to draw conclusions and } \\
\text { determine the applicability of the technology to } \\
\text { their sites. }\end{array}$ \\
\hline
\end{tabular}




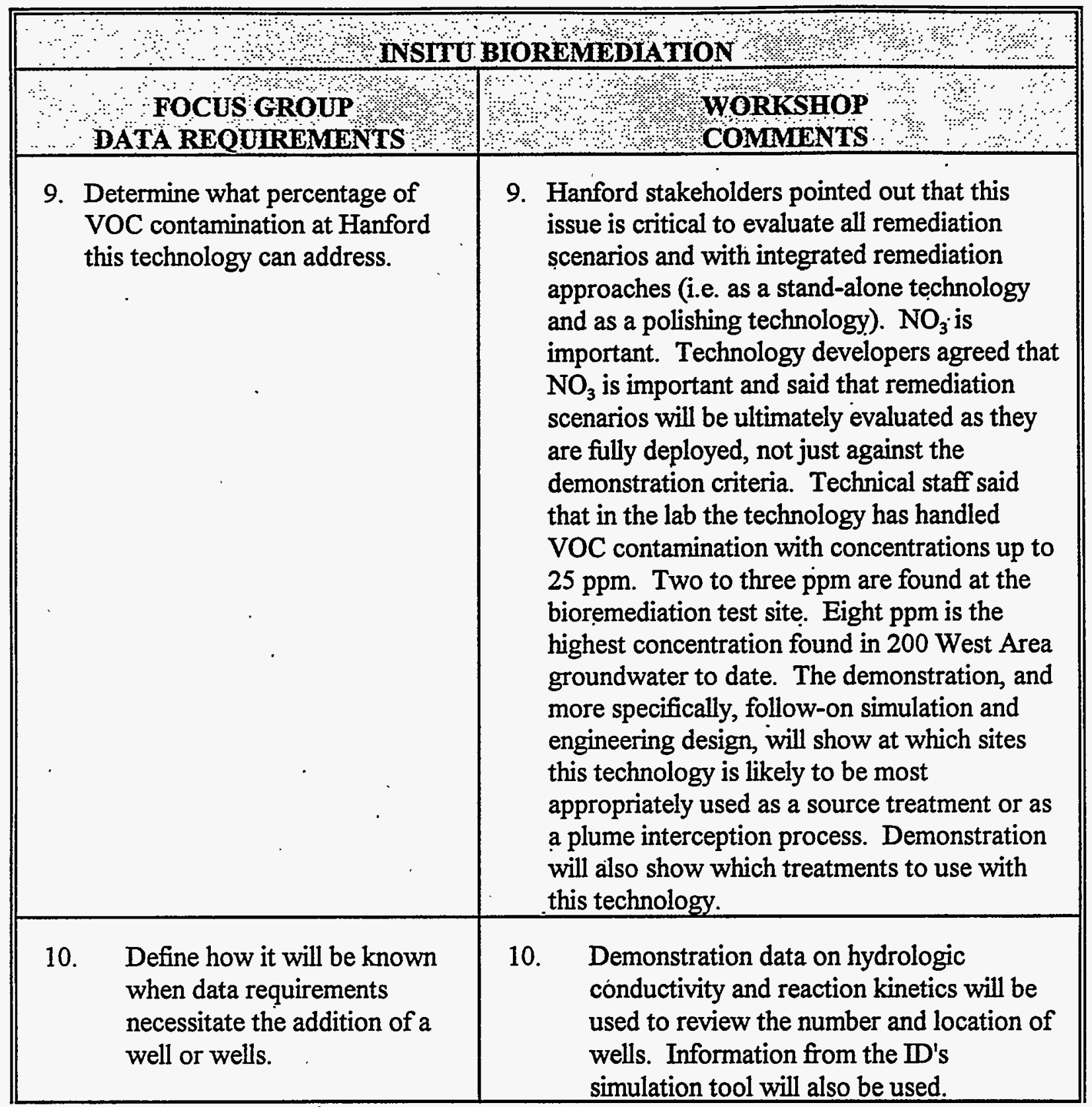




\begin{tabular}{|c|c|c|c|}
\hline \multicolumn{2}{|c|}{$\begin{array}{r}\text { FOCUS GROUP } \\
\text { DATA REQUTREMENTS }\end{array}$} & \multicolumn{2}{|c|}{ 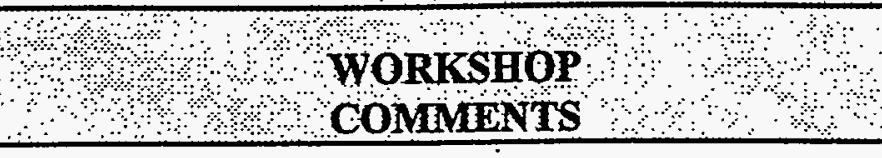 } \\
\hline 11. & $\begin{array}{l}\text { Define how the demonstration } \\
\text { will determine if the } \\
\text { technology would be effective } \\
\text { in working from the outside of } \\
\text { a contaminant plume toward } \\
\text { the source. Conversely, } \\
\text { define if the technology would } \\
\text { be effective at contaminant } \\
\text { source reduction or } \\
\text { elimination. }\end{array}$ & 11. & $\begin{array}{l}\text { Performance data from the demonstration } \\
\text { will indicate under which conditions the } \\
\text { technology is best used as a source } \\
\text { treatment and under which conditions it is } \\
\text { best used as an interception treatment. } \\
\text { Computer simulations will be used to } \\
\text { evaluate alternative approaches to full scale } \\
\text { implementation based on results from the } \\
\text { field demonstration that helped to calibrate } \\
\text { the simulation tool. }\end{array}$ \\
\hline 12. & $\begin{array}{l}\text { Define what bench scale } \\
\text { demonstrations using } \\
\text { microbes and soil from the } \\
\text { demonstration zone will be } \\
\text { conducted to better } \\
\text { understand performance } \\
\text { factors for the field } \\
\text { demonstration. }\end{array}$ & 12. & $\begin{array}{l}\text { Subsequent to the workshop, technical PIs } \\
\text { noted that the following bench scale } \\
\text { demonstrations will be conducted: soil } \\
\text { column tests, batch kinetics, and liquid } \\
\text { culture in the lab for a nutrient addition } \\
\text { strategy and confirming kinetics in the soil. }\end{array}$ \\
\hline 13. & $\begin{array}{l}\text { Define how bioremediation's } \\
\text { ability to perform effectively } \\
\text { in a variety of geologic } \\
\text { conditions will be } \\
\text { demonstrated and/or modeled. } \\
\text { Identify the hydrogeologic } \\
\text { areas where bioremediation } \\
\text { will and won't work. } \\
\text { Determine the extrapolations } \\
\text { that will be made from the } \\
\text { data collected to define } \\
\text { acceptable conditions for use } \\
\text { of this technology. }\end{array}$ & & $\begin{array}{l}\text { D technical staff said that the simulation } \\
\text { tool will allow testing of varying geologic } \\
\text { conditions such as permeability and the } \\
\text { technology's performance. The field } \\
\text { demonstration will calibrate the } \\
\text { simulation's findings, that is make sure that } \\
\text { the simulation's models will reasonably } \\
\text { predict the types of performance that occur } \\
\text { in the field test. The field demonstration } \\
\text { will also provide additional information } \\
\text { about hydrogeologic areas and conditions } \\
\text { appropriate for the technology's use. }\end{array}$ \\
\hline
\end{tabular}




\begin{tabular}{|c|c|c|c|}
\hline & $\begin{array}{l}\text { FOCUS GROUP } \\
\text { ATA REQUIREMENTS }\end{array}$ & & $\begin{array}{l}\text { WORKSHOP } \\
\text { COMMENTS }\end{array}$ \\
\hline 14. & $\begin{array}{l}\text { Describe how the possible } \\
\text { human health effects and } \\
\text { mobility of the acetate and } \\
\text { nitrate injected to stimulate } \\
\text { the growth of microorganisms } \\
\text { will be measured. } \\
\text { Demonstrate that the materials } \\
\text { injected to stimulate } \\
\text { microorganisms and the } \\
\text { stimulated microorganisms } \\
\text { themselves will have no ill } \\
\text { effects on the Columbia River } \\
\text { and its biota. Define the short } \\
\text { and long-term effects on } \\
\text { microorganisms from this } \\
\text { technology. Describe how it } \\
\text { will be demonstrated that } \\
\text { microorganisms will not use } \\
\text { the injected material to } \\
\text { become harmful to the } \\
\text { ecosystem or to grow } \\
\text { uncontrollably. Describe how } \\
\text { such growth would be } \\
\text { controlled, if it occurred. }\end{array}$ & 14. & $\begin{array}{l}\text { Stakeholders pointed out the need to } \\
\text { balance and control (measure and } \\
\text { demonstrate) the fate of } \mathrm{NO}_{3} \text {. Technical } \\
\text { staff noted that when it is injected, nitrate } \\
\text { will be above MCLs but it will be quickly } \\
\text { diluted. Chemical reactions and microbial } \\
\text { growth will be monitored, as will the } \\
\text { possible presence of coliform. Microbes } \\
\text { will be stimulated in a small area ( } 20^{\prime} \\
\text { radius). The microbes' tendency to adsorb } \\
\text { to the soil column will limit their mobility. } \\
\text { The short-term result of injection will be to } \\
\text { increase the number of natural denitrifiers. } \\
\text { Microorganisms ("bugs") will autodigest; } \\
\text { bugs are expected to eat other bugs until } \\
\text { they return to background or at least low } \\
\text { levels. The ID will monitor the site after } \\
\text { the demonstration to learn how the } \\
\text { population of microorganisms changes } \\
\text { with time. The ID will determine exactly } \\
\text { which types and numbers of. } \\
\text { microorganisms are stimulated and will } \\
\text { modify the nutrients injected accordingly. } \\
\text { Stopping the injection of nutrients will stop } \\
\text { the growth of microorganisms. }\end{array}$ \\
\hline 15. & $\begin{array}{l}\text { Define the circumstances } \\
\text { under which microorganisms } \\
\text { are no longer expected to } \\
\text { respond to nutrients. }\end{array}$ & 15. & $\begin{array}{l}\text { Without all three elements -- nitrate, } \\
\text { acetate, and bacteria -- there will be no } \\
\text { response or growth by microorganisms. } \\
\text { Therefore, if either of the nutrients is } \\
\text { withdrawn, microorganisms will no longer } \\
\text { respond. }\end{array}$ \\
\hline
\end{tabular}




\begin{tabular}{|c|c|c|c|}
\hline \multicolumn{2}{|r|}{$\begin{array}{l}\text { FOCUS GROUP } \\
\text { DATA REQUTREMENTS }\end{array}$} & & $4 / 4$ WORKSHOP \\
\hline 16. & $\begin{array}{l}\text { Demonstrate and measure the } \\
\text { effects of the technology on } \\
\text { co-contaminants. }\end{array}$ & & $\begin{array}{l}\text { Stakeholders called for the demonstration } \\
\text { to measure for the mobilization or } \\
\text { demobilization of contaminants. } \\
\text { e applicability of this technology to mixed } \\
\text { ste sites must be made based on mobility (or } \\
\text { nobility) of contaminants. Technical staff } \\
\text { ponded that there is no indication that } \\
\text { bility will be increased. Lab studies have } \\
\text { n ongoing to look at decreased mobility of } \\
\text { tals and radionuclides in the presence of } \\
\text { croorganisms. Additional studies are } \\
\text { ded to address the potential mobilization of } \\
\text { ntaminants. All evidence to date indicates } \\
\text { t mobilization won't occur, but lab studies } \\
\text { uld be done to confirm this. Staff said that } \\
\text { re are no radionuclide co-contaminants at } \\
\text { demonstration site. }\end{array}$ \\
\hline 17. & $\begin{array}{l}\text { Demonstrate and measure the } \\
\text { effects of radionuclides now in } \\
\text { soils at Hanford on } \\
\text { microorganisms stimulated by } \\
\text { the bioremediation } \\
\text { demonstration. }\end{array}$ & & $\begin{array}{l}\text { Technical staff said that there are no } \\
\text { radionuclides at the site for the } \\
\text { technology's demonstration. However, the } \\
\text { full carbon tetrachloride plume does } \\
\text { contain co-contaminants that are important } \\
\text { to the technologies' usefulness. A } \\
\text { combination of lab studies and engineering } \\
\text { analysis will be done to evaluate the } \\
\text { impacts of radionuclides. }\end{array}$ \\
\hline 18. & $\begin{array}{l}\text { Define the costs of } \\
\text { bioremediation in light of the } \\
\text { possible continued use of } \\
\text { pump and treat technology to } \\
\text { bring contaminated } \\
\text { groundwater to the surface. } \\
\text { Define cases in which it might } \\
\text { be cheaper to undertake } \\
\text { remediation above ground. }\end{array}$ & & $\begin{array}{l}\text { The demonstration will provide data on } \\
\text { operating costs. The computer simulation } \\
\text { will be used to make cost comparisons and } \\
\text { determine how to integrate bioremediation } \\
\text { with other treatment methods. The field } \\
\text { test will enable evaluation of the } \\
\text { simulation's results. The use of the } \\
\text { simulation will allow the evaluation of cost } \\
\text { scenarios, treatment scenarios, and the } \\
\text { technology's applicability to other sites. }\end{array}$ \\
\hline
\end{tabular}




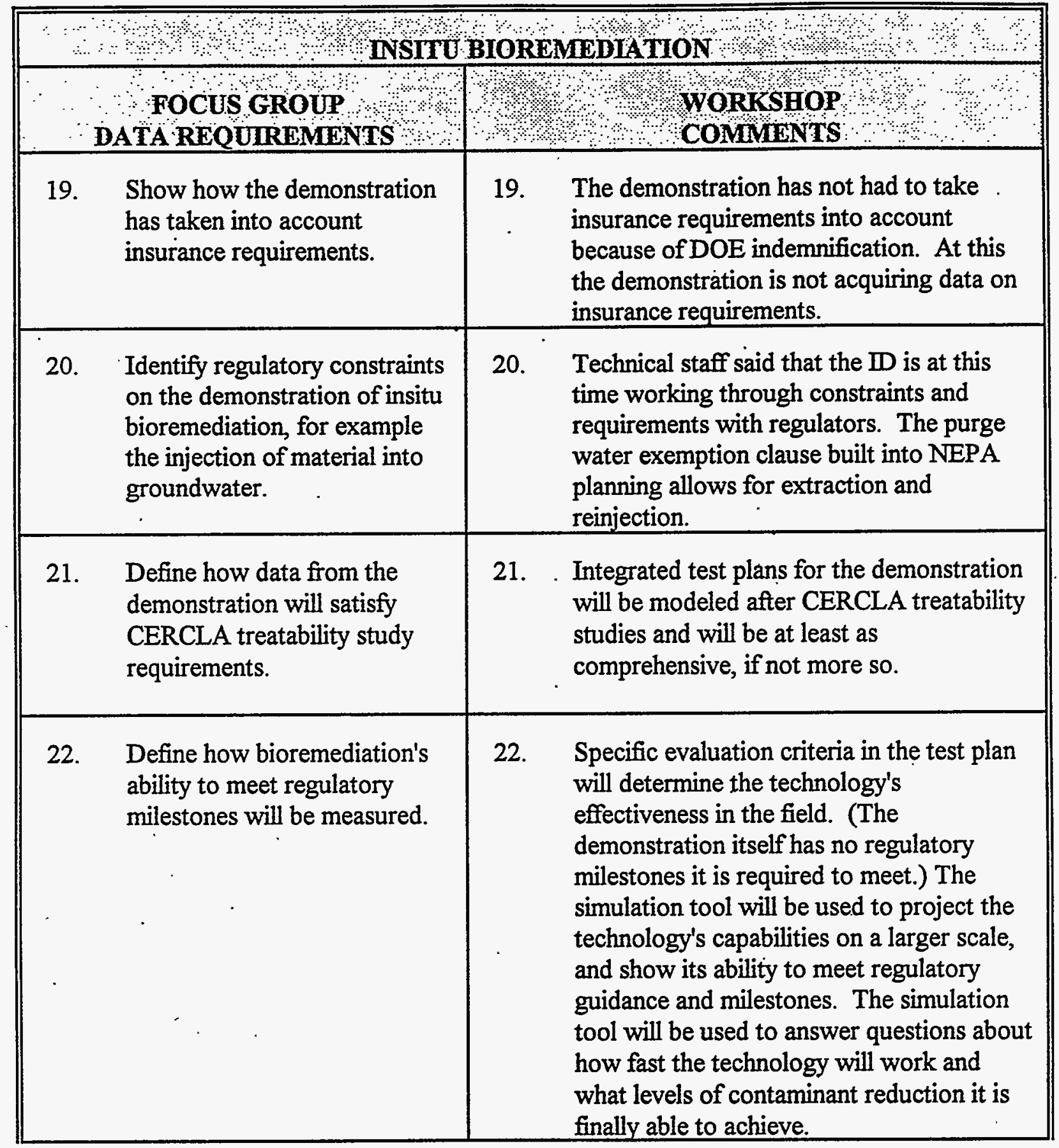




\begin{tabular}{|c|c|c|c|}
\hline \multirow{2}{*}{\multicolumn{4}{|c|}{ 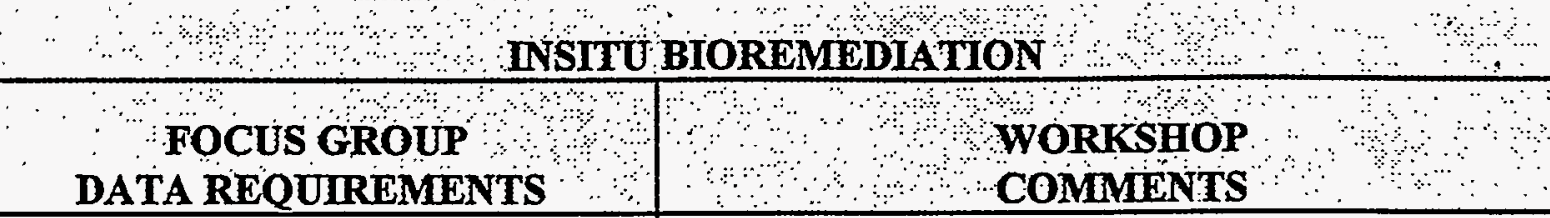 }} \\
\hline & & & \\
\hline 23. & $\begin{array}{l}\text { Define which independent } \\
\text { party, if any, will review the } \\
\text { results of the demonstration. }\end{array}$ & 23. & $\begin{array}{l}\text { Stakeholders suggested an independent } \\
\text { review of the demonstration's results such } \\
\text { as by an Underwriter's Laboratory, a } \\
\text { consumer group, or other separately } \\
\text { funded organization. A stakeholder noted } \\
\text { that DOE contractors are not trusted nor is } \\
\text { DOE itself. The more review the better. } \\
\text { Technical staff said that a characterization } \\
\text { and monitoring Technical Support Group } \\
\text { drawn from industry and science will } \\
\text { review the demonstration's results, and also } \\
\text { noted DOE's demonstration operations } \\
\text { review procedure that stakeholders have } \\
\text { been involved in formulating. Stakeholders } \\
\text { have contributed directly to developing } \\
\text { evaluation criteria for the technology -- } \\
\text { criteria reflected in the plans with which } \\
\text { the technology will be tested. The } \\
\text { Integrated Demonstration will continue to } \\
\text { work with DOE headquarters to develop } \\
\text { more independent review processes for the } \\
\text { technology program. }\end{array}$ \\
\hline
\end{tabular}

C. 11 


\section{Appendix D}

Stakeholders Issues from Other DOE Sites 


\section{Appendix D: Stakeholders Issues From Other DOE Sites}

\section{INSITU BIOREMEDIATION COMMENT LISTING}

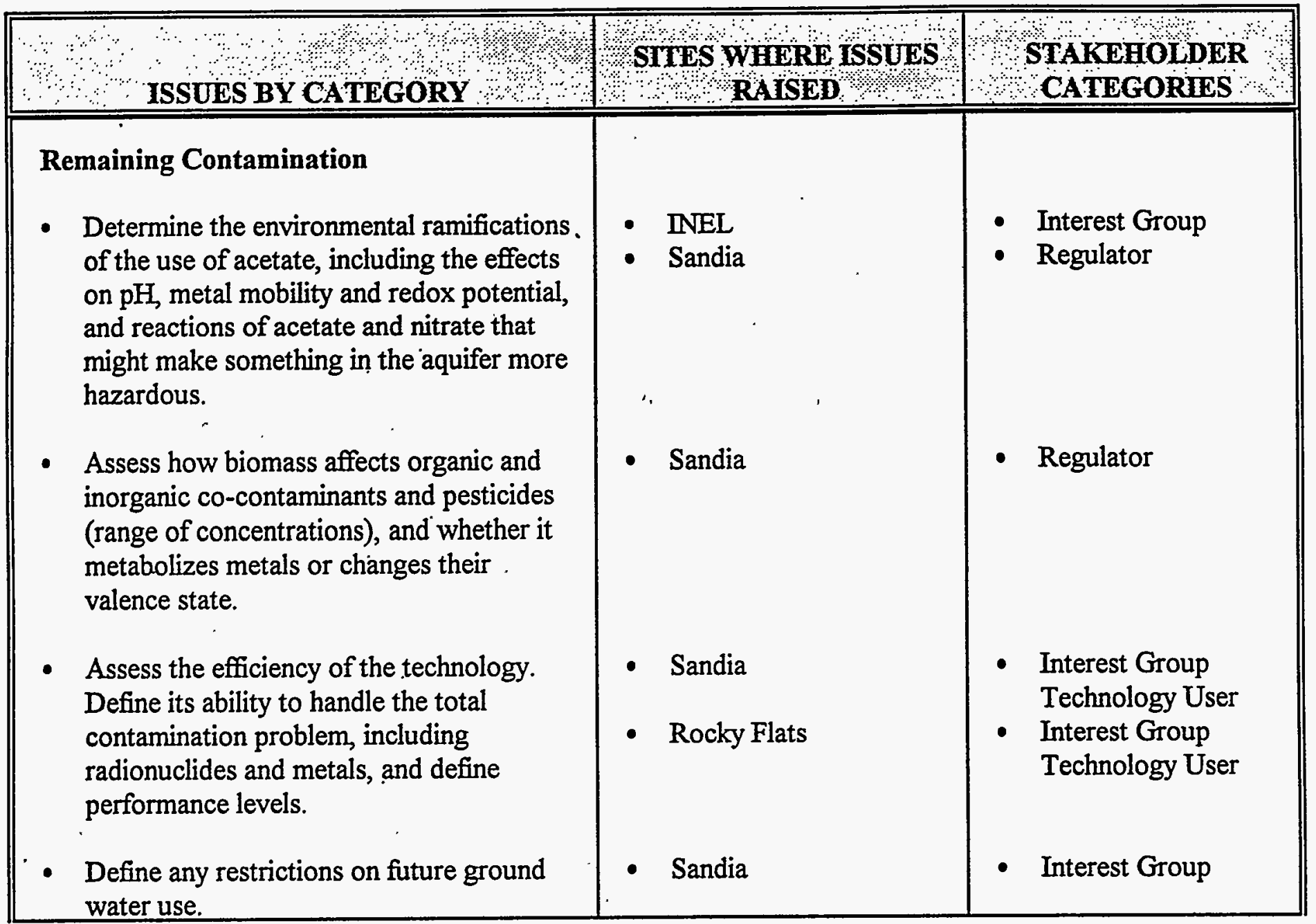

D.1 


\begin{tabular}{|c|c|c|}
\hline SU & 8 SITES WHERE ISSUES & $\begin{array}{l}\text { STAKEHOLDER } \\
\text { CATEGORIES }\end{array}$ \\
\hline $\begin{array}{l}\text { Process Waste } \\
\text { - Evaluate the possibility that the action of } \\
\text { the stimulated microorganisms will } \\
\text { produce unwanted by-products. } \\
\text { Determine the quantities and types of } \\
\text { degradation products, both anticipated and } \\
\text { unanticipated, and their potential } \\
\text { environmental impacts. } \\
\text { Evaluate the secondary waste, including } \\
\text { biomass, produced from microbial } \\
\text { digestion of carbon tetrachloride. } \\
\text { Evaluate approaches to prevent microbial } \\
\text { waste products from eventually shutting } \\
\text { down the system. }\end{array}$ & $\begin{array}{ll}\text { - } & \text { INEL } \\
\text { - } & \text { Los Alamos } \\
\text { - } & \text { Rocky Flats } \\
\text { - } & \text { Sandia } \\
\text { - Los Alamos } \\
\text { - Rocky Flats } \\
\text { - Sandia } \\
\text { - Sandia }\end{array}$ & $\begin{array}{ll}\text { - } & \text { Interest Group } \\
\text { Technology User } \\
\text { - } \\
\text { - } \text { Tegulator } \\
\text { Interest Group } \\
\text { - Regulator } \\
\\
\text { - Interest Group } \\
\text { - } \text { Interest Group } \\
\text { - Technology User }\end{array}$ \\
\hline
\end{tabular}

D. 2 


\begin{tabular}{|c|c|c|}
\hline ISSUES BY CATEGORY & $\begin{array}{l}\text { SITES WHERE ISSUES } \\
\text { RAISED }\end{array}$ & $\begin{array}{c}\text { STAKEHOLDER } \\
\text { CATEGORTES } \\
\end{array}$ \\
\hline Practicality & & \\
\hline $\begin{array}{l}\text { - Insitu techniques are preferable to bringing } \\
\text { contamination to a well or withdrawal } \\
\text { system. The benefit of this technology is } \\
\text { its ability to handle contaminants that } \\
\text { pump and treat cannot fully address. }\end{array}$ & $\begin{array}{l}\text { - } \text { INEL } \\
\text { - Los Alamos }\end{array}$ & $\begin{array}{l}\text { - Interest Group } \\
\text { Technology User } \\
\text { - Technology User }\end{array}$ \\
\hline $\begin{array}{l}\text { Evaluate the usefulness and applicability of } \\
\text { this technology for a broad range of } \\
\text { applications and conditions including: a } \\
\text { range of constituents; co-contaminants; } \\
\text { various soil types and geologies; the ability } \\
\text { to function in the vadose zone, in different } \\
\text { weather conditions, and in plutonium- } \\
\text { contaminated zones. }\end{array}$ & $\begin{array}{l}\text { - } \text { INEL } \\
\text { - Ros Alamos } \\
\text { - Sandia Flats }\end{array}$ & $\begin{array}{l}\text { - Interest Group } \\
\text { - Technology User } \\
\text { Interest Group } \\
\text { Regulator } \\
\text { Technology User } \\
\text { - Interest Group } \\
\text { Technology User }\end{array}$ \\
\hline $\begin{array}{l}\text { Address the technology's ability to work in } \\
\text { changing aquifer characteristics and } \\
\text { transmissivity characteristics, and to } \\
\text { address subsurface aquifer discontinuities. }\end{array}$ & - Sandia & - Regulator \\
\hline - Evaluate and document failure scenarios. & - INEL & - Interest Group \\
\hline $\begin{array}{l}\text { Evaluate the potential for entrainment of } \\
\text { metals and particulates (including } \\
\text { radioactively contaminated particulates) } \\
\text { and the ability to concentrate dispersed } \\
\text { plutonium. }\end{array}$ & - Rocky Flats & $\begin{array}{l}\text { Interest Group } \\
\text { Technology User }\end{array}$ \\
\hline $\begin{array}{l}\text { Evaluate needed nutrient balances in } \\
\text { different conditions. Evaluate the ability to } \\
\text { supply nutrients when microbes sorb onto } \\
\text { soil particles and the ability to deliver } \\
\text { nutrients in arid climates, non-sedimentary } \\
\text { materials, and fast-moving subsurface } \\
\text { ground water. }\end{array}$ & - INEL & $\begin{array}{l}\text { - Regulator } \\
\text { Technology User }\end{array}$ \\
\hline
\end{tabular}




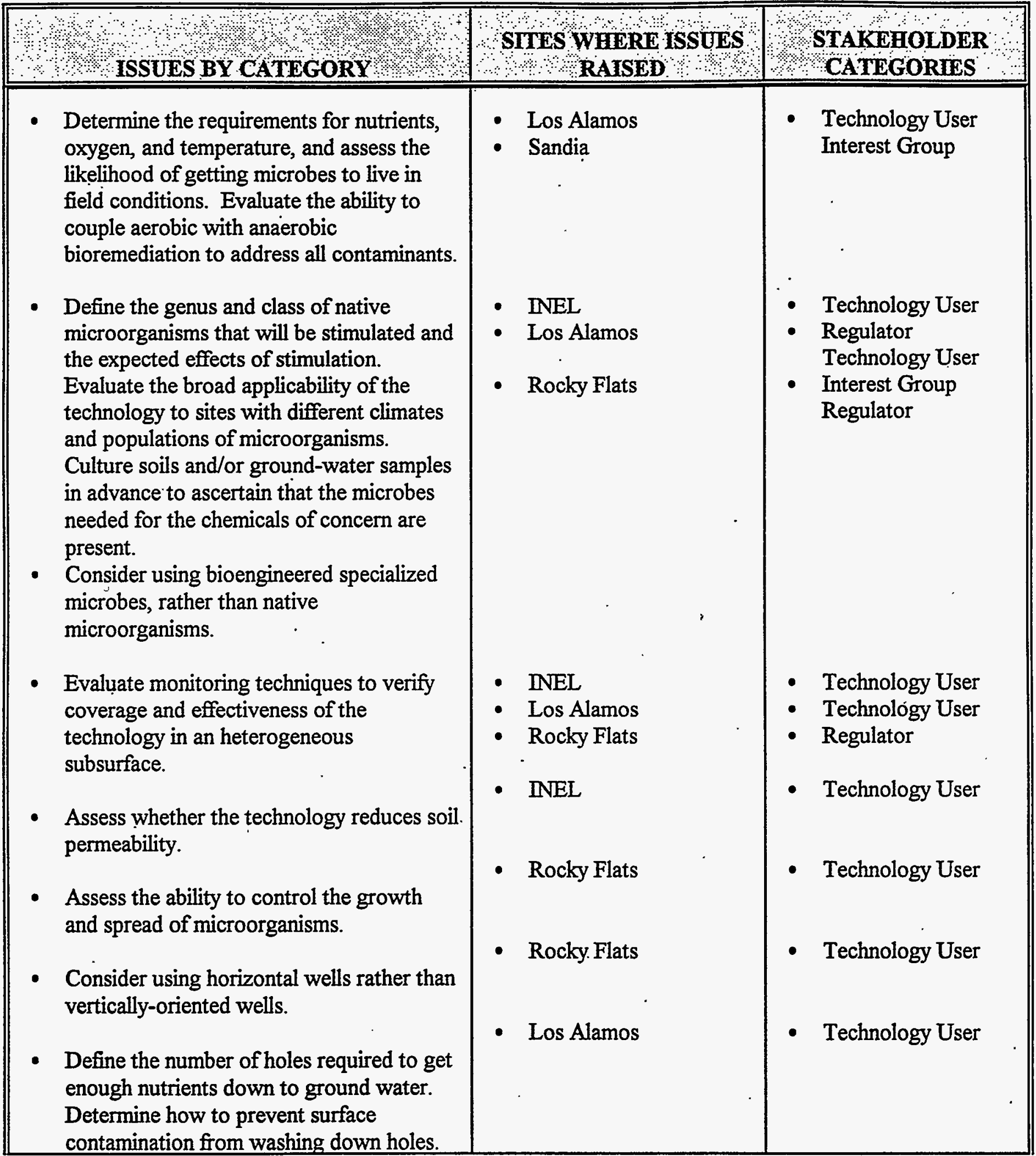


- Evaluate the ability to operate in a pulsed fashion and in a quasi-closed loop system, with inputs (bio-stimulants) equaling output, so that ground-water mounding does not occur.

- Evaluate the usefulness of the technology for near-surface ground-water cleanup.

- Does the potential effect of biomass slowing ground-water flow and stabilizing contamination preclude other treatments later?

- Consider opening up the subsurface geology to allow the movement of stimulated microorganisms.

- Benzene is a primary concern at Rocky Mountain Arsenal. Define whether there is a need to add both nitrates for insitu bioremediation to function effectively.

- Assess bringing waste to the surface and using the technology where it could be observed and controlled.

- Injection and withdrawal wells may be needed at Rocky Flats to create a predictable flow pattern in clay soils.

- Assess whether this technology creates a reduction zone at the edge of plumes, making metals more soluble. Selenium is a problem at Rocky Flats.

- Can the technology be used with other technologies (e.g., air stripper, pump and treat)?
- Sandia

- Los Alamos

- Sandia

- Sandia

- Rocky Flats

- Rocky Flats

- Rocky Flats

- Rocky Flats

- Rocky Flats

- Rocky Flats
- Regulator

- Technology User

- Regulator

- Regulator

- Interest Group

- Regulator

- Technology User

- Technology User

- Technology User

- Technology User 


\begin{tabular}{|c|c|c|}
\hline ISSUES BY CATEGORY & $\begin{array}{l}\text { SITES WHERE ISSUES } \\
\text { RAISED }\end{array}$ & $\begin{array}{l}\text { STAKEHOLDER } \\
\text { CATEGORIES }\end{array}$ \\
\hline $\begin{array}{l}\text { Define skill levels and assess the level of } \\
\text { specialized training needed to operate the } \\
\text { technology. }\end{array}$ & $\begin{array}{l}\text { - Rocky Flats } \\
\text { - Sandia }\end{array}$ & $\begin{array}{l}\text { - Technology User } \\
\text { - Interest Group }\end{array}$ \\
\hline $\begin{array}{l}\text { Evaluate the effectiveness of using insitu } \\
\text { bioremediation first, and then using other } \\
\text { technologies as polishing approaches. }\end{array}$ & - Sandia & - Technology User \\
\hline $\begin{array}{l}\text { - This technology is not useful at Sandia due } \\
\text { to the depth of ground water and the fact } \\
\text { the most contamination is now in the } \\
\text { vadose zone. }\end{array}$ & - Sandia & - Technology User \\
\hline
\end{tabular}

D. 6 


\section{Works as Intended}

- Assess the effects of solvent toxicity on

- INEL microbes.

- Consider the need for a site-specific system design to accommodate differing strata and the nature of contamination.

- It is unclear how microbes would stay in fractured basalt at depth at $\mathbb{N E L}$.

- This appears to be a good polishing technology. Evaluate the upper limits of concentrations the technology can handle (potential application to tank sludge to remove RCRA regulated organics and leave radionuclides only).

- Identify the lower limits of effectiveness.

- Evaluate characterization needs and levels, including the effects of encountering unexpected contaminants or concentrations on effectiveness. Evaluate the effects of geology in order to know if organisms will spread to targeted areas.

- Evaluate the zone of influence and the maximum area possible for treatment with this technology. Evaluate the usefulness of the technology for large plumes versus limited areas of contamination.

- INEL

- INEL

- INEL

- Regulator

- Regulator

- Regulator

- Technology User

- Rocky Flats

- INEL

- Rocky Flats

- INEL

- Los Alamos

- Sandia
- Tribes

- Technology User

- Public Official Regulator Technology User Tribes 


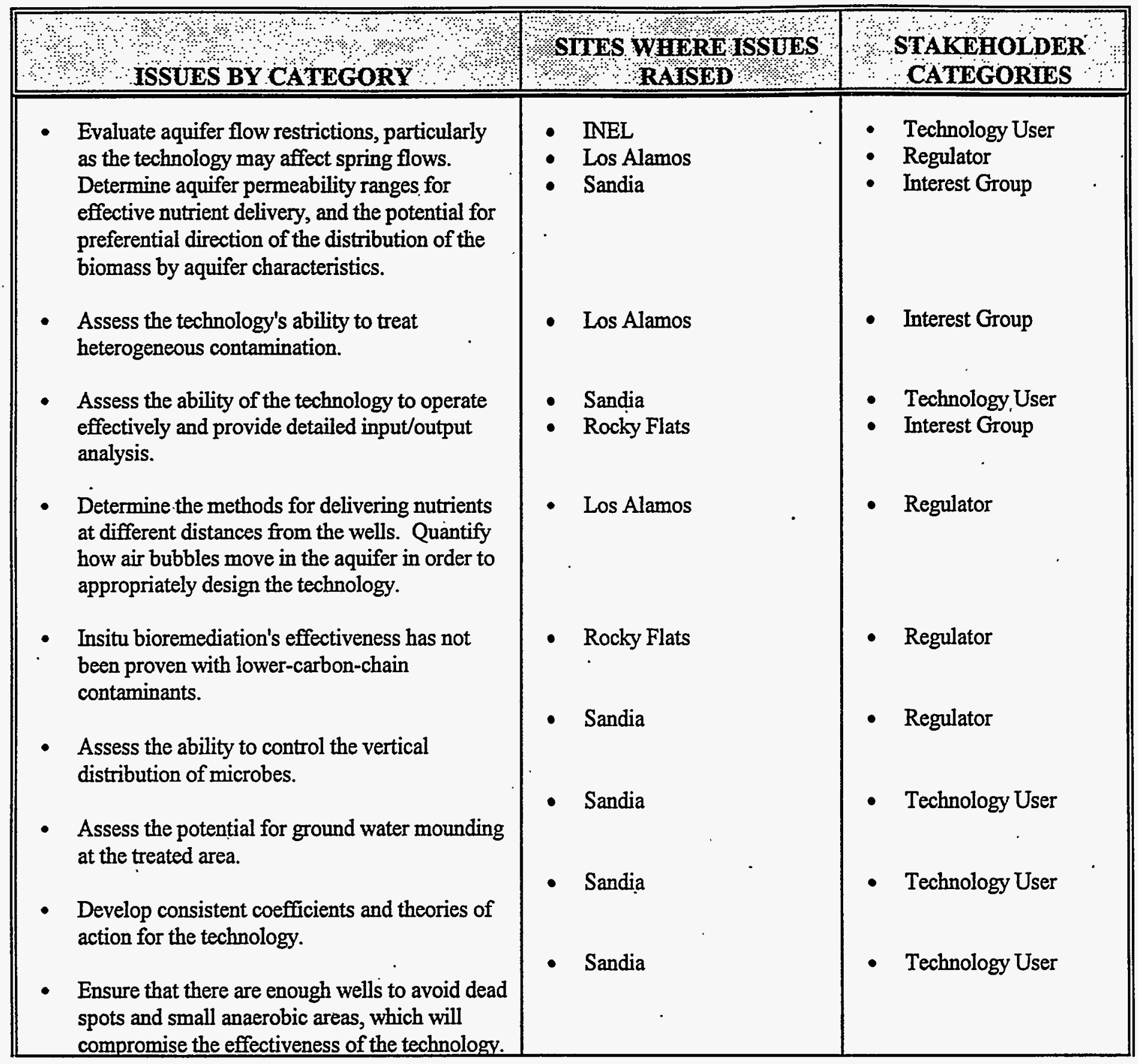




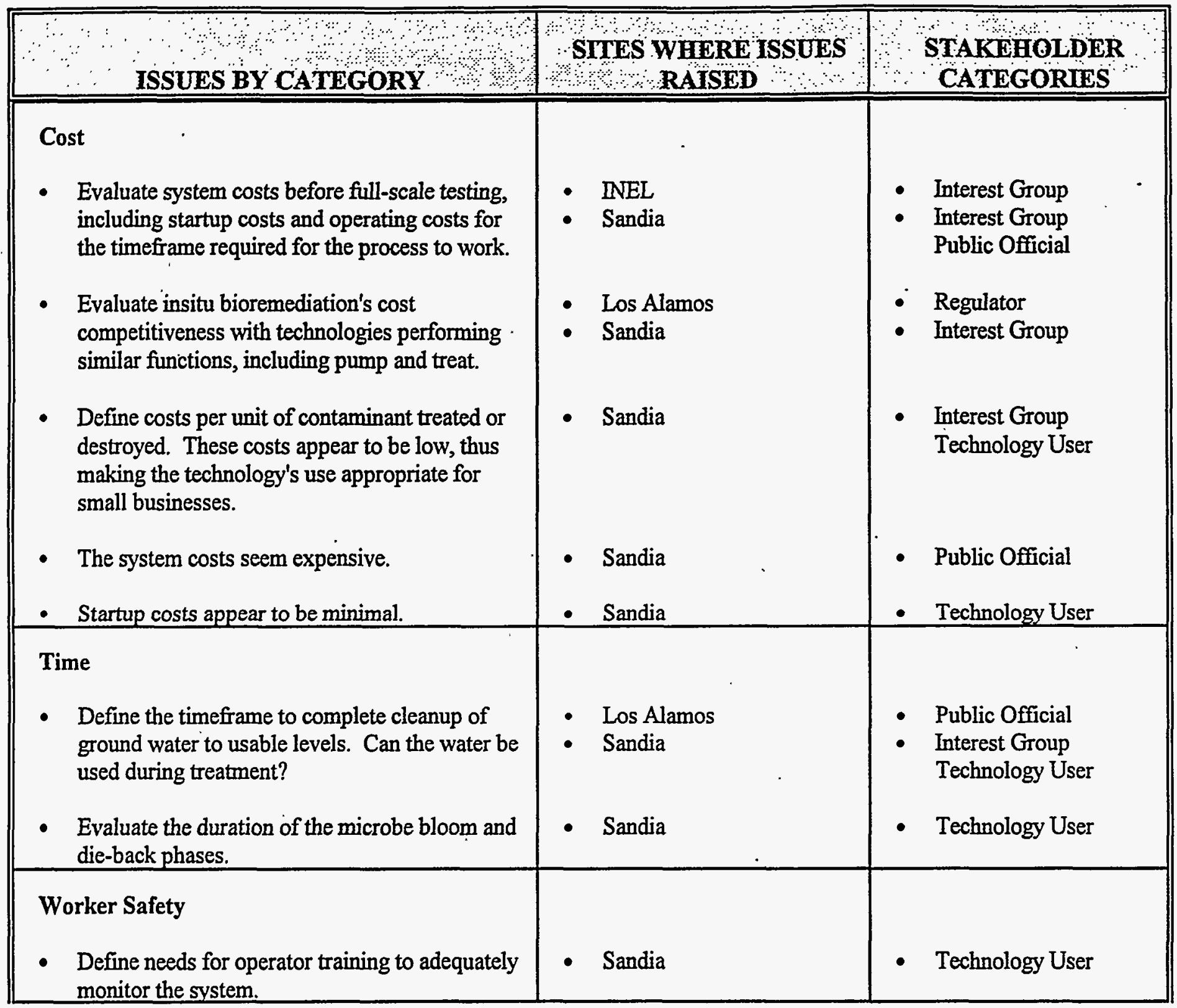

D. 9 


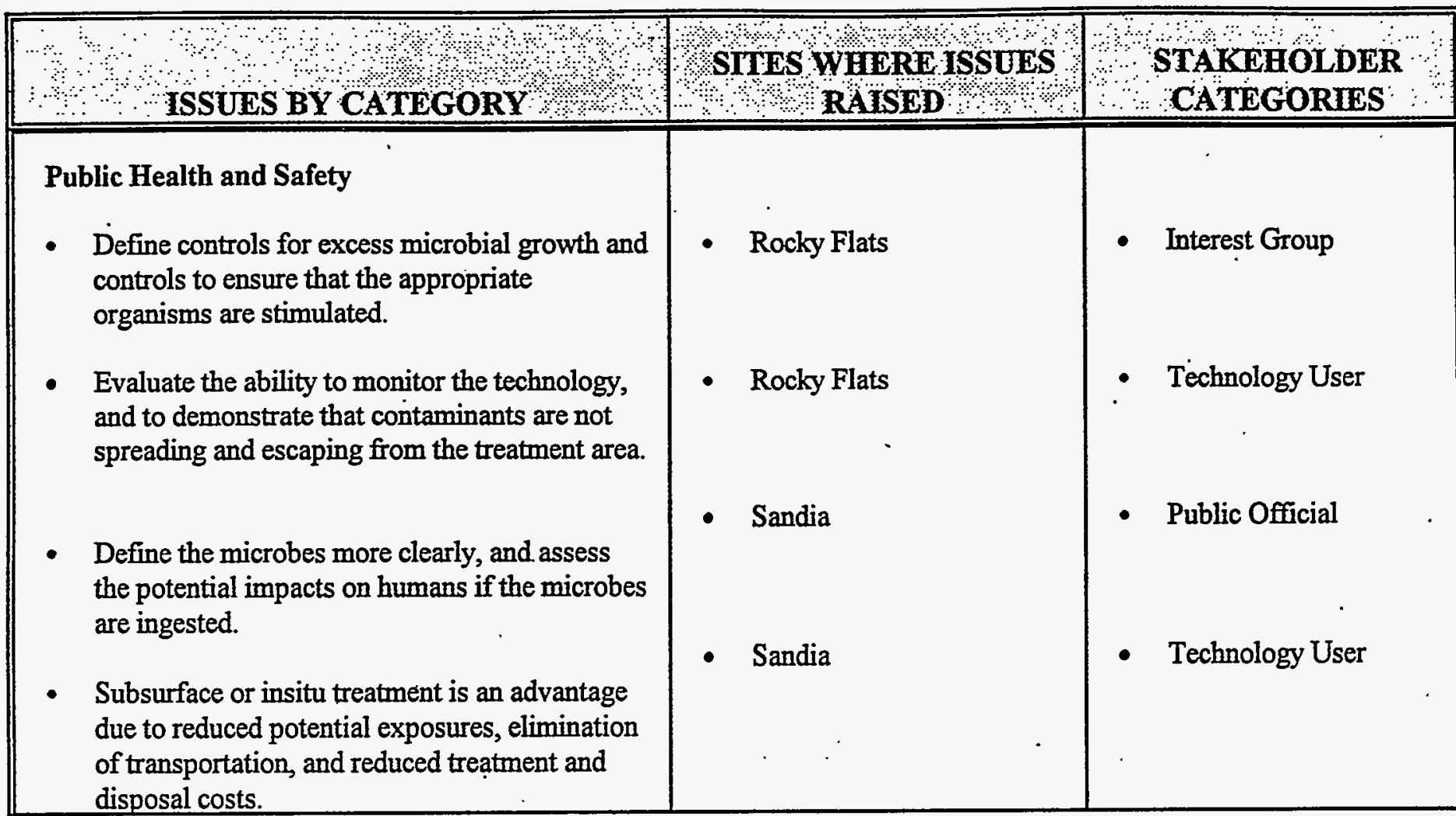

D. 10 


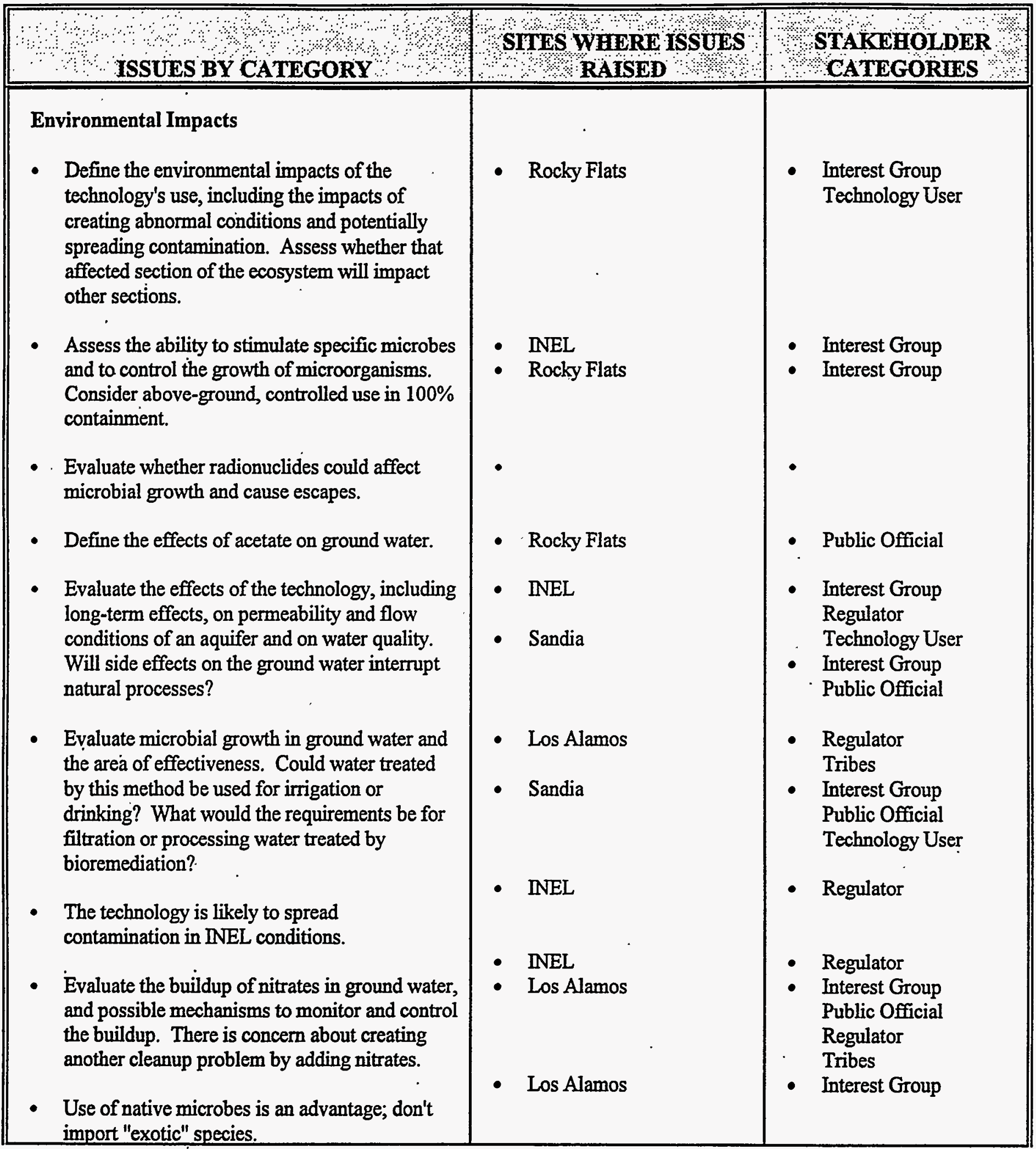

D. 11 


\begin{tabular}{|c|c|c|}
\hline 4) ISSUES BY CATEGORY & $\begin{array}{l}\text { SITES WHERE ISSUES } \\
\text { RAISED }\end{array}$ & $\begin{array}{l}\text { STAKEHOLDER } \\
\text { CATEGORIES } \\
\end{array}$ \\
\hline $\begin{array}{l}\text { - Evaluate the relationship of selected microbes } \\
\text { to other microbes in the area. }\end{array}$ & - Sandia & - Regulator \\
\hline $\begin{array}{l}\text { Evaluate whether the microbes stop growing } \\
\text { when nutrient addition ends. Evaluate how } \\
\text { microbes behave with indigenous food sources. }\end{array}$ & - Sandia & - Regulator \\
\hline $\begin{array}{l}\text { Evaluate the effects of the technology at the } \\
\text { discharge point and the possible creation of an } \\
\text { imbalanced ecosystem. }\end{array}$ & - Los Alamos & - Technology User \\
\hline $\begin{array}{l}\text { Define the size and footprint of necessary } \\
\text { equipment at the surface. }\end{array}$ & - Sandia & - Interest Group \\
\hline $\begin{array}{l}\text { Assess the tendency of the technology to create } \\
\text { a reducing environment (wherein electrons are } \\
\text { being added to ions), and the likelihood of } \\
\text { increased inorganic contaminant mobility. } \\
\text { Evaluate dissolution and precipitation of metals } \\
\text { and biofouling of the well and aquifer in the } \\
\text { vicinity of the well screen. }\end{array}$ & - Sandia & : Regulator \\
\hline $\begin{array}{l}\text { Define monitoring requirements for growth and } \\
\text { spread of microorganisms. How will } \\
\text { degradation of contaminants be measured? }\end{array}$ & - Rocky Flats & $\begin{array}{ll}\text { - } & \text { Regulator } \\
\text { Interest Group }\end{array}$ \\
\hline Evaluate creation of by-products. & - Rocky Flats & - Technology User \\
\hline $\begin{array}{l}\text { Assess differences over time (e.g., increased } \\
\text { biomass) with microbial growth in saturated } \\
\text { soil. }\end{array}$ & - Sandia & - Interest Group \\
\hline $\begin{array}{l}\text { Evaluate the likelihood of releasing product into } \\
\text { free phase and causing it to move into ground } \\
\text { water as free product. }\end{array}$ & & \\
\hline Public Perception & & \\
\hline $\begin{array}{l}\text { - Potential clogging of the aquifer with biomass } \\
\text { and slowing ground water flow will be the } \\
\text { public perception problems at INEL. Evaluate } \\
\text { the potential impacts on aquifer quality and } \\
\text { quantity. }\end{array}$ & - $\quad$ NEL & - Interest Group \\
\hline
\end{tabular}

D. 12 


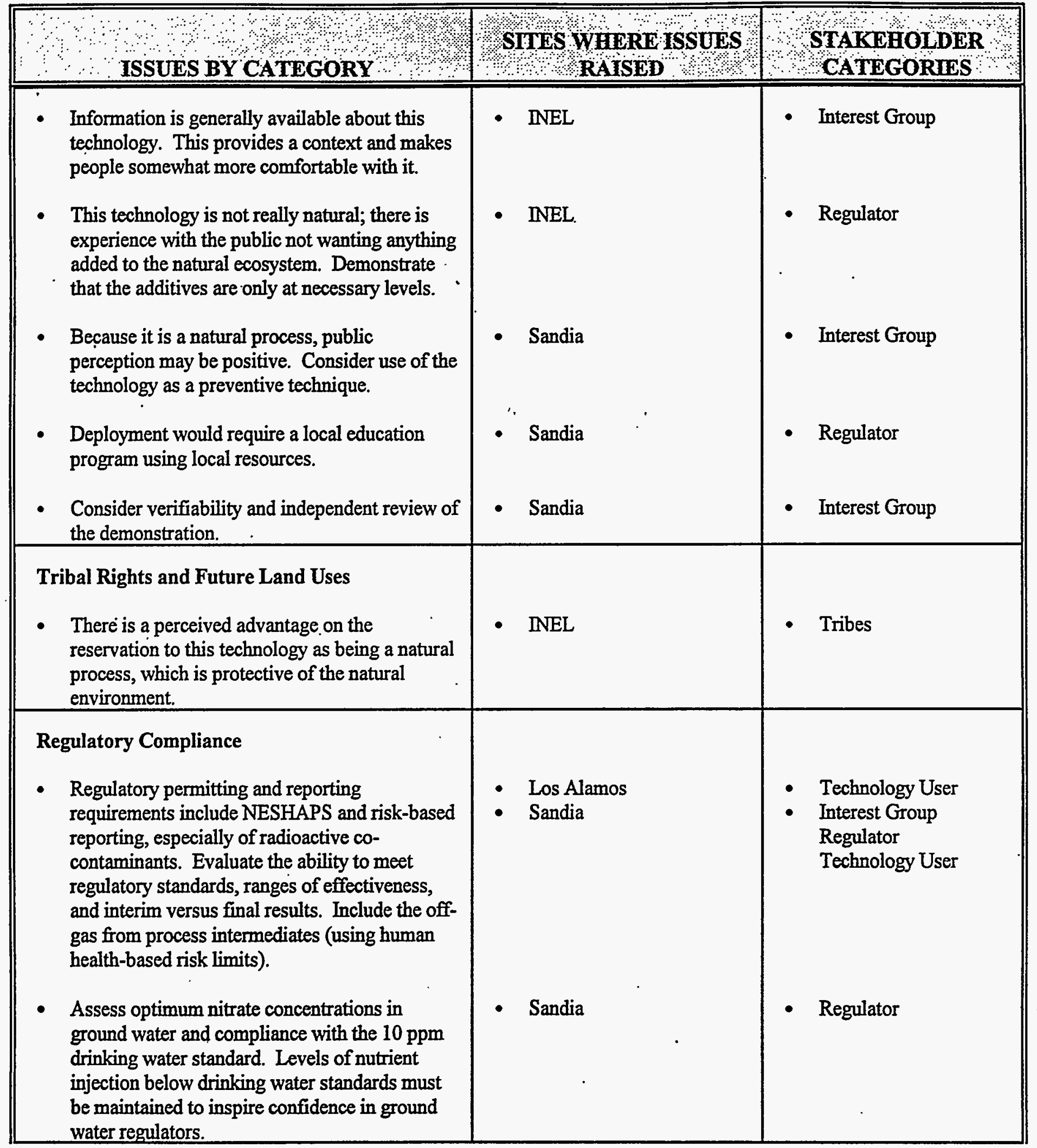

D.13 


\begin{tabular}{|c|c|c|}
\hline W & $\begin{array}{l}\text { SITES WHERE ISSUES } \\
\text { RAISED }\end{array}$ & $\begin{array}{l}\text { STAKEHOLOER } \\
\text { CATEGORIES }\end{array}$ \\
\hline $\begin{array}{l}\text { - New Mexico will not permit the subsurface } \\
\text { injection of anything into ground water or } \\
\text { within } 50 \text { feet of ground water. }\end{array}$ & - Sandia & - Technology User \\
\hline Other & & \\
\hline - This is an attractive technology. & - INEL & - Technology User \\
\hline $\begin{array}{l}\text { - A treatability study of the use of bioremediation } \\
\text { in soils is being conducted at Rocky Flats. }\end{array}$ & - Rocky Flats & - Regulator \\
\hline $\begin{array}{l}\text { Compare bioremediation to other technologies. } \\
\text { Comparison to pump and treat may be biased; a } \\
\text { more comparable baseline technology may be } \\
\text { in-well vapor stripping. }\end{array}$ & - Rocky Flats & - Regulator \\
\hline $\begin{array}{l}\text { The statement in the profile that EPA's strong } \\
\text { endorsement adds credibility to bioremediation } \\
\text { may not be accurate; the public is skeptical of } \\
\text { EPA. }\end{array}$ & - Rocky Flats & - Regulator \\
\hline $\begin{array}{l}\text { - The highest comfort level is with above-ground } \\
\text { technologies. }\end{array}$ & - Rocky Flats & - Technology User \\
\hline $\begin{array}{l}\text { Reduction of soil permeability is not necessarily } \\
\text { of added value in plutonium-contaminated soils } \\
\text { if the plutonium is bound to the soil and non- } \\
\text { mobile. }\end{array}$ & - Rocky Flats & - Public Official \\
\hline
\end{tabular}




\section{Appendix E}

Major Legislative Themes in Federal Technology Transfer 
Appendix E: Major Legislative Themes in Federal Technology Transfer

\begin{tabular}{|c|c|c|c|c|c|}
\hline \multicolumn{6}{|c|}{ Major Legislative Themes in Federal Technology Transfer } \\
\hline Theme & Initiation & \multicolumn{4}{|l|}{ Progression } \\
\hline $\begin{array}{l}\text { Technology } \\
\text { Transfer As a } \\
\text { Milssion }\end{array}$ & $\begin{array}{l}1980 \\
\text { Stevenson-Wydler } \\
\text { Technology Innovation Act } \\
\text { established } \mathrm{T}^{2} \text { as a mission } \\
\text { of the federal government }\end{array}$ & $\begin{array}{l}1986 \\
\text { Federal Technology } \\
\text { Transfer Act (FTTA) } \\
\text { made } T^{2} \text { a priority not } \\
\text { only for GOGOs, but for } \\
\text { every GOGO employee }\end{array}$ & $\begin{array}{l}1987 \\
\text { Executive Order } 12591 \\
\text { emphasized the } \\
\text { government's } \\
\text { commitment to } \\
\text { facilitating access to } \\
\text { science and technology }\end{array}$ & \multicolumn{2}{|c|}{$\begin{array}{l}1989 \\
\text { National Competitiveness Technology Transfer Act (NCTTA) established } T^{2} \text { as a } \\
\text { laboratory mission for GOCOs and GOCO employees }\end{array}$} \\
\hline U.S. Manufacture & $\begin{array}{l}1980 \\
\text { Patent and Trademark } \\
\text { Amendments Act (Bayh- } \\
\text { Dole) provided exclusive } \\
\text { rights to inventions arising . } \\
\text { under funding agreements } \\
\text { with federal agencies to } \\
\text { small businesses and non- } \\
\text { profit organizations agreeing } \\
\text { that products embodying the } \\
\text { invention will be } \\
\text { manufactured substantially } \\
\text { in the U.S. }\end{array}$ & $\begin{array}{l}1980 \\
\text { Stevenson-Wydler } \\
\text { Technology Innovation } \\
\text { Act required that } \\
\text { preference given to } \\
\text { industrial } T^{2} \text { partners } \\
\text { agreeing to substantially } \\
\text { manufacture in the U.S. } \\
\text { any products resulting } \\
\text { from Technology } \\
\text { Transfer }\end{array}$ & $\begin{array}{l}1984 \\
\text { Trademark Clarification } \\
\text { Act (amending Bayh- } \\
\text { Dole) extended } \\
\text { substantial manufacture } \\
\text { in the U.S. provisions to } \\
\text { all partners of federal } \\
\text { agencies }\end{array}$ & $\begin{array}{l}1986 \\
\text { Federal Technology Transfer Act } \\
\text { (FTTA) required that preference be } \\
\text { given to CRADA partners located } \\
\text { in the U.S. and agreeing that } \\
\text { products embodying inventions } \\
\text { made under the CRADA will be } \\
\text { manufactured substantially in the } \\
\text { U.S. }\end{array}$ & $\begin{array}{l}1989 \\
\text { National Competitiveness Technology } \\
\text { Transfer Act (NCTTA) established } \\
\text { Congressional intent that CRADAs be } \\
\text { performed in a manner that fosters the } \\
\text { competitiveness of U.S. industry }\end{array}$ \\
\hline Small Business & $\begin{array}{l}1980 \\
\text { Patent and Trademark } \\
\text { Amendments Act (Bayh- } \\
\text { Dole) permitted small } \\
\text { businesses to obtain title to } \\
\text { inventions developed with } \\
\text { governmental support }\end{array}$ & $\begin{array}{l}1982 \\
\text { Small Business } \\
\text { Innovation Development } \\
\text { Act } \\
\text { - Established the Small } \\
\text { Business Innovation } \\
\text { Research (SBIR) } \\
\text { Program } \\
\text { - Required agencies to } \\
\text { provide special funds } \\
\text { for small business } \\
\text { R\&D connected to the } \\
\text { agencies mission }\end{array}$ & $\begin{array}{l}1991 \\
\text { Defense Authorization } \\
\text { Act established model } \\
\text { programs for laboratories } \\
\text { to demonstrate successful } \\
\text { relationships between } \\
\text { government and small } \\
\text { business }\end{array}$ & $\begin{array}{l}1992 \\
\text { Small Business } T^{2} \text { Act mandated } \\
\text { government agency funding of } \\
\text { cooperative R\&D projects between } \\
\text { small businesses and universities, } \\
\text { federally funded R\&D centers or } \\
\text { non-profit research institutions }\end{array}$ & $\begin{array}{l}1992 \\
\text { FY } 1993 \text { Defense Authorization Act directed } \\
\text { DOE to facilitate and encourage } T^{2} \text { to small } \\
\text { business }\end{array}$ \\
\hline
\end{tabular}




\begin{tabular}{|c|c|c|c|c|c|c|}
\hline \multicolumn{7}{|c|}{ Major Legislative Themes in Federal Technology Transfer } \\
\hline Theme & Initiation & Progression & & & & \\
\hline Title to Inventions & $\begin{array}{l}\text { Specific agency authorizing } \\
\text { legislation }\end{array}$ & $\begin{array}{l}1980 \\
\text { Patent and Trademark } \\
\text { Amendments Act (Bayh- } \\
\text { Dole) permitted } \\
\text { universitics, not-for-profit } \\
\text { organizations, and small } \\
\text { businesses to obtain title } \\
\text { to inventions developed } \\
\text { with governmental } \\
\text { support }\end{array}$ & $\begin{array}{l}1984 \\
\text { Trademark Clarification } \\
\text { Act allowed laboratories } \\
\text { run by universities and } \\
\text { non-profit institutions to } \\
\text { retain title to inventions } \\
\text { within limitations }\end{array}$ & $\begin{array}{l}1986 \\
\text { Federal Technology Transfer Act } \\
\text { (FTTA) allowed GOGOs: } \\
\text { - To make advance agreements } \\
\text { with large and small businesses } \\
\text { on titte to inventions resulting } \\
\text { from CRADAs } \\
\text { - To grant and waive rights to } \\
\text { laboratory inventions and } \\
\text { intellectual property } \\
\text { - The act also required that } \\
\text { inventors who are government } \\
\text { employees share in royalties } \\
\text { from patent licenses } \\
\end{array}$ & $\begin{array}{l}1988 \\
\text { Omnibus Trade and } \\
\text { Competitiveness Act } \\
\text { extended royalty } \\
\text { payment } \\
\text { requirements to } \\
\text { inventors at the } \\
\text { laboratories who are } \\
\text { not government } \\
\text { employees }\end{array}$ & $\begin{array}{l}1989 \\
\text { National } \\
\text { Competitiveness. } \\
\text { Technology } \\
\text { Transfer Act } \\
\text { (NCTTA) granted } \\
\text { essentially the } \\
\text { same CRADA } \\
\text { opportunities and } \\
\text { intellectual } \\
\text { property rights to } \\
\text { GOCOs that had } \\
\text { been established } \\
\text { for GOGOs by the } \\
\text { FTTA }\end{array}$ \\
\hline $\begin{array}{l}\text { Dissemination of } \\
\text { Information/ } \\
\text { FOlA }\end{array}$ & $\begin{array}{l}1966 \\
\text { Freedom of Information Act } \\
\text { (FOIA): } \\
\text { - Provided a vehicle to } \\
\text { inform the public about } \\
\text { federal government } \\
\text { activities } \\
\text { - Gave citizens the right to } \\
\text { request agency records } \\
\text { and have them available } \\
\text { promptly }\end{array}$ & $\begin{array}{l}1980 \\
\text { Stevenson-Wydler } \\
\text { Technology Innovation } \\
\text { Act focused on } \\
\text { dissemination of } \\
\text { government information } \\
\text { through an active } \\
\text { commitment to } \mathrm{T}^{2}\end{array}$ & $\begin{array}{l}1980 \\
\text { Patent and Trademark } \\
\text { Amendments Act (Bayh- } \\
\text { Dole) protected } \\
\text { descriptions of inventions } \\
\text { from public dissemination } \\
\text { and FolA for a } \\
\text { reasonable amount of } \\
\text { time to allow patent } \\
\text { applications to be filed }\end{array}$ & \multicolumn{3}{|c|}{$\begin{array}{l}1986 \text { \& } 1989 \\
\text { Both the FTTA (1986, applying to GOGOS) and the NCTTA (1989, applying to } \\
\text { GOCOs) allowed CRADA information to be protected from disclosure under FOIA } \\
\text { for up to five years }\end{array}$} \\
\hline $\begin{array}{l}\text { Authorization of } \\
\text { CRADAs }\end{array}$ & $\begin{array}{l}1986 \\
\text { FTTA authorized CRADAs } \\
\text { for GOGOs }\end{array}$ & $\begin{array}{l}1989 \\
\text { NCTTA authorized } \\
\text { CRADAs for GOCOs }\end{array}$ & $\begin{array}{l}1992 \\
\text { Energy Policy Act } \\
\text { authorized DOE to enter } \\
\text { into CRADAs directly, } \\
\text { without laboratory : } \\
\text { participation }\end{array}$ & \multicolumn{3}{|c|}{$\begin{array}{l}1992 \\
\text { FY } 1993 \text { Defense Authorization Act extended potential CRADA authority to some } \\
\text { DOD-funded Federally Funded R\&D Centers not owned by the government }\end{array}$} \\
\hline
\end{tabular}




\begin{tabular}{|c|c|c|c|c|c|}
\hline \multicolumn{6}{|c|}{ Major Legislative Themes in Federal Technology Transfer } \\
\hline Theme & Initiation & Progression & & & \\
\hline $\begin{array}{l}\text { Establlshment of } \\
\text { Organtzations to } \\
\text { Advance } \\
\text { Technology } \\
\text { Transfer }\end{array}$ & $\begin{array}{l}1980 \\
\text { Stevenson-Wydler } \\
\text { Technology Innovation Act } \\
\text { enabled funding for the } \\
\text { establishment of Offices of } \\
\text { Rescarch and Technology } \\
\text { Application (ORTAs) at } \\
\text { major federal laboratories }\end{array}$ & $\begin{array}{l}1986 \\
\text { Federal Laboratory } \\
\text { Consortium (FLC) } \\
\text { legislated by the FTTA }\end{array}$ & $\begin{array}{l}1989 . \\
\text { Conference Committee } \\
\text { Report of the FY } 1990 \\
\text { Independent Agencies } \\
\text { Appropriations Act } \\
\text { recommended the } \\
\text { establishment of the } \\
\text { National Technology } \\
\text { Transfer Center (NTTC) } \\
\text { by NASA }\end{array}$ & $\begin{array}{l}1991 \\
\text { FLC mandate extended by the } \\
\text { American Technology Preeminence } \\
\text { Act }\end{array}$ & $\begin{array}{l}1992 \\
\text { NASA established six Regional Technology } \\
\text { Transfer Centers (RTTCs) under authority } \\
\text { granted in the National Aeronautics and } \\
\text { Space Act of } 1958\end{array}$ \\
\hline
\end{tabular}

NOTE: This analysis is provided to the FLC by the U.S. Department of Energy. August 1994 


\section{Distribution}

No. of

Copies

OFFSITE

12 DOE/Office of Scientific and

Technical Information

5. D. W. Drell

U.S. Department of Energy

Office of Energy Research, ER-72

19901 Germantown Road

Germantown, MD 20874-1290

5 K. A. White

976 Embarcadero Rd.

Palo Alto, CA 94303

S. May, Esq.

Davis Wright Tremaine

1100 Jadwin Ave.

Richland, WA 99352

\section{ONSITE}

\section{Pacific Northwest National Laboratory}

W. P. Barchet

K9-30

G. R. Bilyard (50)

M. K. Bowman

D. D. Doneen

J. K. Fredrickson

S. W. Gajewski (5)

G. W. Gee

R. E. Gephart

T. R. Ginn

Y. A. Gorby

B. L. Harper

K9-33

K9-76

K9-36

K3-54
No. Of

Copies

S. W. Heaberlin (3)

$\mathrm{K} 8-31$

P. L. Hendrickson

K8-03

M. H. Huesemann

P7-41

B. S. Hooker

M. A. Kennedy

H. Kirwan-Taylor

P. W. Koppenaal

J. A. Jaksch

J. A. Mahaffey

G. McCabe (5)

D. E. McKinley

M. D. McKinney

F. B. Metting (3)

R. L. Ornstein

M. J. Quadrel

O. H. Paananen

M. E. Peterson

B. M. Peyton

A. C. Rither

M. F. Romine

J. D. Saffer

A. B. Seiders

L. J. Silva (3)

R. S. Skeen

M. J. Truex

P. Van Voris

S. A. Weakley

R. E. Wildung (3)

$\mathrm{K} . \mathrm{K}$. Wong

$\mathrm{X}$. Xie

L. Xun

J. H. Zachará

Publishing Coordination

Technical Reports Files (5)

P7-41

P7-55

BSRC Pouch

P7-07

K.8-03

K1-50

BSRC Pouch

K1-53

K8-03

P7-54

K2-01

K9-70

K8-11

K2-47

P7-41

K1-67

K4-06

P7-58

K8-58

K9-04

P7-41

P7-41

K4-12

K8-11

P7-54

P7-56

K2-12

P7-54

Distr.1 